\title{
Equally \\ Prepared \\ for Life?
}

HOW 15-YEAR-OLD BOYS AND GIRLS PERFORM IN SCHOOL

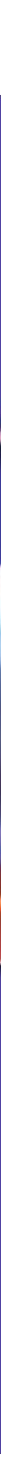

Programme for International Student Assessment

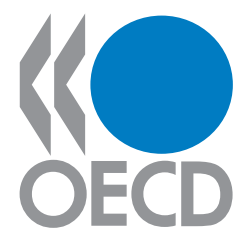





\section{Equally Prepared for Life?}

\section{HOW 15-YEAR-OLD BOYS AND GIRLS PERFORM IN SCHOOL}

Programme for International Student Assessment 


\section{ORGANISATION FOR ECONOMIC CO-OPERATION AND DEVELOPMENT}

The OECD is a unique forum where the governments of 30 democracies work together to address the economic, social and environmental challenges of globalisation. The OECD is also at the forefront of efforts to understand and to help governments respond to new developments and concerns, such as corporate governance, the information economy and the challenges of an ageing population. The Organisation provides a setting where governments can compare policy experiences, seek answers to common problems, identify good practice and work to co-ordinate domestic and international policies.

The OECD member countries are: Australia, Austria, Belgium, Canada, the Czech Republic, Denmark, Finland, France, Germany, Greece, Hungary, Iceland, Ireland, Italy, Japan, Korea, Luxembourg, Mexico, the Netherlands, New Zealand, Norway, Poland, Portugal, the Slovak Republic, Spain, Sweden, Switzerland, Turkey, the United Kingdom and the United States. The Commission of the European Communities takes part in the work of the OECD.

OECD Publishing disseminates widely the results of the Organisation's statistics gathering and research on economic, social and environmental issues, as well as the conventions, guidelines and standards agreed by its members.

This work is published on the responsibility of the Secretary-General of the OECD. The opinions expressed and arguments employed herein do not necessarily reflect the official views of the Organisation or of the governments of its member countries.

ISBN 978-92-64-06394-5 (print)

ISBN 978-92-64-06407-2 (PDF)

Corrigenda to OECD publications may be found on line at: www.oecd.org/publishing/corrigenda.

$\mathrm{PISA}^{\mathrm{TM}}, \mathrm{OECD} / \mathrm{PISA}^{\mathrm{TM}}$ and the PISA logo are trademaks of the Organisation for Economic Co-operation and Development (OECD). All use of OECD trademarks is prohibited without written permission from the OECD.

(c) OECD 2009

You can copy, download or print OECD content for your own use, and you can include excerpts from OECD publications, databases and multimedia
products in your own documents, presentations, blogs, websites and teaching materials, provided that suitable acknowledgment of OECD as source
and copyright owner is given. All requests for public or commercial use and translation rights should be submitted to rights@oecd.org. Requests for
permission to photocopy portions of this material for public or commercial use shall be addressed directly to the Copyright Clearance Center (CCC)
at info@copyright.com or the Centre français d'exploitation du droit de copie (CFC) at contact@cfcopies.com. 


\section{Foreword}

In the past few decades there has been an increasing interest in the different educational experiences, success and eventual outcomes that prevail for males and females. Women often excel at school, however men often earn more and are more likely to hold positions of power in political and economic life. Looking at these inequalities, government policies cannot afford to be 'gender-blind' and must aim to develop policies for parity. If governments wish to create growth, employment and a better standard of living, policy advice reflecting gender differences is needed, and education could play a major role in this.

In the educational area, there are at least three reasons for studying gender differences. These include identifying the source of inequalities, fostering average performance and improving our understanding of how students learn.

Gender differences point to areas where student background, attitudes and characteristics significantly affect student performance. Understanding what can influence differences in student performance can help policy makers address quality and equity concerns. Using data from the OECD's Programme for International Student Assessment (PISA), this report addresses the following questions:

- Why do female and male students perform differently?

- What drives gender differences?

- Is there a need for gender-specific policies?

- Are there specific policies that would improve male or female student performance?

PISA explores the educational performance and attitudes of adolescent males and females. This report begins with a general summary of gender differences measured independently from PISA. It then considers the knowledge gained about gender-related issues through the PISA 2000, PISA 2003 and PISA 2006 assessments.

Some key findings include:

- In reading in PISA 2000, females significantly outscored males in all countries.

- In mathematics in PISA 2003, males often outscored females.

- In science overall in PISA 2006, there was no significant difference between males and females in the level of performance. However, when examining the different science competencies, females were better than males at identifying scientific issues, while males were better at explaining phenomena scientifically.

- Males and females did not have significantly different attitudes to to school science, but looking at their future aspirations, there were marked differences in their expectations of having a career in science at the age of 30 .

The report is the product of a collaborative effort between the countries participating in PISA, the experts and institutions working within the framework of the PISA Consortium, and the OECD. The report was drafted by John Cresswell, Miyako Ikeda, Maciej Jakubowski, Andreas Schleicher, Sophie Vayssettes and Pablo Zoido. The development of the report was steered by the PISA Governing Board, which is chaired by Ryo Watanabe (Japan). The report is published on the responsibility of the Secretary-General of the OECD.

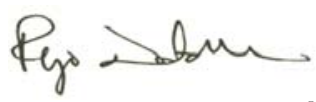

Ryo Watanabe

Chair of the PISA Governing Board

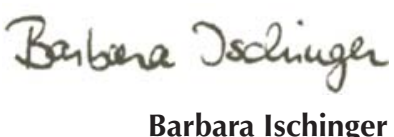

Director for Education, OECD 


\section{Table of Contents}

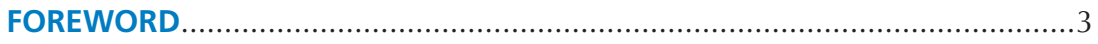

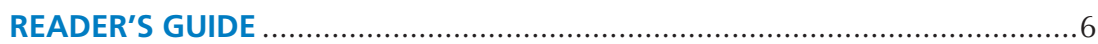

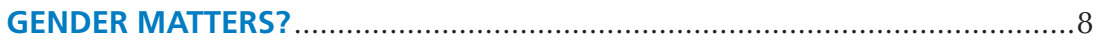

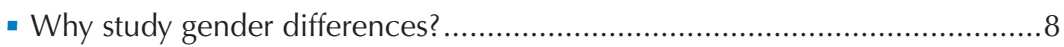

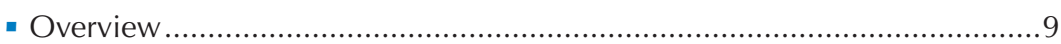

WHAT DOES THE LITERATURE SAY ABOUT GENDER DIFFERENCES

FROM EARLY CHILDHOOD TO THE LABOUR MARKET? ...........................

- The structure of the brain ........................................................................

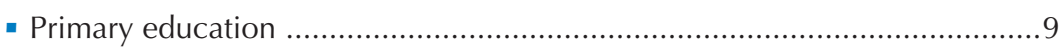

- Reading at grade 4 (PIRLS) ............................................................... 9

- Mathematics and Science at grade 4 (TIMSS) .......................................10

- Secondary education ............................................................................. 10

- Mathematics and science at grade 8 (TIMSS) .......................................10

- Secondary level attainment............................................................... 10

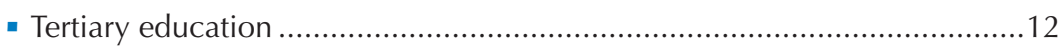

- Entrance into tertiary education ....................................................... 12

- Graduation from tertiary education.................................................... 13

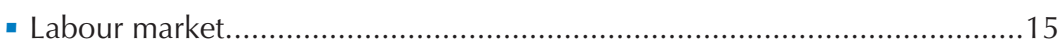

WHAT CAN PISA SAY ABOUT GENDER DIFFERENCES? ............................. 15

WHAT DID PISA 2000 TELL US ABOUT

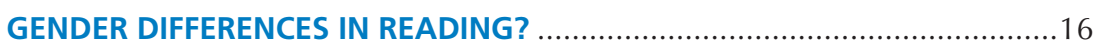

- Student performance ..................................................................... 16

- Trends in gender differences in reading between PISA 2000

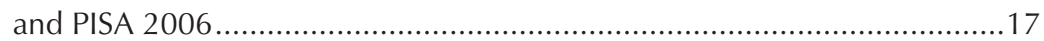

- Student interest and engagement in reading ............................................ 17

- Other gender differences found in PISA 2000 .......................................18

WHAT DID PISA 2003 TELL US ABOUT GENDER

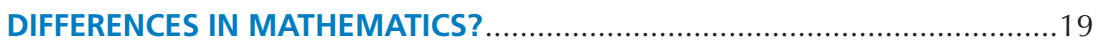

- Student performance................................................................. 19

- Trends in gender differences in mathematics between PISA 2003

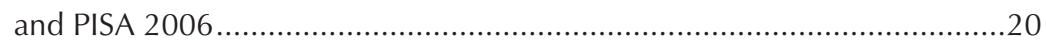

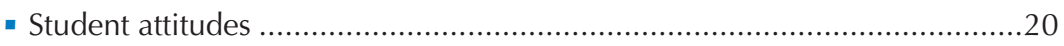

WHAT DID PISA 2003 TELL US ABOUT GENDER

DIFFERENCES IN PROBLEM SOLVING? .................................................21 
WHAT DID PISA 2006 TELL US ABOUT GENDER DIFFERENCES IN SCIENCE?.. 22

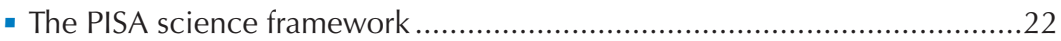

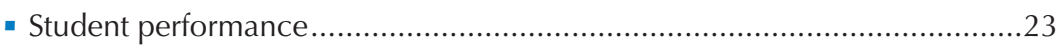

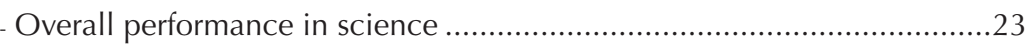

- Performance in the competency identifying scientific issues .....................24

- Performance in the competency explaining phenomena scientifically .......27

- Performance in knowledge about science ................................................32

- Performance in the "Physical systems" area of knowledge of science ......32

- Performance in the "Living systems" area of knowledge of science ...........33

- Performance in the "Earth and space systems" area of knowledge of science .. 33

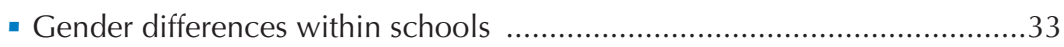

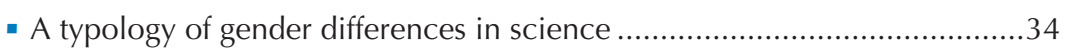

- Computer-based assessment of science (CBAS) in PISA 2006 ......................34

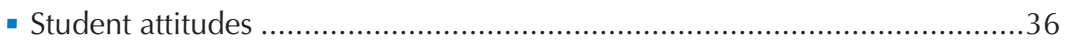

- Science performance and attitudes towards science ...................................37

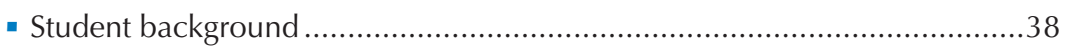

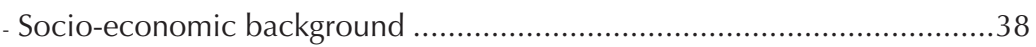

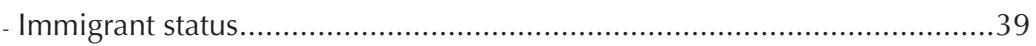

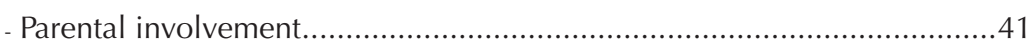

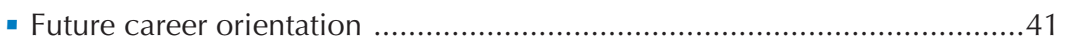

- Information on science-related careers and preparation for the future ......41

- Do students expect to pursue a scientific career? ........................................43

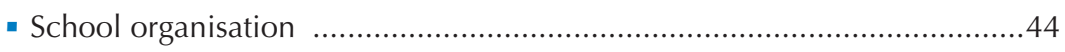

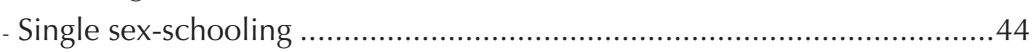

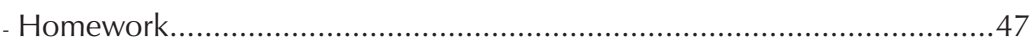

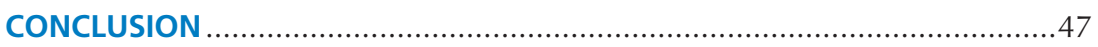

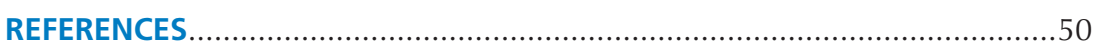

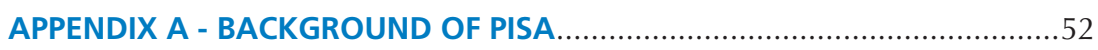

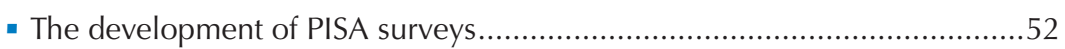

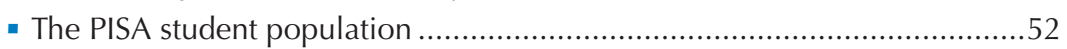

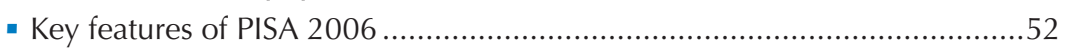

- The PISA 2006 science assessment framework ..............................................54

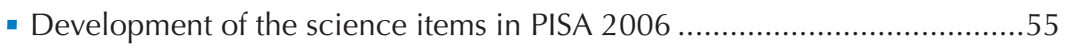

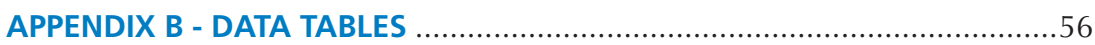




\section{Reader's Guide}

\section{Data underlying the figures}

The data referred to in this report are presented in Appendix B and, with additional detail, on the PISA website (www.pisa.oecd.org). Five symbols are used to denote missing data:

a The category does not apply in the country concerned. Data are therefore missing.

c There are too few observations to provide reliable estimates (i.e. there are fewer than 30 students or less than $3 \%$ of students for this cell, or too few schools for valid inferences).

$\mathrm{m}$ Data are not available or have been removed for technical reasons.

w Data have been withdrawn at the request of the country concerned.

$x$ Data are included in another category or column of the table.

\section{Calculation of the OECD average}

An OECD average was calculated for most indicators presented in this report. The OECD average corresponds to the arithmetic mean of the respective country estimates.

\section{Rounding of figures}

Because of rounding, some figures in tables may not exactly add up to the totals. Totals, differences and averages are always calculated on the basis of exact numbers and are rounded only after calculation.

All standard errors in this publication have been rounded to two decimal places. Where the value 0.00 is shown, this does not imply that the standard error is zero, but that it is smaller than 0.005 .

\section{Reporting of student data}

The report uses "15-year-olds" as shorthand for the PISA target population. PISA covers students who are aged between 15 years 3 months and 16 years 2 months at the time of assessment and who have completed at least 6 years of formal schooling, regardless of the type of institution in which they are enrolled and of whether they are in full-time or part-time education, of whether they attend academic or vocational programmes, and of whether they attend public or private schools or foreign schools within the country.

\section{Reporting of school data}

The principals of the schools in which students were assessed provided information on their schools' characteristics by completing a school questionnaire. Where responses from school principals are presented in this publication, they are weighted so that they are proportionate to the number of 15 year-olds enrolled in the school. 


\section{Reporting of parent data}

The parents of the students who were assessed provided information on their perception of their son's or daughter's schools and on the activities undertaken by their children at the age of 10 , by completing a parent questionnaire.

\section{Abbreviations used in this report}

The following abbreviations are used in this report:

ISCED International Standard Classification of Education

ISCO International Standard Classification of Occupations

S.D. Standard deviation

S.E. $\quad$ Standard error

\section{Significance tests and subgroup comparisons}

The significant statistics in this report have been highlighted in the figures and tables, using darker tone and bold print respectively. For further information, see the Annex A3 in PISA 2006: Science Competencies for Tomorrow's World (OECD, 2007a).

\section{Further documentation}

For further information on the PISA assessment instruments and the methods used in PISA, see the PISA 2006 Technical Report (OECD, 2009b) and the PISA website (www.pisa.oecd.org). 


\section{GENDER MATTERS?}

For the past few decades there has been an increasing interest in the different educational experiences, success and eventual outcomes that prevail for males and for females. The interest in this area was fuelled in part by a perceived lack of interest and success of females in a number of areas of schooling - notably mathematics and the physical sciences. In more recent times there has also been a focus on the lack of engagement and success of males, especially in the area of reading.

Educational policy has to take into account the existence of gender differences in performance to be effective in promoting quality student outcomes and equity. This report draws heavily on the OECD's Programme for International Assessment (PISA) where it has been found that female students do better in reading (OECD, 2001) and male students do somewhat better in mathematics (OECD, 2004). In science, the picture is more complex. It has been found that student attitudes and engagement explain, in part, gender difference in mathematics and reading, a finding that, by itself, can foster a better understanding of how students learn and thereby help design more effective educational policies (OECD, 2007a).

This report will look at the development of gender related issues during the years of childhood and adolescence. The report will:

- consider briefly gender differences measured outside the PISA assessment programme;

- review the knowledge gained about gender related issues from PISA 2000 and PISA 2003 when reading and mathematics respectively were the major domains of assessment, with attention also paid to the relationship between student performance and student attitudes;

- consider in more detail the results from the most recent PISA survey, PISA 2006, when science was the major assessment domain, considering also student attitudes to science and the environment.

\section{Why study gender differences?}

There are at least three reasons to study gender differences: $i$ ) to understand the source of any inequalities; ii) to improve average performance; and iii) to improve our understanding of how students learn. Gender differences point to areas where student background and characteristics significantly affect student performance. Understanding what drives differential student performance can foster the design of effective educational policies to address quality and equity concerns. Why do female and male students perform differently? What drives gender differences? Is there a need for gender specific policies? Are there specific policies that would improve male or female student performance? These are some of the questions that can be analysed by looking into gender differences.

The imperative for gender equity can be seen in a number of lights. Firstly there is a moral reason to ensure that one of the sexes is not disadvantaged compared to the other. The disadvantage may be the end result of many years of treatment based on culture, religion and tradition. The second imperative to raising the performance of one of the sexes to be similar to the other is the concomitant increase in economic and social benefits that this will bring. Belfield and Levin (2007) calculated the costs and benefits associated with an increase in education level (as measured by high school graduation). They found that there are both private benefits to the individual who graduates and fiscal benefits to the taxpayer through higher tax revenues because of increased earnings and lower government expenditures on health, crime, welfare, remedial education and other public services.

The countries with the smallest number of gender differences in performances and attitudes (Table 3.21, OECD, 2007a) include Portugal, Poland, Belgium, Switzerland, Ireland, Mexico, the Slovak Republic and 
Spain. In these countries it may be that efforts to improve student performance need to be targeted at both males and females, whereas in countries with a larger number of gender differences - for example the Netherlands, Iceland and Norway - it may be more useful to focus on one of the sexes.

\section{Overview}

This report begins with a short summary of gender differences from early childhood through to labour market participation. A discussion of how PISA can inform the consideration of gender differences follows. A brief section reviews gender differences in reading from PISA 2000 and in mathematics and problem solving from PISA 2003. A discussion of science in PISA 2006 follows, including information derived from the computer based assessment of science in PISA 2006. This section also includes discussion of parents' perceptions, and of the relationships between performance and socio-economic background, single-sex and mixed-sex schooling, students' attitudes to school and the amount of time that they spend on homework. The report also looks at trends in some of these relationships over time.

In summary, the report concludes that there are significant gender differences in educational outcomes, and these appear as students grow older and gain education and labour market experience. Despite differences in the structure of the brains of females and males, there is no conclusive evidence that these differences lead to later differences in educational outcomes. There is some evidence of gender difference in early educational experiences but they are confined to reading. As students progress in their education, however, gender differences become more pronounced. In addition, labour market outcomes show significant earning gaps in favour of males.

\section{WHAT DOES THE LITERATURE SAY ABOUT GENDER DIFFERENCES FROM EARLY CHILDHOOD TO THE LABOUR MARKET?}

\section{The structure of the brain}

In recent years there has been much interest in investigating potential links between the structure of the brain and differing educational outcomes for males and females. The OECD report, Understanding the Brain: The Birth of a Learning Science (OECD, 2007b), synthesised progress on the brain informed approach to learning (that is a detailed consideration of the relationship between the structure of the brain and a child's capacity and approach to learning) and addressed a number of key educational issues. There are, indeed, functional and morphological differences between the male and female brain. The male brain is larger, for instance, but when it comes to language, the relevant areas of the brain are more strongly activated in females. Determining the importance of these differences in structure is extremely difficult. No study to date has shown gender-specific processes involved in building up the networks in the brain during learning.

\section{Primary education}

Small gender differences appear at early stages of education. Universal primary education is widespread in most countries and few gender differences appear in attainment, that is, in terms of the proportions of males and females completing primary education. In terms of performance, on the other hand, international assessments of primary school students show significant gender differences in reading in favour of females. On the other hand, there are few gender differences apparent in mathematics and science.

\section{Reading at grade 4 (PIRLS)}

The latest cycle of the Progress in International Reading Literacy Study (PIRLS) conducted by the International Association for the Evaluation of Educational Achievement (IEA) took place in 40 countries in 2006 (including 19 OECD countries and 10 non-OECD countries and economies which also participated in PISA 2006). The target population was fourth-grade students. 
PIRLS found that females had significantly higher reading achievement than males in all except two countries, Luxembourg and Spain, where average achievement for males and females was equal. On average across the participating countries females scored 17 score points more than males in a test where the mean score was 500 and the standard deviation 100. In the OECD countries that participated the difference in favour of females was highest in New Zealand (24 score points). In terms of behaviour, PIRLS found that females reported more time than males reading books or magazines (1.5 hours vs. 1.3 hours), a difference being found in almost all participating countries. In comparison, on average, males reported more time than females reading on the Internet (1.0 hours vs. 0.9 hours) (Mullis, Martin, Kennedy and Foy, 2007).

\section{Mathematics and science at grade 4 (TIMSS)}

The IEA also conducts an assessment of student capacity in mathematics and science at grade 4 - the Trends in International Mathematics and Science Study (TIMSS). There were 36 countries and economies participating in TIMSS 2007. At grade 4 level, the TIMSS 2007 data show that on average in the participating countries there was not a gender difference in overall mathematics performance. Females had significantly higher scores in eight countries, while males had significantly higher scores in twelve countries (Mullis, Martin \& Foy, 2008).

In science, at the fourth grade, performance for females was slightly higher than for males across the participating countries (3 points), although the situation varied from country to country. In more than half the countries (22), the difference in average achievement in science between females and males was negligible at the fourth grade. Males had higher average science achievement than females in 8 countries (Martin, Mullis \& Foy, 2008).

\section{Secondary education}

\section{Mathematics and science at grade 8 (TIMSS)}

The second component of TIMSS is a study of the mathematics and science achievement of students at grade 8 . At the eighth grade, on average across the TIMSS 2007 countries, females had higher average achievement than males in mathematics. Females had higher achievement than males in 16 of the participating countries, while males had higher achievement than females in 8 countries (Mullis, Martin \& Foy, 2008).

In science, at the eighth grade, on average across the TIMSS 2007 countries, females had higher average achievement than males by 6 points. Females had higher achievement than males in 14 of the participating countries. Males had higher achievement than females in 11 countries (Martin, Mullis \& Foy, 2008).

\section{Secondary level attainment}

Graduation rates for female students are generally higher than for males. The 2008 edition of the OECD report Education at a Glance 2008 - OECD Indicators (OECD, 2008) gives a detailed description of education systems in all OECD member countries and some partner countries (Brazil, Chile, Estonia, Israel, the Russian Federation and Slovenia). Data on gender differences in secondary education cover a number of important areas including overall attainment and graduation rates in different programmes. In general, the data show a gap in favour of females in terms of graduation rates, especially in general programmes.

In Table 1 it can be seen that across the OECD in 2006 there was an average of $79 \%$ of males and $87 \%$ of females who were upper secondary graduates. However, within some countries the differences between males and females were marked. The largest differences in favour of females were observed in New Zealand $(23 \%)$, Norway $(23 \%)$ and Iceland (19\%). The country with the biggest difference in favour of males was Turkey (7\%). Comparing the 2006 data with the figures for 2000 shows that there has been a slight overall 
Figure 1

Graduation rate at upper secondary level for general programmes, by gender (2006)

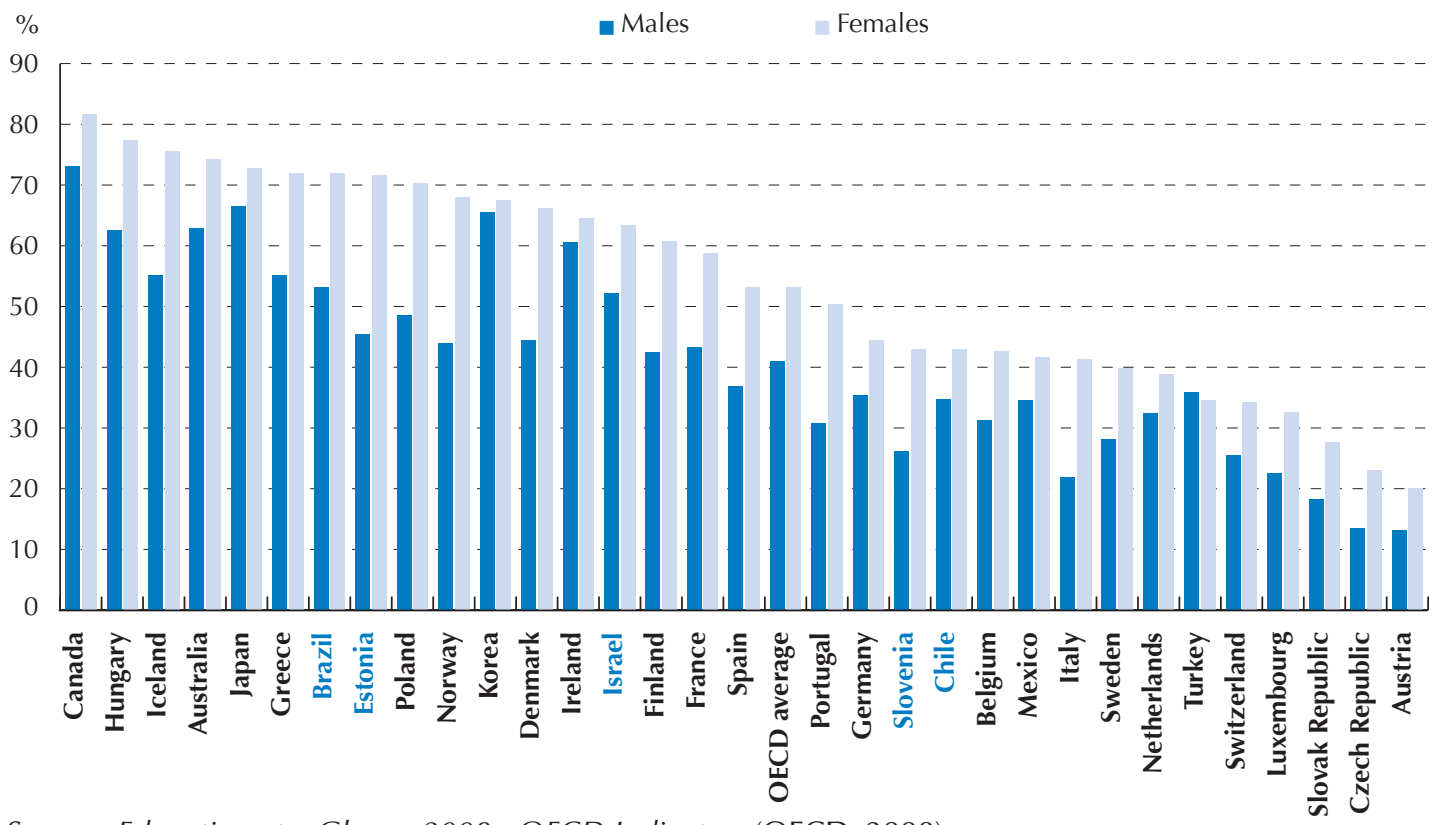

Source: Education at a Glance 2008 - OECD Indicators (OECD, 2008).

Figure 2

Graduation rate at upper secondary level for vocational and pre-vocational programmes, by gender (2006)

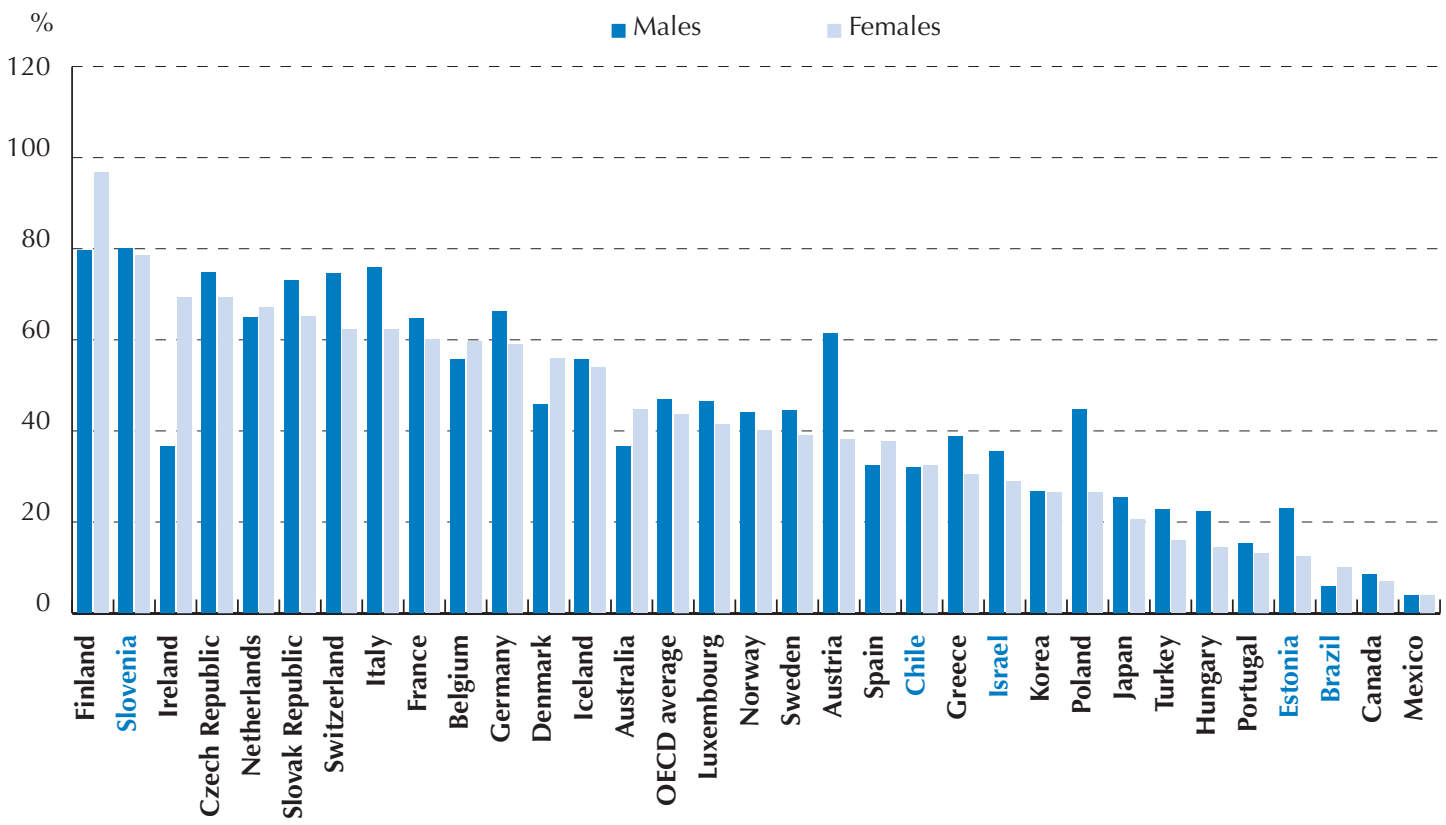

Source: Education at a Glance 2008 - OECD Indicators (OECD, 2008). 
increase in the percentage of upper secondary school graduates, but the overall difference between percentages of males and females is little changed, the figures for 2000 having been $74 \%$ of males and $80 \%$ of females (OECD, 2000).

It is possible to further analyse upper secondary graduation rates into graduation rates for general programmes and for pre-vocational and vocational programmes. Figure 1 shows that graduation rates for general programmes are higher for females in all countries. The largest difference in the OECD countries is in Norway where $44 \%$ of males compared to $68 \%$ of females graduate. Across the OECD the average is $41 \%$ for males and $53 \%$ for females. In the partner countries the largest difference is in Estonia $(45 \%$ for males and $72 \%$ for females).

Looking at graduation rates for pre-vocational and vocational programmes, Figure 2 shows a different pattern, with around two-thirds of the countries having a greater percentage of males graduating. In Austria there are $23 \%$ more males than females graduating in pre-vocational and vocational programmes. In Poland this figure is $18 \%$ and in Italy $14 \%$. Among the countries where females predominate in pre-vocational and vocational programmes, Ireland has the largest difference with 33\% more females, followed by Finland (17\%) and Denmark (10\%).

\section{Tertiary education}

In tertiary education, females have been narrowing traditional gaps with male students. In mathematics and computer science however, graduation rates for females are still lower than the graduation rates for males. In today's global economy, where education and human capital accumulation drive innovation and competitive advantage, increasing graduation rates among female students is for many countries the most immediately available opportunity for increasing the output of graduates in these critical areas.

As the more detailed analysis below indicates, while the number of female students in tertiary education has increased more rapidly than that of males, the proportion of women choosing science and technology studies is still lower than that of men. Furthermore, even though the share has often increased in countries which had the lowest proportions of female science and technology students, trend analysis suggests that the overall proportion of female science and technology graduates tends to level out at around $40 \%$.

\section{Entrance into tertiary education}

Since PISA focused on science in 2006, it is relevant to look at the entry of students into tertiary education and, in particular, to examine the taking up of various science based courses (life sciences, physical sciences, computing, and mathematics and statistics). It can be seen (Figure 3) that females dominate in the life sciences in all countries. The highest percentage is in Slovenia where $76 \%$ of students in life science courses are female. At the other extreme the numbers of females taking up computing courses remain much lower than males. In Belgium only $7 \%$ of entrants to computing courses are female, with the highest proportion of female entrants being $34 \%$ in Mexico.

The OECD's Global Science Forum in its policy report, Evolution of Student Interest in Science and Technology Studies (OECD, 2006b), found that women were strongly under-represented in science and technology studies. This was considered to be important because, with the number of males at a level where a large increase is not likely, female students are the most obvious resource for increasing science and technology enrolments.

The choice of discipline appears to be highly gender-dependent. In most countries, women constitute less than $25 \%$ of computing and engineering students. In contrast, women are consistently more numerous than men in life sciences. 
Figure 3

Proportion of females in new entrants at tertiary level, by field of education

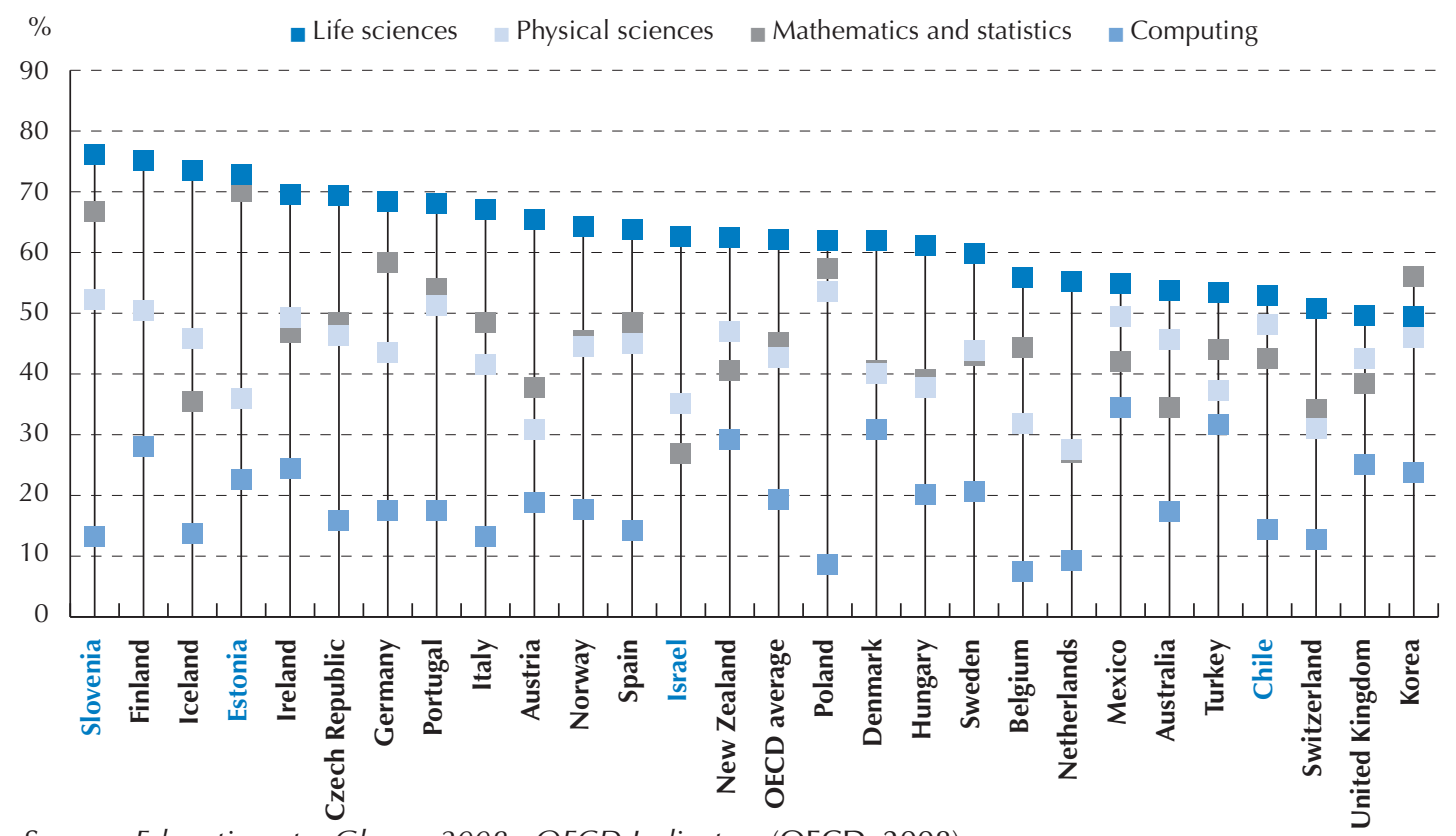

Source: Education at a Glance 2008 - OECD Indicators (OECD, 2008).

The report also concluded that there were significant differences between males and females in their attitudes to science. The Global Science Forum reported that it appeared young female students may suffer from stereotypes in relation to external expectations (those of parents, teachers and society in general) because despite having marks at least as good as males, females are usually not encouraged to pursue science and technology career paths by their families, teachers and career advisors. Females tended to undervalue their own performance, and hence their ability to pursue science and technology. There also may be a lack of role models for females (famous scientists, family members, etc.). Students' attitudes to careers are formed at secondary school and PISA provides a great deal of information on this which is discussed later in the report.

\section{Graduation from tertiary education}

As Figure 4 shows, in nearly all OECD countries the percentage of females graduating for the first time is larger than the percentage of males (OECD, 2008). Furthermore, as Figure 5 shows, on average in OECD countries, more than $70 \%$ of the tertiary graduates in the humanities, arts, education, and health and welfare are females, whereas only around $25 \%$ of those graduating in mathematics and computer science or engineering are females.

Figure 5 also shows that the percentage of graduates who are female declines as the level of education increases (OECD, 2008). The proportions of first or second tertiary-type A degree graduates in 2006 who were female were $58 \%$ and $56 \%$ respectively, and only $43 \%$ of advanced research qualifications, the highest level of education, were awarded to females. In OECD countries, the gap between males and females at this highest level of education has decreased between 2000 and 2006 - in $200039 \%$ of the graduates were female. 
Figure 4

Tertiary-type A graduation rates, by gender (2006)

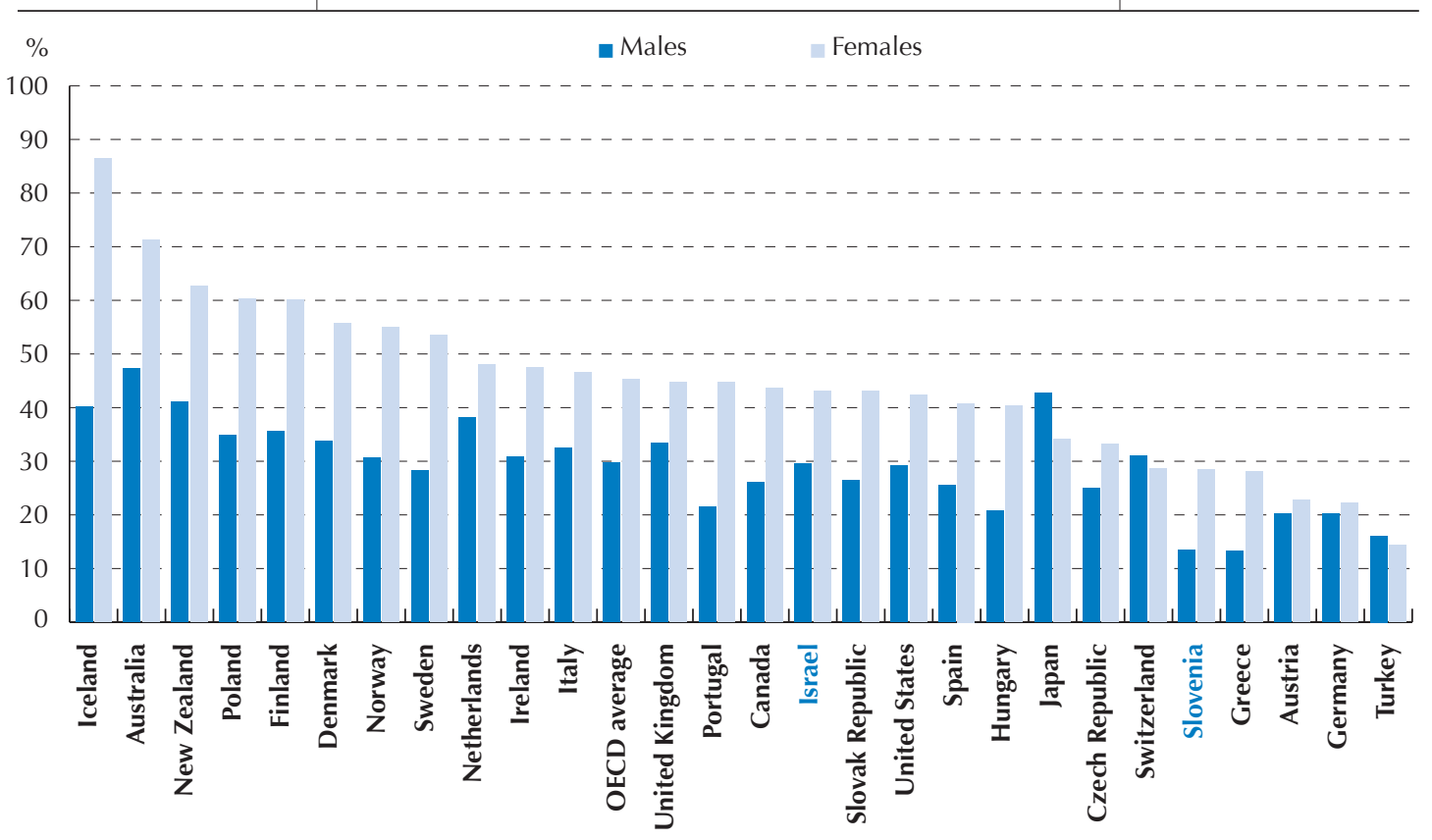

Source: Education at a Glance 2008 - OECD Indicators (OECD, 2008).

Figure 5

Percentage of tertiary-type A qualifications awarded to females and breakdown of tertiary graduates by field of education, OECD average $(2000,2006)$

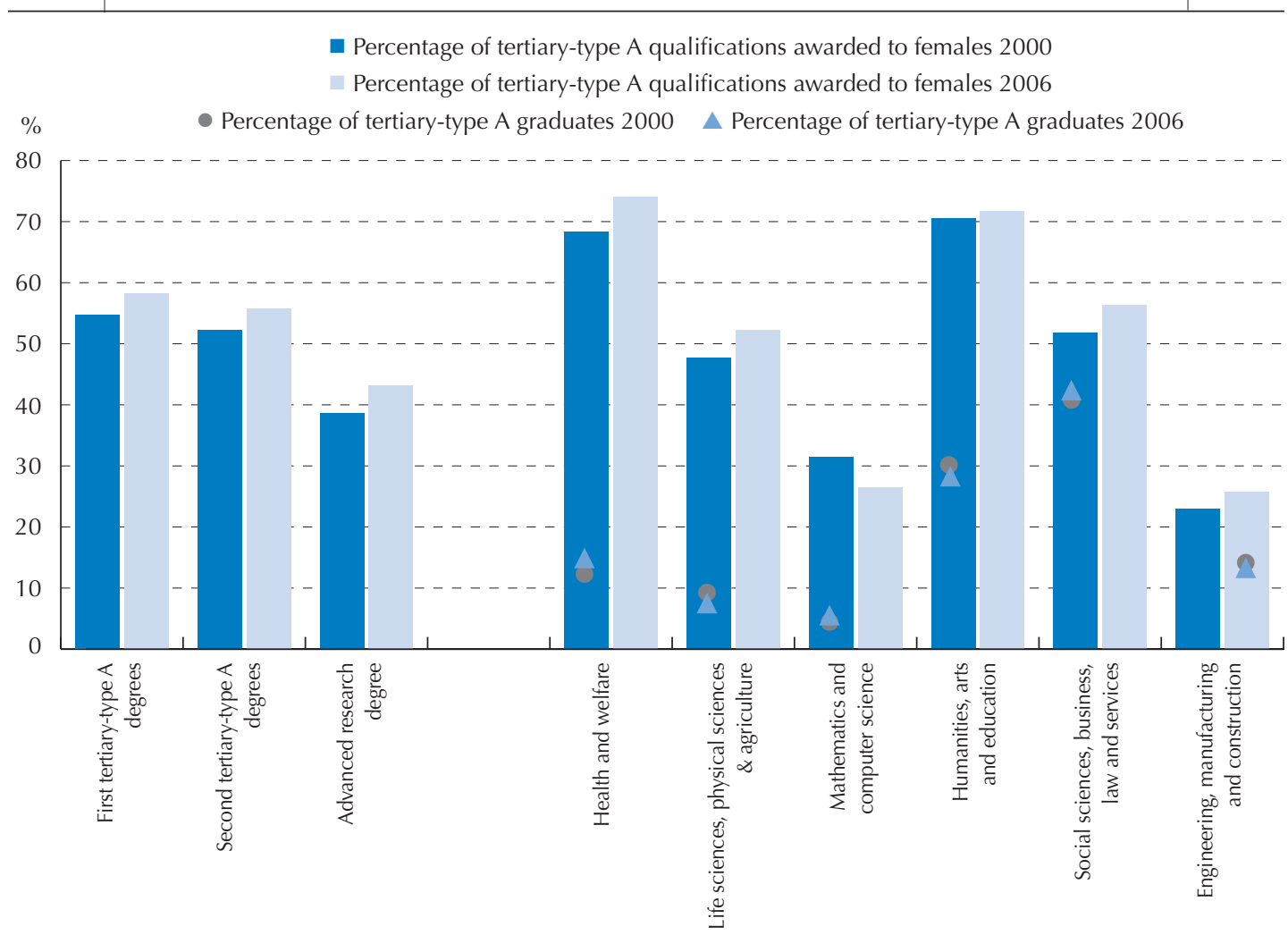

Source: Education at a Glance 2008 - OECD Indicators (OECD, 2008). 
The United States may provide an example of what is happening in a number of OECD countries. In examining the physical sciences in the US, Taasoobshirazi and Carr (2008) wrote that the underrepresentation of women in the sciences is a significant and well documented societal concern and they cite Miller (2006) and Stake (2006). Using figures from the National Science Foundation, they found that in recent years, women had received $34 \%$ of the master's degrees in computer science, $21 \%$ of the master's degrees in physics, $41 \%$ of the master's degrees in chemistry, and $21 \%$ of the master's degrees in engineering. Results for doctoral degrees were similar: women received 19\% of the doctoral degrees in computer science, $13 \%$ in physics, $32 \%$ in chemistry, and $17 \%$ in engineering. Thus, they concluded that women were greatly underrepresented in more advanced science degrees and degrees involving physics and engineering.

In relation to attitudes to science, the Global Science Forum report (OECD, 2006b) noted that "many surveys have shown clear differences between males and females in their experience with, interest in, and attitudes to science and engineering, so it is not surprising to see these attitudes transposed into differences in their choice of studies. Furthermore, females tend to show a stronger interest in people rather than facts or things, and these differences may be amplified in the way science and technology are taught, and in the perception of science and technology careers. These differences do not appear to be related to ability, since females tend to succeed well in science and technology, especially in the early stages. Some experts are working on the re-engineering of the education process to offer equal opportunity to both genders, but no consensus has yet emerged concerning the assumptions, methods, or results that can be achieved."

\section{Labour market}

Gender differences are apparent in labour market outcomes. In many countries the earnings of males and females are different for all levels of educational attainment. With few exceptions, females earn less than males with similar levels of educational attainment. For all levels of education, average earnings of females between the ages of 30 and 44 range from $51 \%$ of those of males in Korea to $89 \%$ in Slovenia (OECD, 2008, p.163).

Although the gap in earnings between males and females is explained in part by factors other than education (that is by different choices of career and occupation, by differences in the amount of time that males and females spend in the labour force, and by the relatively high incidence of part-time work among females), it is appropriate to examine these differences further, including using data from PISA 2006 to look at the attitudes of students to science before they enter the workforce.

\section{WHAT CAN PISA SAY ABOUT GENDER DIFFERENCES?}

PISA is well placed to further our understanding of the emerging patterns of gender differences developing through childhood and adolescence suggested by the evidence presented above. Because of its widespread implementation and the nature of the assessment, PISA can provide a great deal of information about gender differences in student performance and attitudes at the secondary level. These measurements are made at an important and formative time of an adolescent's life and can provide some insight into the patterns of behaviour that may develop. ${ }^{1}$

PISA seeks to provide information about the key competencies of 15-year-old students and is administered every three years in OECD member countries and a group of partner countries and economies. It assesses the extent to which students near the end of compulsory education have acquired the knowledge and skills that are needed for participation in society, focusing on student competencies in the key areas of reading, mathematics and science. PISA seeks to assess how well students can extrapolate from what they have learned at school and apply their knowledge in novel settings. 
PISA can be used to give information about the performance of education systems, the equity in distribution of learning opportunities, consistency of school performance within a country and student dispositions to learning and to issues in the community. Performance in PISA is reported both in terms of a score (with mean of 500 and a standard deviation of 100 across OECD countries) and also as a proficiency level, which describes the tasks that a student can do. In science there are six proficiency levels, with Level 6 representing the highest capacity.

This report focuses on the gender differences observed in the first three PISA surveys. In PISA 2000 reading was the major area of assessment, in 2003 it was mathematics and in 2006 it was science. There are sections below devoted to each of these areas of assessment, with a more detailed description of the most recent survey in 2006 which focused on students' competency in science, offering a comprehensive international measurement in this area. In today's technology-based societies, understanding fundamental scientific concepts and theories and the ability to structure and solve scientific problems are more important than ever. PISA 2006 assessed not only science knowledge and skills, but also the attitudes which students had towards science.

\section{WHAT DID PISA 2000 TELL US ABOUT GENDER DIFFERENCES IN READING?}

PISA 2000 focused on reading and studied gender differences in great detail. One of the main findings of the initial PISA 2000 report was that females outperform males in reading and in all of its subcomponents. It was also the case that females showed a lot more interest than males in reading and in part this explains the performance gap.

\section{Student performance}

The study of gender differences has always been one of the main areas of interest to countries participating in PISA. In the first cycle of PISA in 2000 the main focus of assessment was reading and a chapter of the initial report, Knowledge and Skills for Life: First results from PISA 2000 (OECD, 2001), was devoted to gender differences. There were some large gender differences observed in both student performance and student attitudes.

In all participating countries females significantly outperformed males. The advantage to females, on average across the OECD, was 32 score points. This is nearly one half of a proficiency level (there are five proficiency levels in reading). There was, however, significant variation between countries in the size of gender differences. The largest difference between males and females was in Finland (the top-scoring country overall) with a difference of 51 score points. It must be pointed out, however, that males in Finland did not score poorly in PISA - there is no other country where males scored more highly - it is just that the females obtained exceptionally high results.

The distribution of performance showed strong contrasts between females and males. In the PISA 2000 assessment $11.9 \%$ of females performed at the highest level of proficiency (Level 5) compared with $7.2 \%$ of males. In all OECD countries males were more likely than females to be among the lowest-performing students. At Level 1 and below on the combined reading literacy scale, the ratio of males to females ranged from 1.3 to 3.5 .

In PISA 2000 three areas of reading competency were measured on the retrieving information scale, the interpretation scale and the reflection and evaluation scale. With few exceptions, females outperformed males on every scale, with gender differences strongest in reflection and evaluation. On average, gender differences were 45 score points in favour of females on the reflection and evaluation scale, compared with 29 score points on the interpretation scale and 24 score points on the retrieving information scale. 


\section{Trends in gender differences in reading between PISA 2000 and PISA 2006}

Since 2000 there has been a great deal of interest in whether any changes have occurred in reading performance. Overall, performance in reading declined slightly (though not statistically significantly) between 2000 and 2006 - by 6 score points on average in the countries where valid comparisons could be made (Table 6.3a, OECD, 2007a). ${ }^{2}$ At the same time the difference between males and females increased from 32 to 38 score points.

This increased difference is largely due to the fact that between 2000 and 2006 the performance of males decreased (statistically significantly) by 10 score points. The largest decline in an OECD country was in Spain with a 38 score point decrease. There were also statistically significant decreases in the performances of males in eight other OECD countries - Iceland (28 score points), Japan (25 score points), Greece and Norway (24 score points), Italy (22 score points), France (21 score points), Mexico and Australia (18 score points).

Among the partner countries the largest decline in male scores was in Argentina (48 score points) with statistically significant declines also in Romania (47 score points), Bulgaria (34 score points), the Russian Federation (23 score points) and Thailand (21 score points).

In terms of the distribution of performance, the proportions of males and females performing at the highest level in 2006 (6\% of males and $11 \%$ of females) were very similar to those in 2000 (7\% of males and $12 \%$ of females). For the students who were at the lower proficiency levels (i.e. Level 1 and below) in 2006 there were $26 \%$ of males and $14 \%$ of females, compared to the results of PISA 2000 where there were $22 \%$ of males and $13 \%$ of females.

\section{Student interest and engagement in reading}

In PISA 2000 students were also asked questions about their interest in reading, their reading habits, what sort of material they read and how long they read for. The responses from these questions were combined to construct a number of indices about students' interest and engagement in reading. These indices revealed some significant differences between males and females. PISA 2000 found that students' interest and engagement was associated with a significant portion of the gender differences in performance.

The PISA index of interest in reading was derived from students' level of agreement with the following statements: i) I read because reading is fun, I wouldn't want to give it up; ii) I read in my spare time; and iii) when I read, I sometimes get totally absorbed. A four-point scale with the response categories "disagree", "disagree somewhat", "agree somewhat" and "agree" was used.

As for many of the indices discussed below, the average score across the OECD on the PISA index of interest in reading was standardised at 0 with a standard deviation of 1 . Across the OECD males had an average score of -0.24 while females had an average score of 0.26 (i.e. half of a standard deviation difference). In all countries males expressed less interest in reading than females. More generally, however, about half of the students surveyed in PISA 2000 were positive about reading with 48\% of them agreeing or agreeing somewhat that reading is fun and that they would not want to give it up.

While it is not possible to make a causal link between student interest and performance because many factors are involved, the evidence in PISA 2000 suggests that they are associated. One standard deviation difference in the index of student interest is associated with a change of 27.9 score points on the PISA reading scale. 
Students were also asked about their habits regarding reading. The PISA index of engagement in reading was derived from students' level of agreement with the following statements: $i$ ) I read only if I have to; ii) reading is one of my favourite hobbies; iii) I like talking about books with other people; iv) I find it hard to finish books; v) I feel happy if I receive a book as a present; vi) for me reading is a waste of time; vii) I enjoy going to a bookstore or a library; viii) I read only to get information that I need; and $i x$ ) I cannot sit still and read for more than a few minutes. A four-point scale with the response categories "strongly disagree", "disagree", "agree" and "strongly agree" was used.

Across the OECD in 2000, $46 \%$ of males read only if they had to, compared with $26 \%$ of females. In addition, $58 \%$ of males read only to obtain information that they needed, as opposed to $33 \%$ of females. Similarly, $25 \%$ of males reported that reading is one of their favourite hobbies, compared with $45 \%$ of females. Males also tend to spend much less time reading than females, with $30 \%$ of them, on average, reporting that they read for enjoyment for more than 30 minutes each day, compared to $45 \%$ of females.

Following the production of the PISA initial reports for each cycle of PISA, further focused reports are also produced. In the thematic report Reading for Change - Performance and Engagement across Countries: Results from PISA 2000 (OECD, 2002) students were categorised into different clusters according to their reading habits - there were four types of students described: i) least diversified readers; ii) moderately diversified readers; iii) diversified readers in short texts; and iv) diversified readers in long texts.

As shown in Table 3, the classification highlights a clear difference in the reading patterns of males and females. Roughly equal proportions of males and females fell into each of the first two groups. However, $34 \%$ of males fell into the "diversified readers in short texts" group, compared with $23 \%$ of females, while conversely $29 \%$ of females, compared with $16 \%$ of males, fell in the "diversified readers in long texts" group, where students identify themselves as readers of newspapers, magazines, books (especially fiction), but not comics.

\section{Other gender differences found in PISA 2000}

PISA 2000 investigated a number of other student characteristics including students' sense of belonging to school and students' level of participation at school, i.e., their level of participation in school activities. The thematic report Student Engagement At School, a Sense Of Belonging and Participation: Results from PISA 2000 (Willms, 2003) found a similar sense of belonging for females and males. It is possible to express a comparison between two measures using odds ratios, which express the likelihood of an event occurring in one group of the population compared to the likelihood of the same event occuring in another group - if the value is 1.0 then the both events are equally likely to occur. On average, the odds of a female having a low sense of belonging were 0.98 that of a male, not statistically significantly different, indicating that males and females were equally likely to have a low sense of belonging. However, the odds ratio of females having a low sense of participation in school was 0.93 , which suggested that the likelihood of a female having low participation was about $7 \%$ less than that of a male. This difference was statistically significant.

PISA 2000 also showed differences between males and females in their preferred modes of learning. These differences were described in the thematic report Learners For Life: Student Approaches To Learning: Results From PISA 2000 (Artelt et al, 2003). The main findings of the report were:

- In general, when approaching a learning task, females were better at working out what knowledge and skills they needed to know to solve the problem, whereas males were better at processing information.

- Motivation showed contrasting gender differences. In most countries females expressed significantly greater reading interest and claimed more effort and persistence. On the other hand, males showed significantly more interest in mathematics in most countries. 
- Students' self-related beliefs showed similar patterns, with females generally confident in their verbal abilities and males in their mathematical abilities. A particular advantage for male students, their biggest strength outside the mathematics domain, was their confidence in being able to succeed in tasks, even where they found them difficult. Even though the extent of this advantage was modest, its incidence was widespread: it was identifiable at a statistically significant level in all but three OECD countries.

- Males and females have different preferences in the way that they learn with their peers: in most countries males were more likely than females to be positive about competitive learning situations. In about half of countries, females were more likely than males to say that they like learning co-operatively; in the rest there was no difference, except in Korea where males favoured co-operative learning more.

In summary the results of PISA 2000 show clearly an advantage to females in reading, not only in the performance on the assessment, but also in the attitudes and engagement that females have to reading.

\section{WHAT DID PISA 2003 TELL US ABOUT GENDER DIFFERENCES IN MATHEMATICS?}

The broader gender patterns in later career and occupational choices are already apparent in the mathematics performance of 15-year-old males and females as observed by PISA. Gender patterns in mathematics performance are fairly consistent across OECD countries (Learning for Tomorrow's World - First Results from PISA 2003). In most countries male students outperformed female students in the combined mathematics scale and every subscale. In terms of attitudes, the study found even greater gender differences. Female students consistently reported lower levels of enjoyment, interest and motivation than their male peers, as well as higher levels of anxiety, helplessness and stress in class.

Taken together, the difference between males and females in performance in mathematics, on the one hand, and attitudes towards the subject, on the other, are highly relevant for policy makers, as these data reveal inequalities between the sexes in the effectiveness with which schools and societies promote motivation and interest.

\section{Student performance}

The results from the PISA 2003 mathematics assessment revealed an overall gender difference of 11 score points in favour of males, the largest difference in favour of males being 23 score points in Korea. The only country with a significant difference in favour of females was Iceland with a 15 score point difference. Some were are also apparent in the distribution of performance across the six proficiency levels in mathematics. On the combined mathematics scale, $17 \%$ of males on average across the OECD achieved the highest two proficiency levels (Levels 5 and 6) compared with 12\% of females. However, there were no such large differences at the lowest levels, with $21 \%$ of males and $22 \%$ of females achieving at Level 1 or below.

In addition to the overall mathematics scale, PISA 2003 provided measures of students' achievements in four content areas. Taking account of the research literature on this subject, and following an in-depth consensus building process among OECD countries on what would be an appropriate basis to compare mathematics performance internationally, the four content areas established were:

- Space and shape which relates to spatial and geometric phenomena and relationships;

- Change and relationships which involves mathematical manifestations of change as well as functional relationships and dependency among variables;

- Quantity which involves numeric phenomena as well as quantitative relationships and patterns; and

- Uncertainty which involves probabilistic and statistical phenomena and relationships. 
Overall, the gender differences were largest in the space and shape scale, where there were statistically significant performance differences between males and females in all OECD countries except Finland, Norway, the Netherlands and Japan. Across the OECD countries, males performed on average 17 score points higher than females on this scale. Females outperformed males in only one country, Iceland. The difference in favour of males reached more than 35 score points, equivalent to half a proficiency level in mathematics, in the Slovak Republic and in the partner country Liechtenstein (Table 2.1c, OECD, 2004a).

In terms of proficiency levels, gender differences in space and shape were most clearly visible at the top end of the scale: on average across OECD countries, $7 \%$ of males reached Level 6 , while only $4 \%$ of females did so. In the Czech Republic, Japan, Korea, the Slovak Republic, Switzerland and the partner country Liechtenstein, the gender gap at Level 6 was around 6\% (Table 2.1b, OECD, 2004a).

On the change and relationships scale males outperformed females in 17 OECD countries and four partner countries, but generally only by small amounts (Table 2.2c, OECD, 2004a). The average performance difference between males and females was only 10 score points, a somewhat smaller gap than the 16 score point difference found for the space and shape scale. Only in Iceland did females outperform males. Nevertheless, as in the case of space and shape, gender differences tended to be larger at the top end of the scale (Table 2.2b, OECD, 2004a).

Consistent with the findings for the two scales described above, males showed an advantage on the quantity scale, but gender differences here tended to be even smaller than for either the space and shape or the change and relationships scales. The distributions of males and females by proficiency level were relatively similar, with a few more males than females at the top end of the scale (Table 2.3b, OECD 2004a). Sixteen countries showed differences in favour of males. Again, Iceland was the only country where females performed statistically significantly above males (Table 2.3c, OECD, 2004a).

Gender differences were also observed in the uncertainty scale in favour of males, where performance differences occurred in 24 out of the 30 OECD countries.

\section{Trends in gender differences in mathematics between PISA 2003 and PISA 2006}

Comparisons of mathematics performance between different cycles of PISA can only be made between 2003 and 2006, since 2003 was the first cycle in which mathematics was the major assessment domain. Comparisons over such a short time do not necessarily indicate a long term trend and need to be treated with caution.

Overall there was no change to the gender difference on the combined mathematics scale between 2003 and 2006 - the performance advantage of males remained unchanged at 11 score points. However, there were changes in gender differences in some individual countries. In Austria, there was a 15 score point increase in the gender difference in favour of males, the average score for females having decreased by 8 score points while that for males increased by 7 score points. There was a significant decrease in gender difference in Iceland, the position changing from females having significantly outperformed males in 2003 to no significant difference in 2006: between 2003 and 2006 the average scores for females and males decreased by 15 score points and 4 score points respectively. In Greece, there was a gender difference change of 15 score points in favour of females over the period, the average female score having risen by a significant 21 score points while the male average score rose by 7 score points.

\section{Student attitudes}

PISA 2003 showed that gender differences in students' attitudes and approaches towards mathematics are even more pronounced than gender differences in performance. 
While performance differences in mathematics tended to be modest, there were marked differences between males and females in their levels of interest in and enjoyment of mathematics as well as in their self-related beliefs, emotions and learning strategies related to mathematics. For example, in 21 out of the 40 participating countries and economies males expressed stronger levels of interest in and enjoyment of mathematics than females. Gender differences in instrumental motivation in mathematics (which is the motivation related to doing a subject with the aim of gaining an advantage sometime in the future) tended to be even greater than the gender differences in interest in mathematics, suggesting that males may be more motivated to learn because they believe that mathematics will help them in their later careers. With respect to students' use of learning strategies, gender differences were less pronounced.

A similar picture emerged when looking at students' mathematics-related self-efficacy beliefs, self-concepts and anxiety. Females tended to report lower mathematics-related self-efficacy than males in almost all countries, while males tended to have a more positive view of their abilities than females. Females experienced significantly more feelings of anxiety, helplessness and stress in mathematics classes than males in 32 out of the 40 countries and economies.

\section{WHAT DID PISA 2003 TELL US ABOUT GENDER DIFFERENCES IN PROBLEM SOLVING?}

In PISA 2003, the opportunity was taken by participating countries to implement an innovative assessment of students' problem-solving skills. The aim was to design a test that measured students' cross-disciplinary problem-solving skills, with performance therefore not dependent on students' capacities in mathematics or science. Students were required to identify problems in various settings, choose relevant information or constraints, represent possible alternatives or solution paths, develop solution strategies, solve the problem and communicate the solution. The problem-solving component was an integral part of the survey and gave further information about the link between the analytical reasoning skills needed in mathematics and those needed in problem solving. The extent to which the advantage of male students in mathematics performance was replicated in problem solving could give clues as to whether males do better in mathematics because they have mastered the subject better or because they have particular generic skills that help them solve mathematical problems.

As in the other assessment areas, scores were standardised to an OECD average of 500 score points and a standard deviation of 100 - all countries participating in PISA 2003 participated in the problem-solving assessment. There were three proficiency levels described in problem solving.

Only a few countries showed statistically significant gender differences in problem solving. In Iceland, Norway and Sweden, as well as in the partner countries Indonesia and Thailand, female students outperformed male students in problem solving. The partner economy Macao-China was the only participant where male students outperformed female students. As in mathematics and reading (Table 5.1, OECD, 2004b), the advantage that female students had in problem solving in Iceland was by far the largest compared to the other participating countries and economies: female students scored 30 score points more than male students, representing a third of a proficiency level. In the remaining countries the largest gap in either direction was 12 score points or less.

In terms of proficiency levels, there were typically slightly more male than female students at both the lowest and the highest proficiency levels. On average in OECD countries, $18 \%$ of male students and $16 \%$ of female students were below Level 1 , while $19 \%$ of male students and $18 \%$ of female students reached Level 3.

The small number of gender differences observed in problem solving may indicate that female and male students can draw on their own specific strengths when it comes to cross-disciplinary tasks. Male 
students' strengths in mathematics do not appear to derive from a superiority in analytical reasoning skills. Rather, it seems that gender-specific strengths balanced out in a way that led to relatively equal outcomes for both genders in problem-solving performance. This may be an indication that in many countries there were no strong overall disadvantages for either male students or female students as learners, but merely gender-specific strengths or preferences for certain subjects.

In this sense, the problem-solving assessment provided a good overall indicator of educational outcomes for males compared with those of females in individual countries, and hence also an indicator of the extent to which societies have removed gender-based disadvantages in cognitive performance. Problem solving is, therefore, an area not affected by particular characteristics of one part of the curriculum that may favour one group over another.

\section{WHAT DID PISA 2006 TELL US ABOUT GENDER DIFFERENCES IN SCIENCE?}

The remainder of the report focuses on the most recent PISA survey in 2006 when science was the major domain of assessment. There is a detailed description of the assessment framework and some sample items are also described. An analysis of results from the computer based assessment of science (CBAS) is undertaken in an attempt to further understand the reasons behind gender differences in science.

The results of the most recent PISA survey are described in PISA 2006 - Science Competencies for Tomorrow's World (OECD, 2007a). Gender differences on the overall science scale were small. In PISA 2006 , for the first time, it was possible to study science performance in detail. As will be described in more detail in subsequent sections, unlike the position in reading and mathematics, gender patterns in science were not consistent across subscales. Males outperformed females in explaining phenomena scientifically while females outperformed males in the scale identifying scientific issues. In the scale using scientific evidence no clear gender differences emerged. An analysis of gender patterns in different areas of knowledge revealed some significant differences. Males tended to outperform females in the areas of "Physical systems" and "Earth and space systems". The area of "Living systems" however showed few significant gender differences.

While in many countries the differences between the genders are small relative to differences within each gender, overall performance could be raised significantly if the factors behind the various gender differences could be identified and tackled.

The differential gender patterns across the scales highlight the difficulties in designing educational policies that promote gender equity.

It is also important to note the finding that science assessments must be balanced in their treatment of the different competencies - for example a test containing an overwhelming percentage of items from the identifying scientific issues competency would generate the belief that females have an advantage in science, whereas a test dominated by items from the explaining phenomena scientifically competency would do the opposite.

\section{The PISA science framework}

PISA 2006 gave an opportunity, not available previously, to explore gender differences in each separate competency and in the knowledge domains. Each of the assessment domains in PISA has a group of experts which guides the development of the assessment. The PISA 2006 Science Expert Group was charged with 
the responsibility of updating the science framework that had been produced for the first PISA cycle in 2000. PISA 2006 defined scientific literacy as the extent to which an individual: i) possesses scientific knowledge and uses that knowledge to identify questions, acquire new knowledge, explain scientific phenomena and draw evidence-based conclusions about science-related issues; ii) understands the characteristic features of science as a form of human knowledge and enquiry; iii) shows awareness of how science and technology shape our material, intellectual and cultural environments; and iv) engages in science-related issues and with the ideas of science, as a reflective citizen. Scientific literacy requires an understanding of scientific concepts, as well as the ability to apply a scientific perspective and to think scientifically about evidence.

With more than one-half of the total assessment time devoted to science, PISA 2006 was able to report in much greater detail on science performance than was the case in PISA 2000 and PISA 2003. As well as calculating overall performance scores, it was possible to report separately on different science competencies and to establish for each performance scale conceptually grounded proficiency levels that related student performance scores to what students are able to do. Students received scores for their capacity in each of the three science competencies (identifying scientific issues, explaining phenomena scientifically and using scientific evidence). Estimates were also obtained for students' knowledge about science (i.e. their knowledge of the processes of science as a form of enquiry) and knowledge of science (i.e. their capacity in the science content areas of "Earth and space systems", "Physical systems", and "Living systems").

PISA 2006 also explored student attitudes to various science issues by including questions in the test instruments, in addition to including questions in the student questionnaire. This was done to put the attitude questions into a more clearly defined context (an example is given below in Figure 10, Question 10S). In this way, students' opinions regarding contemporary science topics were obtained. Two attitude scales were developed, one on interest in science and the other on support for scientific enquiry.

\section{Student performance}

\section{Overall performance in science}

Across OECD countries, gender differences in performance on the combined science scale in PISA 2006 tended to be small, both in absolute terms and when compared with the gender gaps in reading and mathematics performance. For the OECD countries as a whole, there was a statistically significant difference of two score points between the mean scores of male and female students, in favour of males (Table 2.1a, OECD, 2007a). Only six OECD countries, the United Kingdom, Luxembourg, Denmark, the Netherlands, Mexico and Switzerland, showed a statistically significant advantage for males (between 6 and 10 score points) while two, Turkey and Greece, showed an advantage for females (between 11 and 12 score points). For the remaining OECD countries there were no statistically significant differences.

As shown in Table 4, in all subject areas and in all countries, males had a greater range of performance than females. This is demonstrated in the combined science scale by the standard deviation being an average of 6 score points greater for males than for females, with differences of 6 in the competency identifying scientific issues, 6.3 in explaining phenomena scientifically and 7 in using scientific evidence. The implications of these results vary from one competency to another according to the mean score comparison. For the competency identifying scientific issues females outscored males by an average of 17 score points. The greater variation in results for males suggests that there must be a large number of underperforming males in this competency and efforts could be concentrated there to seek an improvement in performance. On the other hand for the competency explaining phenomena scientifically males scored a more highly than females. To gain an overall improvement efforts should be focused at enhancing the performance of females at the high end of performance. 
Analysis of the questions which were tested in the field trial for PISA 2006 revealed that some questions favoured males, some favoured females and others were neutral. In the final selection of items for PISA 2006 it was necessary to have a balance of questions which could provide information about real differences in the response patterns of males and females. The final selection of items is critical - it is vital that the composition of the final test reflects a balance of these types of questions to ensure against falsely generating a gender difference.

Figure 6 shows the percentage of each of the item types in the PISA 2006 science assessment. It can be seen that this ranges from $5 \%$ for closed-constructed responses to 35\% for simple multiple choice.

An alternative measure of gender differences in responses can be obtained by examining the percentage of students who get each item correct. A simple measure of the gender differences for item types is not sufficient because males and females demonstrated strengths and weaknesses in the three different competencies. An assessment of the gender difference associated with item types, therefore, needs to keep in mind the average gender difference for each competency.

It can be seen in Figure 7, for example, that for identifying scientific issues, the average difference in the percentage correct for all items was 3.3\% in favour of females and that for each of the item types there were differences in the range $3.0 \%$ to $3.6 \%$. For explaining phenomena scientifically the overall difference was $2.6 \%$ in favour of males, with the largest percentage point difference of $5.5 \%$ being for closed-constructed responses. For using scientific evidence, the overall difference was only $0.2 \%$ in favour of females. The largest difference was $2.7 \%$ in favour of males for closed-constructed items. The full list of items, item format, science competency and the results for males and females is shown in Table 5.

Following are examples of units from the PISA 2006 science assessment. These units, which were publicly released, demonstrate some gender differences. ${ }^{3}$ It can be seen that in each example the stimulus is given, in one case a photo, in another a drawing, and in the third some text. This is followed by the questions. There is also an indication given of the type of question, the science competency being assessed, the knowledge being assessed, the application and setting of the question, the difficulty of the question (on a scale where 500 is the mean score), the proficiency level of the question and the percentage of students across the OECD who get the question correct. For each question, the correct answer is given in a guide. To guarantee consistency, the same guide was used by all countries that participated in PISA.

\section{Performance in the competency identifying scientific issues}

As noted above, gender differences are visible across the OECD as a whole for two of the three competency scales. On the identifying scientific issues scale females outperformed males on average across OECD countries by 17 score points. In a number of countries the advantage of females was large, for example, in Greece (31 score points) and in the partner countries Qatar (37 score points), Bulgaria (34 score points), Thailand (33 score points), Jordan (32 score points) and Latvia (31 score points) (Table 2.2c, OECD, 2007a).

It would thus appear that females are better able than males to distinguish scientific issues and content from other issues. On average, they are better able to recognise questions that can be solved scientifically and to identify keywords to search for information on a given topic. They can better recognise key features of a scientific investigation, for example what variables should be used, changed or controlled and what extra information is needed.

An example of this type of question is contained in the unit GRAND CANYON (Figure 8). This unit has a brief introductory stimulus and then asks students to identify those questions regarding damage to the 
Figure 6

Percentage of each item type, PISA 2006

Item type

Number of items

Percentage of total

Simple multiple-choice

38

$35 \%$

Complex multiple-choice

29

$27 \%$

Closed-constructed response

5

$5 \%$

Open-constructed response

36

$33 \%$

TOTAL

108

$100 \%$

Source: PISA 2006 Technical Report (OECD, 2009).

Figure 7

Summary of percentages of correct answers by item types and competencies, PISA 2006

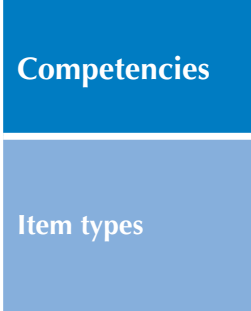

Simple multiple-choice

Complex
multiple-choice

Closed-constructed response

Open-constructed
response

Overall difference

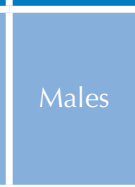

54.9

60.8
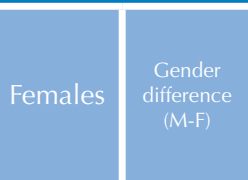

57.8

$-3.0$

64.2

61.6

2.6

61.9

47.7

1.8

37.9

32.4

5.5

46.8

44.1

2.7

25.4

28.4

$-3.0$

42.8

40.2

2.6

46.0

47.8

$-1.8$

51.2

54.5

$-3.3$

52.6

50.0

2.6

50.0

50.2

$-0.2$

Source: OECD PISA 2006 Database. 
Figure 8

\section{Science unit - GRAND CANYON}

The Grand Canyon is located in a desert in the USA. It is a very large and deep canyon containing many layers of rock. Sometime in the past, movements in the Earth's crust lifted these layers up. The Grand Canyon is now $1.6 \mathrm{~km}$ deep in parts. The Colorado River runs through the bottom of the canyon.

See the picture below of the Grand Canyon taken from its south rim. Several different layers of rock can be seen in the walls of the canyon.

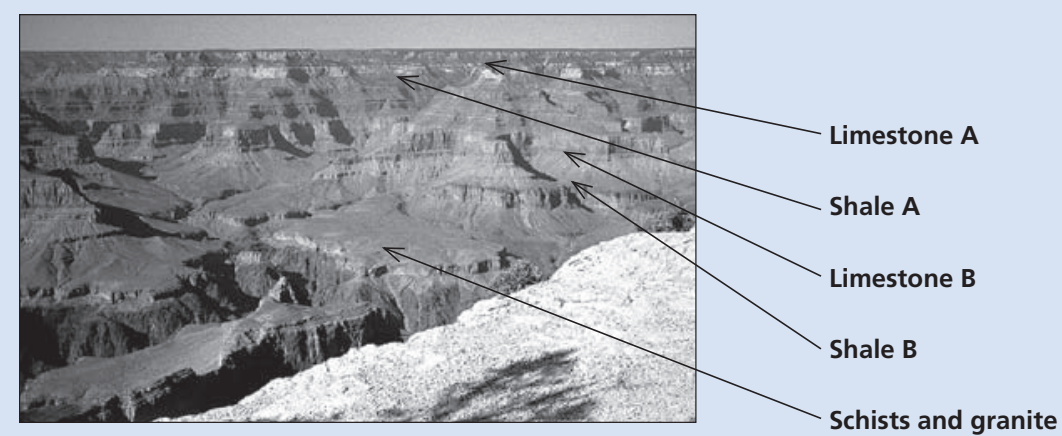

\section{GRAND CANYON - QUESTION 7 (S426Q07)}

Question type: Complex multiple choice

Competency: Identifying scientific issues

Knowledge category: "Scientific enquiry" (knowledge about science)

Application area: "Environment"

Setting: Social

Difficulty: 485 ..

Percentage of correct answers (OECD countries): $61.3 \%$

About five million people visit the Grand Canyon national park every year. There is concern about the damage that is being caused to the park by so many visitors.

Can the following questions be answered by scientific investigation? Circle "Yes" or "No" for each question.

\begin{tabular}{l|c}
\hline Can this question be answered by scientific investigation? & Yes or No? \\
\hline How much erosion is caused by use of the walking tracks? & Yes / No \\
\hline Is the park area as beautiful as it was 100 years ago? & Yes / No \\
\hline
\end{tabular}

\section{Scoring}

Full Credit: Both correct: Yes, No in that order.

\section{Comment}

This is a complex multiple-choice question, where the students must make a selection of "Yes"or "No"for each of the two options presented. To gain credit a student must correctly answer both of the options presented, in the order "Yes", "No". The student must have some notion of the capacities and limits of scientific investigations, so the question is assessing the competency of identifying scientific issues. The setting of the question is located out side the immediate personal life experiences of the student and the setting is social. The question, at a difficulty level of 485, is just below average difficulty and is placed at the lower part of Level 3. At this level, students can identify clearly described scientific issues in a range of contexts. 
environment which can be answered scientifically. Sixty three per cent of females across the OECD answered this correctly compared to $60 \%$ of males.

\section{Performance in the competency explaining phenomena scientifically}

In contrast, (Figure 2.16 and Table 2.3c, OECD, 2007a) on the explaining phenomena scientifically scale males outperform females on average across OECD countries by 15 score points. Again, in some cases this difference is large - for example among OECD countries it is 25 score points in Luxembourg, 22 in Hungary and in the Slovak Republic, and 21 in the United Kingdom, Denmark, the Czech Republic and Germany and in the partner country Chile it is 34 score points The gender differences on this scale are particularly pronounced at the highest level of proficiency. Across OECD countries the percentage of males in the two highest proficiency levels (Levels 5 and 6) is 12\% compared to $8 \%$ for females (Table 2.3b, OECD 2007a).

Students demonstrating this competency can apply appropriate knowledge of science in a given situation. The competency includes describing or interpreting phenomena and predicting changes, and may involve recognising or identifying appropriate descriptions, explanations and predictions.

An example of a question assessing this competency is question 3 in the unit PHYSICAL EXERCISE. In this question, shown in Figure 9, 49\% of males scored correctly, compared with $41 \%$ of females.

There were exceptions to the general pattern of males performing better than females in explaining phenomena scientifically. An example is question 4 in the science unit entitled MARY MONTAGU. In this question, shown in Figure 10, students are asked why vaccination is especially important for the very old and the very young. Fifty-nine per cent of males scored correctly, compared with $65 \%$ of females. This result might be explained, at least in part, by student interests and career preferences. The question has a focus on community health, and as is shown in the section on future career planning later in the report, females tend to have a greater interest than males in health and nursing and intend to follow careers in these areas.

Figure 9

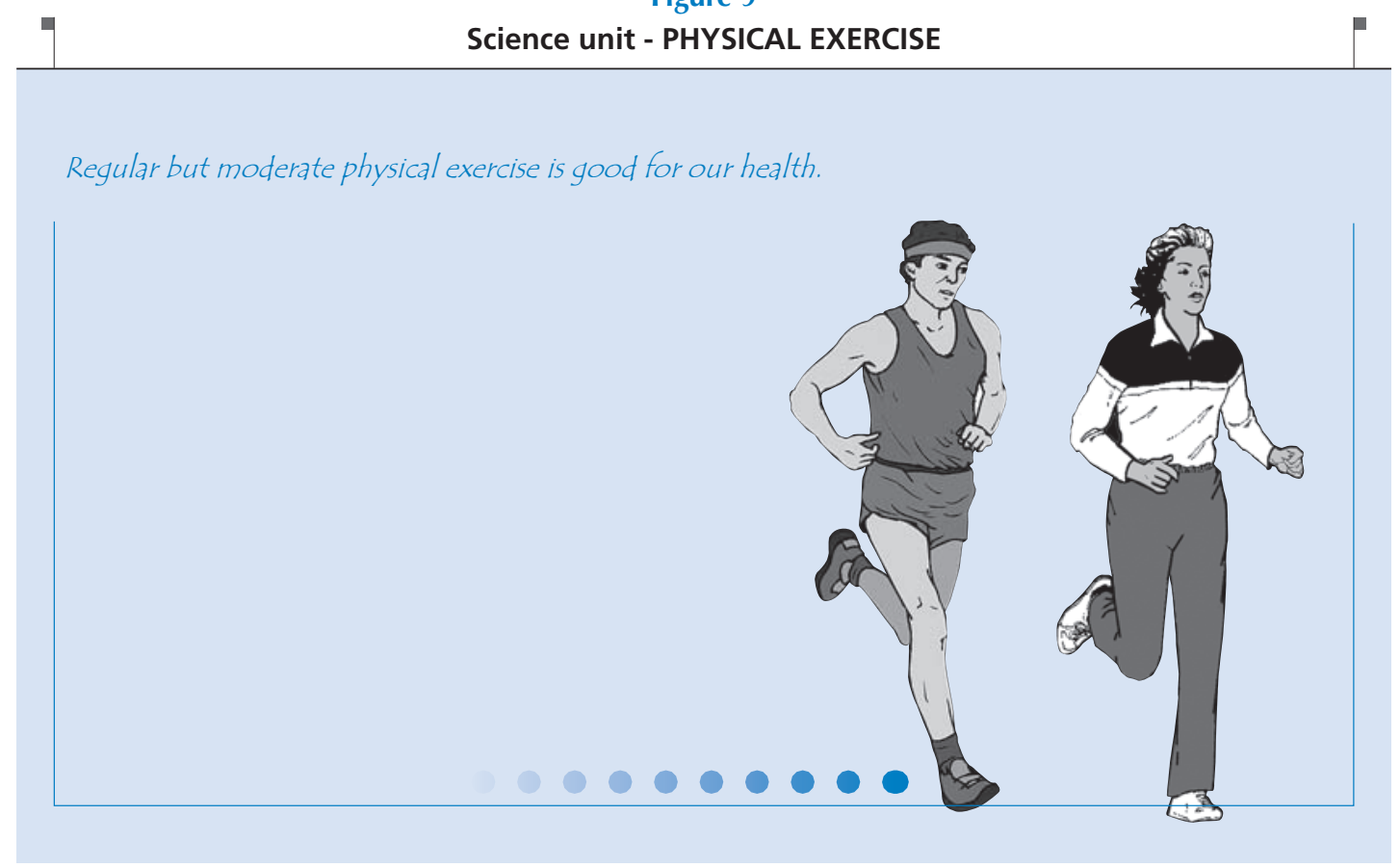


PHYSICAL EXERCISE - QUESTION 1 (S493Q01)

Question type: Complex multiple choice

Competency: Explaining phenomena scientifically

Knowledge category: "Living systems" (knowledge of science)

Application area: "Health"

Setting: Personal

Difficulty: 545 .

Percentage of correct answers (OECD countries): $56.6 \%$

What are the advantages of regular physical exercise? Circle "Yes" or "No" for each statement.

\begin{tabular}{l|l}
\hline Is this an advantage of regular physical exercise? & Yes or No? \\
\hline Physical exercise helps prevent heart and circulation illnesses. & Yes / No \\
\hline Physical exercise leads to a healthy diet. & Yes / No \\
\hline Physical exercise helps to avoid becoming overweight. & Yes / No \\
\hline
\end{tabular}

\section{Scoring}

Full Credit: All three correct: Yes, No, Yes in that order.

\section{Comment}

This is a complex multiple-choice question, where the students must make a selection of "Yes" or "No" for each of the three options presented. To gain credit a student must correctly answer all three of the options presented, in the order "Yes", "No", "Yes". The student must have some knowledge of the advantages of physical exercise, so the question is assessing the competency explaining phenomena scientifically. The question is highly relevant to 15-year-olds as it relates to their own personal health. The question, at a difficulty level of 545, is of above-average difficulty and is placed at the upper part of Level 3. At this level, students can select facts and knowledge to explain phenomena and can interpret and use scientific concepts from different disciplines and can apply them directly.

\section{PHYSICAL EXERCISE - QUESTION 3 (S493Q03)}

Question type: Complex multiple choice

Competency: Explaining phenomena scientifically

Knowledge category: "Living systems" (knowledge of science)

Application area: "Health"

Setting: Personal

Difficulty: 386 .

Percentage of correct answers (OECD countries): $82.4 \%$

What happens when muscles are exercised? Circle "Yes" or "No" for each statement.

\begin{tabular}{l|c}
\hline Does this happen when muscles are exercised? & Yes or No? \\
\hline Muscles get an increased flow of blood. & Yes / No \\
\hline Fats are formed in the muscles. & Yes / No \\
\hline
\end{tabular}

\section{Scoring}

Full Credit: Both correct: Yes, No in that order.

\section{Comment}

For this question, to gain credit a student has to correctly recall knowledge about the operation of muscles and about the formation of fat in the body, i.e. students must have knowledge of the science fact that active muscles get an increased flow of blood and that fats are not formed when muscles are exercised. This enables the student to accept the first explanation of this complex multiple-choice question and reject the second explanation. 
The two simple factual explanations contained in the question are not related to each other. Each is accepted or rejected as an effect of the exercise of muscles and the knowledge has widespread currency. Consequently, the question is located at Level 1. PHYSICAL EXERCISE, CLOTHES and GRAND CANYON (Figures 2.29, 2.26 and 2.27) are at Level 1 (below the cut-point), at the very bottom of the scale for the competency explaining phenomena scientifically.

\section{PHYSICAL EXERCISE - QUESTION 5 (S493Q05)}

Question type: Open-constructed response

Competency: Explaining phenomena scientifically

Knowledge category: "Living systems" (knowledge of science)

Application area: "Health"

Setting: Personal

Difficulty: 583 .

Percentage of correct answers (OECD countries): $45.2 \%$

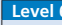
Level 4

558.7

484.1

409.5

Level 3

Level 2

334.9

Level 1

Below Level 1

Why do you have to breathe more heavily when you're doing physical exercise than when your body is resting?

Scoring

\section{Full Credit:}

To remove increased levels of carbon dioxide and to supply more oxygen to your body. [Do not accept "air" instead of "carbon dioxide" or "oxygen".] For example:

- When you exercise your body needs more oxygen and produces more carbon dioxide. Breathing does this.

- Breathing faster allows more oxygen into the blood and more carbon dioxide to be removed.

To remove increased levels of carbon dioxide from your body or to supply more oxygen to your body, but not both. [Do not accept "air" instead of "carbon dioxide" or "oxygen".]

- Because we must get rid of the carbon dioxide that builds up.

- Because the muscles need oxygen. [The implication is that your body needs more oxygen when you are exercising (using your muscles).]

- Because physical exercise uses up oxygen.

- You breathe more heavily because you are taking more oxygen into your lungs. [Poorly expressed, but recognises that you are supplied with more oxygen.]

- Since you are using so much energy your body needs double or triple the amount of air intake. It also needs to remove the carbon dioxide in your body. [Code 12 for the second sentence - the implication is that more carbon dioxide than usual has to be removed from your body; the first sentence is not contradictory, though by itself it would get Code 01.]

\section{Comment}

For this question the student must explain how breathing more heavily (meaning deeper and more rapidly) is related to an increase in physical activity. Credit is given for an explanation that recognises that exercising muscles requires more oxygen and/or must dispose of more carbon dioxide than when not exercising. Since the student must recall knowledge in order to formulate an explanation the question belongs in the knowledge of science category. Relevant knowledge relates to the physiology of the human body, so the application area is "Health" while the setting is personal.

The student needs to draw on knowledge of body systems in order to relate the gas exchange occurring in the lungs to increased exercise. Consequently, several pieces of specific knowledge are related in order to produce an explanation of the phenomenon. This locates the question at Level 4. 


\section{THE HISTORY OF VACCINATION}

Mary Montagu was a beautiful woman. She survived an attack of smallpox in 1715 but she was left covered with scars. While living in Turkey in 1717, she observed a method called inoculation that was commonly used there. This treatment involved scratching a weak type of smallpox virus into the skin of healthy young people who then became sick, but in most cases only with a mild form of the disease.

Mary Montagu was so convinced of the safety of these inoculations that she allowed her son and daughter to be inoculated.

In 1796, Edward Jenner used inoculations of a related disease, cowpox, to produce antibodies against smallpox. Compared with the inoculation of smallpox, this treatment had less side effects and the treated person could not infect others. The treatment became known as vaccination.

\section{MARY MONTAGU - QUESTION 2 (S477Q02)}

Question type: Multiple choice

Competency: Explaining phenomena scientifically

Knowledge category: "Living systems" (knowledge of science)

Application area: "Health"

Setting: Social

Difficulty: 436 .

Percentage of correct answers (OECD countries): $74.9 \%$

\section{What kinds of diseases can people be vaccinated against? \\ A. Inherited diseases like haemophilia. \\ B. Diseases that are caused by viruses, like polio. \\ C. Diseases from the malfunctioning of the body, like diabetes. \\ D. Any sort of disease that has no cure.}

\section{Scoring}

Full Credit: B. Diseases that are caused by viruses, like polio.

\section{Comment}

To gain credit the student must recall a specific piece of knowledge that vaccination helps prevent diseases, the cause for which is external to normal body components. This fact is then applied in the selection of the correct explanation and the rejection of other explanations. The term "virus" appears in the stimulus text and provides a hint for students. This lowered the difficulty of the question. Recalling an appropriate, tangible scientific fact and its application in a relatively simple context locates the question at Level 2. 
MARY MONTAGU - QUESTION 3 (S477Q03)

Question type: Multiple choice

Competency: Explaining phenomena scientifically

Knowledge category: "Living systems" (knowledge of science)

Application area: "Health"

Setting: Social

Difficulty: 431 .

Percentage of correct answers (OECD countries): $75.1 \%$

(2) Level 4

84.1

409.5

Level 1

334.9

Below Level 1

If animals or humans become sick with an infectious bacterial disease and then recover, the type of bacteria that caused the disease does not usually make them sick again.

What is the reason for this?

A. The body has killed all bacteria that may cause the same kind of disease.

B. The body has made antibodies that kill this type of bacteria before they multiply.

C. The red blood cells kill all bacteria that may cause the same kind of disease.

D. The red blood cells capture and get rid of this type of bacteria from the body.

Scoring

Full Credit: B. The body has made antibodies that kill this type of bacteria before they multiply.

\section{Comment}

To correctly answer this question the student must recall that the body produces antibodies that attack foreign bacteria, the cause of bacterial disease. Its application involves the further knowledge that these antibodies provide resistance to subsequent infections of the same bacteria. The issue is community control of disease, so the setting is social.

In selecting the appropriate explanation the student is recalling a tangible scientific fact and applying it in a relatively simple context. Consequently, the question is located at Level 2.

MARY MONTAGU - QUESTION 4 (S477Q04)

Question type: Open-constructed response

Competency: Explaining phenomena scientifically

Knowledge category: "Living systems" (knowledge of science)

Application area: "Health"

Setting: Social

Difficulty: 507

Percentage of correct answers (OECD countries): $61.7 \%$

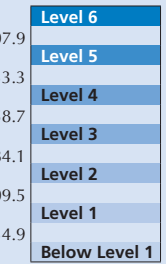

Give one reason why it is recommended that young children and old people, in particular, should be vaccinated against influenza (flu). 


\section{Scoring}

Full Credit: Responses referring to young and/or old people having weaker immune systems than other people, or similar. For example:

These people have less resistance to getting sick.

The young and old can't fight off disease as easily as others.

They are more likely to catch the flu.

If they get the flu the effects are worse in these people.

Because organisms of young children and older people are weaker.

Old people get sick more easily.

\section{Comment}

This question requires the student to identify why young children and old people are more at risk of the effects of influenza than others in the population. Directly, or by inference, the reason is attributed to young children and old people having weaker immune systems. The issue is community control of disease, so the setting is social.

A correct explanation involves applying several pieces of knowledge that are well established in the community. The question stem also provides a cue to the groups having different resistance to disease. This locates the question at Level 3.

\section{MARY MONTAGU - QUESTION $10 S$ (S477Q10S)}

How much do you agree with the following statements?

Tick only one box in each row.

\section{a) I am in favour of research to develop vaccines for new strains of influenza.}

b) The cause of a disease can only be identified by scientific research.

c) The effectiveness of unconventional treatments for diseases should be subject to scientific investigation.

\begin{tabular}{|c|c|c|c|}
\hline Strongly agree & Agree & Disagree & Strongly disagree \\
\hline$\square_{1}$ & $\square_{2}$ & $\square_{3}$ & $\square_{4}$ \\
\hline$\square_{1}$ & $\square_{2}$ & $\square_{3}$ & $\square_{4}$ \\
\hline$\square_{1}$ & $\square_{2}$ & $\square_{3}$ & $\square_{4}$ \\
\hline
\end{tabular}

\section{Performance in knowledge about science}

The PISA 2006 framework identified two categories of knowledge about science: $i$ ) scientific enquiry which centres on enquiry as the process of science and ii) scientific explanations - which are the results of scientific enquiry. Across the OECD countries females significantly outperformed males in 15 countries, with no countries showing an advantage to males. The average difference was 10 score points, with the largest differences being in Greece, Turkey and Iceland with performance advantages to females of 24, 22 and 20 score points respectively.

\section{Performance in the "Physical systems" area of knowledge of science}

An analysis of the knowledge of science content areas by gender revealed some differences. In all OECD countries except Turkey, males significantly outperformed females in the content area "Physical systems", 
which relates to the structure and properties of matter, changes of matter and energy transformations. The OECD country with the largest difference between males and females was Austria with a 45 score point advantage to males. These Austrian results were mirrored in other comparative studies, most notably the TIMSS upper secondary assessment (Mullis et al., 1998). Analyses of these data revealed that this gender gap was closely associated with the difference in the cumulative number of physics lessons which males and females attended, essentially because of different programmes and study choices (Stadler, 1999). There were four other OECD countries with an advantage for males 35 score points or more: the Czech Republic, Luxembourg, Hungary and the Slovak Republic.

In the partner countries and economies the pattern was similar, with males significantly outperforming females in all but nine countries, the nine exceptions being Qatar, Jordan, Azerbaijan, Bulgaria, Argentina, Kyrgyzstan, Thailand and Liechtenstein (Table 2.10, OECD, 2007a). Among the partner countries and economies, the largest differences in favour of males were in Chile (40 score points) and Hong KongChina (34 score points). Other partner countries with differences of 30 or more were Croatia, the Russian Federation (both 30 score points) and Slovenia (31 score points).

These observations support the popular notion that the physical sciences are the domain of males, a finding which is mirrored in a much larger share of males among physics graduates (OECD, 2008).

\section{Performance in the "Living systems" area of knowledge of science}

In the knowledge of science content area "Living systems", which refers to cell structure, human biology, the nature of populations and ecosystems, the gender pattern was less uniform and there were few significant gender differences. The five OECD countries with significant gender differences in this category in favour of males were Mexico (13 score points), Hungary (12 score points), and Denmark, Luxembourg and the Slovak Republic (all 11 score points). The two OECD countries with a significant difference in favour of females were Greece (12 score points) and Finland (10 score points). Among the partner countries and economies, there were seven with differences in favour of males and seven in favour of females. The larger differences in favour of females were in Qatar (37 score points), Jordan (31 score points), Bulgaria (19 score points), Thailand (13 score points) and Estonia (12 score points). The larger differences in favour of males were in Chile (27 score points), Chinese Taipei (15 score points), Colombia (13 score points) and Hong Kong-China (12 score points) (Table 2.9, OECD 2007a).

\section{Performance in the "Earth and space systems" area of knowledge of science}

In the content area "Earth and space systems", which focuses on the structure and energy of the Earth and its systems, the Earth's history and its place in space, males tended to outperform females, but there were fewer significant differences than in "Physical systems". The largest differences in favour of males in this category among OECD countries were in the Czech Republic (29 score points), Luxembourg (27 score points), Japan, Switzerland and Denmark (all 26 score points) and the Netherlands ( 25 score points) and in the partner countries Chile (35 score points), Colombia (26 score points), Israel and Uruguay (25 score points) (Table 2.8, OECD 2007a).

\section{Gender differences within schools}

A further issue which is relevant to the gender differences observed in PISA is that males and females, in some countries, make different choices in terms of the schools, academic tracks and/or educational programmes they attend. PISA 2006 compared the observed gender difference in science for all students within countries, then considered the gender differences within schools both before and after taking into 
account the various programme and school characteristics that might influence performance (further analysis of this issue is undertaken in the section on socio-economic background later in the report).

In most countries, gender differences in science performance were much larger within schools than they were in the country overall (Table 2.5, OECD, 2007a). While across the OECD the average overall gender difference in PISA 2006 was 2 score points in favour of males, the within-school gender difference was an average of 8 score points in favour of males. This difference increased to 9 score points after accounting for the programme level and destination in which students are enrolled. In most countries the higher within-school gender difference may reflect the fact that females tend to choose the higher performing, academically oriented tracks and schools at a higher rate than males.

\section{A typology of gender differences in science}

Gender differences in science performance paint a complex picture but a general pattern is discernible. There appear to be three different types of countries with respect to gender differences across countries and within schools.

In a first group of countries, type A, gender differences are small and insignificant overall, for each of the three competency scales of science performance and also within schools. A good example of a type A country is Australia where there is no overall gender difference observed for science and there is an insignificant difference within schools, both before and after accounting for programme level and destination. Finland, Iceland, Ireland, Japan, Korea, New Zealand, Norway and Sweden are OECD countries similar in this respect. Among the partner countries, Estonia also falls into this category.

In the second group of countries, type B, there is an insignificant overall gender difference but gender differences within school are significant, even after accounting for programme level and destination. Hungary is a good example of a type B country within the OECD. It shows a statistically insignificant difference of 6 points in favour of males in the mean science score. The gender difference within schools in Hungary, however, is large and significant, 27 score points in favour of males. Other type B countries with a large disparity within schools (more than 10 score points) were France, Belgium, the Czech Republic, the Slovak Republic, Germany and Italy and the partner countries and economies Serbia, Croatia, Romania, Tunisia, Hong Kong-China, Macao-China, Montenegro and Uruguay (Table 2.5, OECD, 2007a).

In the third group of countries, type $\mathrm{C}$, gender differences are significant for both the overall science score and within schools (before and after accounting for programme level and destination). The United Kingdom, Luxembourg and Denmark are examples of type $\mathrm{C}$ countries with consistently high gender differences in favour of males.

What are the main drivers of gender differences across and within countries? Why is one country type A, B or $\mathrm{C}$ ? The structure of the education system and specific educational policies play a role but there may also be pressures operating outside the school which may contribute to gender differences. For example, in PISA 2003, the performance advantage of females in all subject areas in Iceland, most notably in rural areas has for example, been attributed to labour-market incentives that deter males in rural areas from focusing on academic studies which are seen by females as a lever to social and regional mobility (Ólafsson et al., 2003).

\section{Computer-based assessment of science (CBAS) in PISA 2006}

In PISA 2006, countries were given the option of participating in a computer-based assessment of science. The aim of this was to assess some facets of the science framework which were not easily assessed by a pencil-and-paper test. The tasks given to students were often video based, involving a simulation or otherwise displaying a problem that could not be done so easily or effectively on a pencil-and-paper test. 
The tests were delivered to a sub-sample of the students at a school undertaking the PISA assessment, using a set of standardised computers. CBAS was implemented in 2006 in Denmark, Iceland and Korea. Their mean scores in the computer-based assessment of science were 463, 472 and 504 points, respectively. This compares to the same students' mean scores in the standard PISA science assessment of 481, 471 and 502 points, respectively (note, however, that these CBAS scores are not directly comparable to the normal PISA mean scores as they were analysed separately).

One of the goals of the computer-based assessment of science was to reduce the reading load of the questions, at the same time retaining the science content. It was found that the correlation between scores on the computer-based assessment of science and scores in PISA reading, at 0.73, was lower than the correlation between PISA science and PISA reading scores (0.83), so by this measure the goal of reducing the reading load was successful.

In Figure 11 it can be seen for each of the three countries there was a significant gender difference in favour of males in the computer-based assessment of science: 45 score points in Denmark, 25 score points in Iceland and 26 score points in Korea. It can also be seen (Table 6) that the gender differences in scores on the paper-and-pencil science test for the same students were much less: 23 score points in favour of males, a statistically insignificant 7 score points in favour of females and a statistically insignificant 1 score point in favour of females in Denmark, Iceland and Korea respectively. The decreased reading load in the CBAS may be the reason why males score higher in that form of assessment.

PISA will continue with the development of computer-delivered testing in PISA 2009 - this time with a focus on assessing students' skills in searching for, reading, and understanding material presented on computers.

One might also conclude, given the significant differences in these results and the relative lack of interest by females in pursuing tertiary education in computer science, that some countries may benefit from a programme in school to make this area more appealing. Given that there could be a need to increase the

Figure 11

\section{Differences in results in the computer-based assessment of science (CBAS) by gender, PISA 2006}

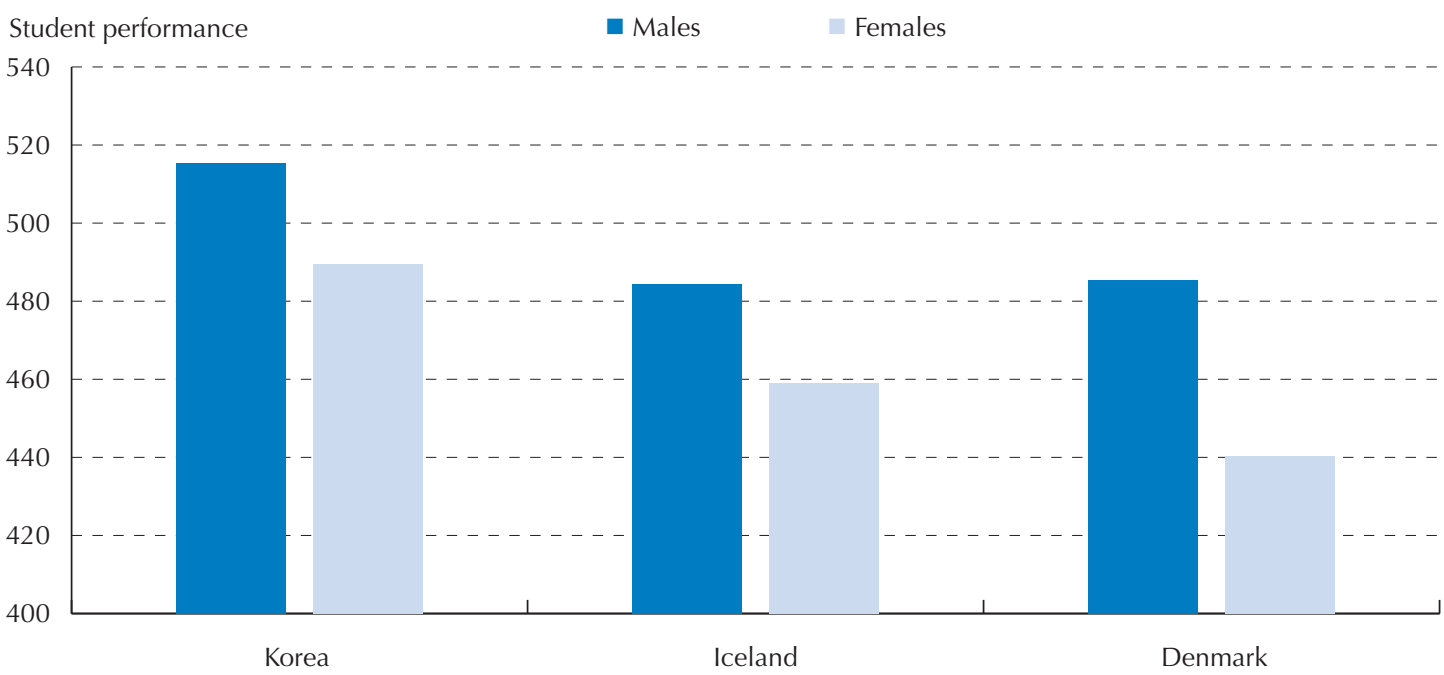

Source: OECD PISA 2006 Database, Table 6. 
total number of computer science graduates, and that the number of male students in this field may be near its maximum, this is especially important.

\section{Student attitudes}

Unlike the position in mathematics and reading, gender differences in science performance cannot be traced back to gender differences in attitudes, motivation or confidence. In PISA 2006, countries focused attention on student attitudes to science both inside and outside the classroom. Male and female students report similar attitudes, motivations and confidence regarding science. PISA 2006 sought information on attitudinal measures comprising self-efficacy, self-concept, interest in science, enjoyment of science, instrumental motivation to learn science, career intentions, awareness of environmental issues, optimism regarding environmental issues, and responsibility for sustainable development and looked at the gender differences in attitudes using effect sizes. An effect size allows a comparison of differences between males and females across measures that differ in their metric as, for example, between the PISA indices and the PISA test scores (Table 3.21, OECD, 2007a).

To assess self-efficacy in PISA 2006, students were asked to rate the ease with which they believed they could perform eight listed scientific tasks. On average in OECD countries, each unit increase on the index of self-efficacy in science corresponded to a performance difference of 38 score points (Table 3.3, OECD, 2007a), with the majority of countries showing no gender differences on the index. In the PISA 2003 mathematics assessment, males reported higher levels of self-efficacy in mathematics both overall and in many countries, whereas in PISA 2006 males reported higher levels of self-efficacy in science only in Japan, the Netherlands, Iceland and Korea and in the partner economy Chinese Taipei.

Students' academic self-concept is both an important outcome of education and a trait that correlates strongly with student success. It can also affect other factors such as well-being and personality development, factors that are especially important for students from less advantaged backgrounds. In contrast to self-efficacy in science, which asked students about their level of confidence in tackling specific scientific tasks, the index of self-concept measured the general level of belief that students had in their academic abilities. PISA 2006 showed gender differences in students' self-concept in science, but they tended to be small to moderate (Table 3.21, OECD, 2007a). In 22 OECD countries and 8 partner countries and economies, males were more likely than females to agree that learning school science topics was easy or that they could give good answers to test questions on science topics. On average, gender differences in self-concept in science were slightly less than those in mathematics in PISA 2003.

Levels on the index of general interest in learning science were similar for males and females across most participating countries while in the majority of countries there were no gender differences on the index of enjoyment of science (Table 3.21, OECD, 2007a). Males and females also reported similar levels of instrumental motivation to learn science in the majority of countries.

Similar proportions of male and female 15-year-olds reported that they would like to work in a career involving science, continue to study science after secondary school, work on science projects as adults or spend their life doing advanced science. However, there were small gender differences in some countries on the index of future-oriented motivation to learn science, with more males than females, on average, being motivated to learn science because they wanted to use it in the future. This was the case in Japan, Greece, Korea, Iceland, the Netherlands, Italy and Germany, as well as in the partner countries and economies Hong Kong-China, Qatar, Macao-China and Chinese Taipei where the gender difference in favour of males was quite large. The Czech Republic was the only participating country where females reported higher levels of future-oriented motivation to learn science (Table 3.21, OECD, 2007a). 
On average, males and females reported similar attitudes toward the environment, although there were some gender differences among participating countries (Table 3.21, OECD, 2007a). In general, males were more aware than females about environmental issues, with significant differences in 12 OECD countries, although females were more environmentally aware in the partner countries Jordan, Thailand and Kyrgyzstan. The index of awareness of environmental issues had the strongest relationship with science performance among the attitudinal measures in PISA 2006 and was associated with better performance in all participating countries.

Regarding the outlook for selected environmental issues over the next 20 years, the position varied quite significantly from country to country. Males were more optimistic than females in 12 OECD countries and in three partner countries and economies, though the gender differences tended to be small. In contrast, females reported stronger levels of concern for environmental issues in 16 OECD countries and in 8 partner countries and economies. Higher values on the index of optimism regarding environmental issues were linked with lower science performance. Males in Finland, Norway, the United Kingdom and Germany were both more aware of and more optimistic about environmental issues (Table 3.21, OECD, 2007a).

Similarly, there were small gender differences on the index of students' responsibility for sustainable development in nine countries: Finland, Iceland, Denmark, Norway, Sweden, Canada, Australia, New Zealand and the partner country Thailand. In all these countries females reported higher levels of responsibility (Table 3.21, OECD 2007a).

\section{Science performance and attitudes towards science}

PISA 2006 found that there is no significant relationship, at the country level, between the average level of gender differences in attitudes and the overall average student performance in a country, that is a large gender difference is equally likely to be apparent with a high performing or a low performing country. For example, Finland, with a quite high total of six (out of nine) significant gender differences in attitudes has the highest score of 563 score points whereas the partner country, Estonia, with no significant gender differences in attitudes also scores very highly with 531 score points. At the other end of the scale, some countries with no significant gender differences in attitudes have scores well below the OECD average - for example, Azerbaijan (382 score points), Tunisia (386 score points), Montenegro (412 score points), Romania (418 score points) and Serbia (436 score points). Among the countries with a relatively high number of gender differences in attitudes scoring below the OECD average are Thailand (421 score points), Greece (473 score points) and Norway (487 score points). It appears then that there is no clear relationship between gender differences in attitudes and overall performance in science, at the country level.

Within countries, however, there are several different patterns of relationships between gender differences in attitudes and gender differences in performance. A number of participating countries showed no gender differences in either science performance or attitudes towards science (Table 3.21, OECD, 2007a). These included Portugal and the partner countries Azerbaijan, Israel and Montenegro. In another group of countries (Ireland, Mexico, Poland, the Slovak Republic, Spain, and the partner countries Argentina, Brazil, Colombia, Croatia, Estonia, Indonesia, Romania, the Russian Federation, Serbia, Tunisia and Uruguay), there were moderate gender differences in a maximum of two of the measures, whether performance or attitudinal.

Another group of countries, was characterised by a combination of similar performance by males and females, but with significant differences in the attitudes of male and female 15-year-olds. Gender differences in attitudes were most prominent in Germany, Iceland, Japan, Korea, the Netherlands and the United Kingdom, and in the partner economies Chinese Taipei, Hong Kong-China and Macao-China where males 
recorded higher values on at least five of the attitudinal measures (although in Iceland, Germany and the Netherlands females reported either higher concern for environmental issues or higher responsibility for sustainable development). To a lesser extent this was the case also in France, Italy, and the United States. In Austria, Greece, Iceland, Korea and Norway, females had more negative attitudes on at least three of the attitudinal measures, despite the fact that they perform better on the identifying scientific issues scale. Conversely, in the partner countries Jordan and Thailand, females both performed better on the science assessment and reported more positive science attitudes (Table 3.21, OECD, 2007a).

\section{Student background}

\section{Socio-economic background}

What is the relationship between gender and student socio-economic background? Do 15-year-old male students tend to have more advantaged socio-economic background than female students, or vice versa?

The measurement of equity of educational outcomes has been a focus of PISA analyses since the first survey in 2000. In each of the initial reports a chapter has been dedicated to this issue. To construct a measure of socio-economic background students were asked a number of questions in the student questionnaire about their parents' occupation and education, and about some features that may be present in their homes. The PISA index of economic, social and cultural status (ESCS) was created to capture wide aspects of a student's family and home background. ${ }^{4}$

In most countries, there is no difference between the average scores of males and females on the PISA index of economic, social and cultural status. However, there are significant differences between them in some countries (see Table 7). On average, females in PISA 2006 were socio-economically more advantaged than males only in the partner economy Hong Kong-China, while males were socio-economically more advantaged than females in Luxembourg, Italy, Poland, Iceland, Sweden, and Norway, as well as the partner countries Israel, Estonia, Montenegro, Brazil and Latvia. This gender difference in students' socio-economic background could be due to males with disadvantaged socio-economic background being less likely than females with equally disadvantaged socio-economic backgrounds to stay at school until the age of 15 .

Since students' socio-economic background is associated with performance (OECD, 2007a), the observed gender differences in countries' average science performance could be affected by the imbalance in the average socio-economic background between males and females. Among countries with a gender difference in average socio-economic background a change in the gender difference in performance in science before and after adjusting for students' socio-economic background can be observed only in Iceland and the partner country Estonia (Table 8). In these two countries, there was no gender difference in the raw performance data, but after adjusting it to account for socio-economic background, females performed slightly higher than males.

The PISA 2006 initial report (OECD, 2007a) shows that across the OECD countries there is a 40 score point difference in science performance associated with a one standard deviation difference in socio-economic background. This measure of the effect of socio-economic background on performance is known as the socioeconomic gradient (Willms, 2006). While the socio-economic gradients vary greatly among OECD countries, from 25 score points per standard deviation in Mexico to 54 score points in France, the socio-economic gradients do not vary between males and females in any OECD country except the Czech Republic and Austria. In each of these countries the gradient is higher for females than for males. In the Czech Republic the gradient for males is 43 score points, whereas for females it is 60 score points; in Austria the difference is slightly smaller with 40 score points for males and 52 for females. This means that, on average, in both the Czech Republic and Austria, the score for a female student will increase more than it will for a male with the same rise in socio-economic background. 
It has been shown that the relationship between students' socio-economic background and performance does not differ between males and females (except for Iceland and Estonia as described above). But what is the effect of the average socio-economic background of a school's student body, that is of the school contextual effect?

As described in an earlier section, the PISA 2006 initial report (OECD, 2007a) showed that gender differences in performance within schools were much larger than gender differences in performance in the countries overall. Do within-school gender differences in performance vary according to the school's socio-economic intake? Or is the within-school gender difference consistent regardless of school average socio-economic background?

A two-level regression analysis by country was conducted. ${ }^{4}$ In 23 OECD countries, the within-school gender difference in science is consistent across schools with varying levels of socio-economic intake (Table 9). In some countries, however, the within-school gender difference varies according to the level of schools' socioeconomic intake. The countries for which this is the case include Australia, Austria, Belgium, Spain, France, Italy and the Slovak Republic. As Figure 12 shows, in Australia there is no gender difference in performance in schools which have the national average socio-economic intake, but in schools with a more advantaged socio-economic intake (i.e. schools with average socio-economic background one standard deviation above the national average ESCS) males outperform females, while in schools with a more disadvantaged socioeconomic intake average females outperform males. Another example is Austria, where males outperform females in general but this within-school gender gap decreases as the school socio-economic intake increases. The opposite pattern is observed in Belgium, where the within-school gender difference favouring males increases as the school socio-economic intake increases.

These different patterns in within-school gender difference according to the level of school socio-economic background are important from a policy perspective - and for school principals and teachers - as strategies and interventions for mitigating any within-school gender gap in performance need to be adapted according to the level of school socio-economic intake in those countries in which within-school gender differences vary across schools according to their socio-economic intake.

\section{Immigrant status}

In most OECD countries, increasing attention is being paid to issues surrounding migration. In part, this is a consequence of the growth of migration flows - between 1990 and 2000, the number of people living outside their country of birth nearly doubled worldwide, to 175 million (OECD, 2006c). Among 15-year-old students, the proportion of students who were foreign born or who had foreign born parents exceeded $10 \%$ in many PISA countries, being higher than 35\% in Luxembourg, Liechtenstein, and in the partner countries and economies Macao-China, Hong Kong-China and Qatar (Table 4.2c, OECD, 2007).

Native students are defined as those who were born in the country of assessment and who have at least one parent born in the country of assessment. First-generation students are those students who came to the country of assessment as a migrant and whose parents were also born outside that country. Second-generation students are those who were born in the country of assessment, but whose parents were born outside the country of assessment. Among the countries with significant numbers of 15-year-olds with an immigrant background, ${ }^{6}$ first-generation students lag, on average, 58 score points behind their native counterparts. Much of this difference remains even after accounting for socio-economic factors. Comparing native females with immigrant females and native males with immigrant males echoes this result (Table 10).

When examining the difference between native students and immigrant students, the extent to which there is a difference between the way that males and females settle into a new country (as indicated by school 
Figure 12

Within-school gender difference in science performance, by school ESCS

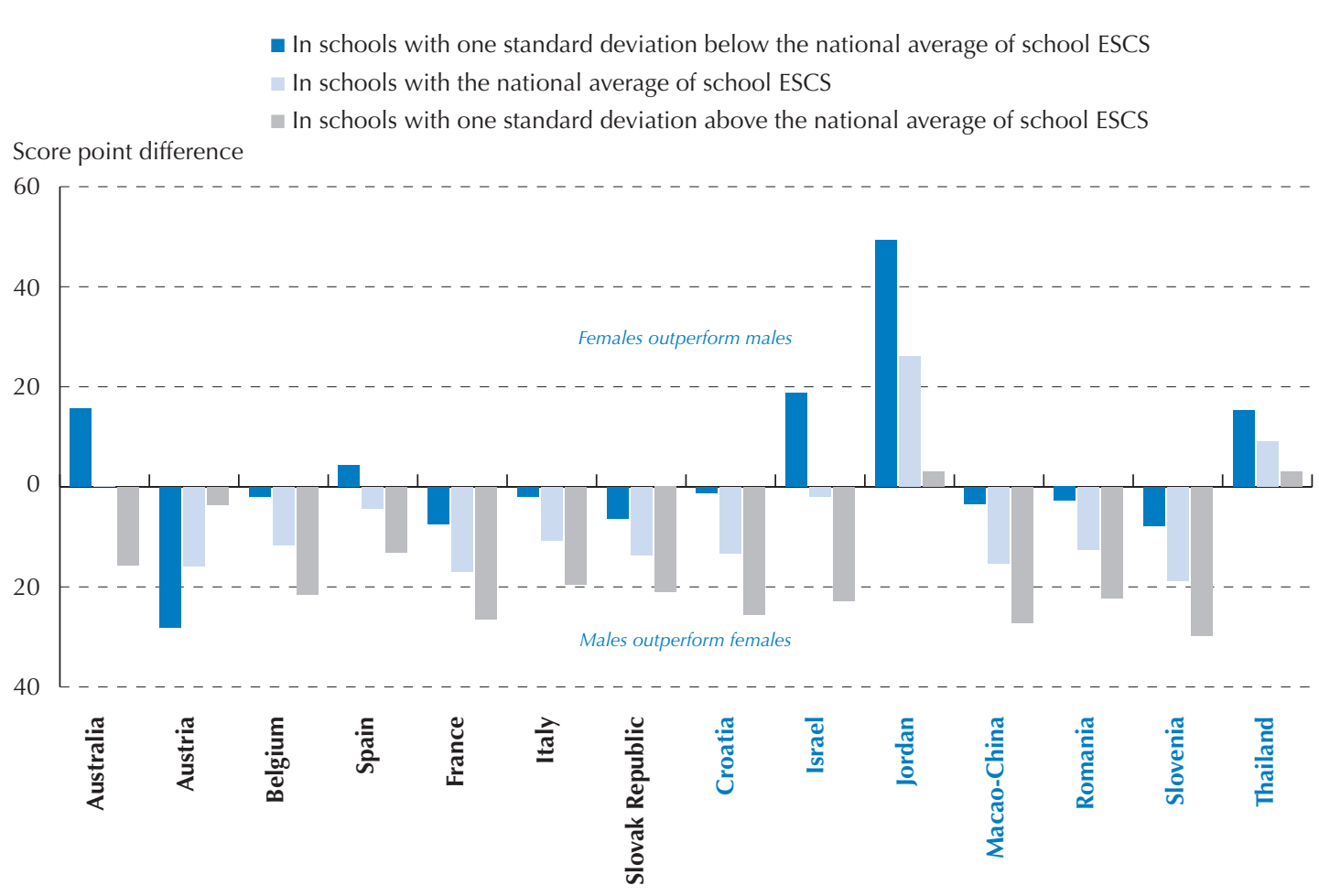

Source: OECD PISA 2006 Database, Table 9.

Figure 13

Percentage of students whose parents report various science activities at age 10

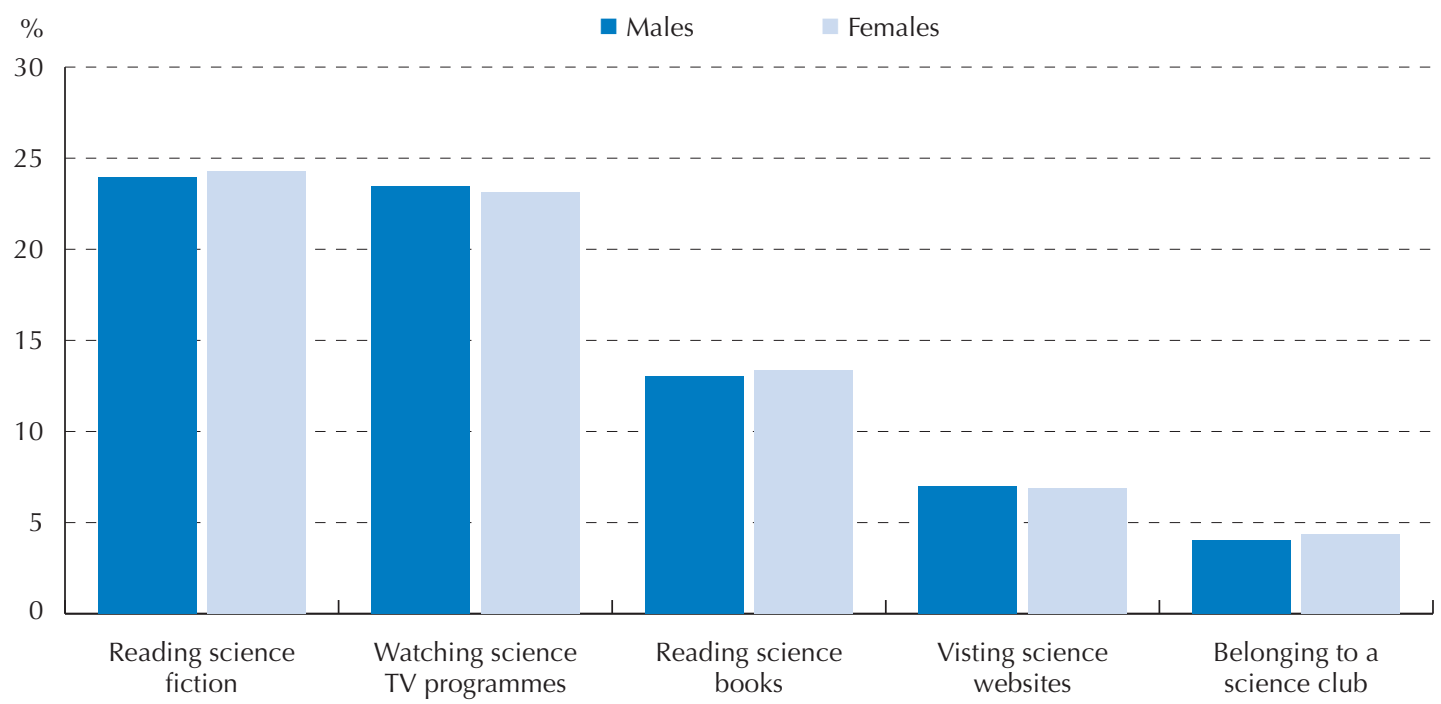

Source: OECD PISA 2006 Database, Table 11. 
performance) could provide policy makers with valuable information in planning induction programmes for migrant students. This can be done using PISA data. Put simply the measure is a comparison of the difference for immigrant and native females and the difference for immigrant and native males. A larger measure will indicate more difficulty settling into the new country. In only one country is there a statistically significant difference between males and females - that is Qatar where there is a 16 score point advantage to males. In all the other countries there was no statistically significant difference between males and females (see Table 10).

\section{Parental involvement}

Can data provided by parents shed any light on gender differences in science performance? In PISA 2006, 16 countries implemented a questionnaire for parents of students participating in PISA. The data collected from these questionnaires provided information about the activities that children undertook when they were younger. The data in PISA 2006 showed that parents reported that both males and females had equal access to different types of science activities at age 10.

It was found that there was a strong association between a student's involvement in science-related activities around age 10 and performance in PISA at age 15. Students whose parents reported that their child had, at age 10, read books on science "very often" or "regularly" performed an average of 39 points higher than did students whose parents reported that their children had done this "never" or "only sometimes". As shown in figure 13 there were no gender differences in the extent to which males and females undertook these activities as 10 year olds.

To obtain information on parents' impressions of the quality of the schools that their sons and daughters attend, they were asked their views on the following statements: $i$ ) Most of my child's school teachers seem competent and dedicated; ii) Standards of achievement are high in my child's school; iii) I am happy with the content taught and the instructional methods used in my child's school; iv) I am satisfied with the disciplinary atmosphere in my child's school; $v$ ) My child's progress is carefully monitored by the school; vi) My child's school provides regular and useful information on my child's progress; and vii) My child's school does a good job in educating students. Parents responded using a four point scale: "strongly agree", "agree", "disagree" and "strongly disagree".

Figure 14 shows the extent to which parents agreed with three of these statements: that the teachers are competent, that they are satisfied with the disciplinary atmosphere and that the standards of achievement are high. It can be seen that there are no significant differences between the perceptions of the parents of male students and the parents of female students.

\section{Future career orientation}

It is possible future career opportunities may provide an incentive for students to perform better. Students' career preferences and the extent to which they are well informed about science-related careers, are measured by PISA 2006. The data suggested that students who demonstrated strong scientific skills and the required competencies to pursue more advanced scientific studies did not tend to report aspiring to science careers unless they also valued or enjoyed science.

\section{Information on science-related careers and preparation for the future}

Earlier in this report it was seen that females entering tertiary level science courses tend to opt for the life sciences and avoid the computer sciences (Figure 3). In PISA 2006 students were asked about their perceptions of how well their school has prepared them for the future in terms of science-related careers. The index of school preparation for science-related careers was derived from students' level of agreement with the following statements: $i$ ) the subjects available at my school provide students with the basic skills 
Figure 14
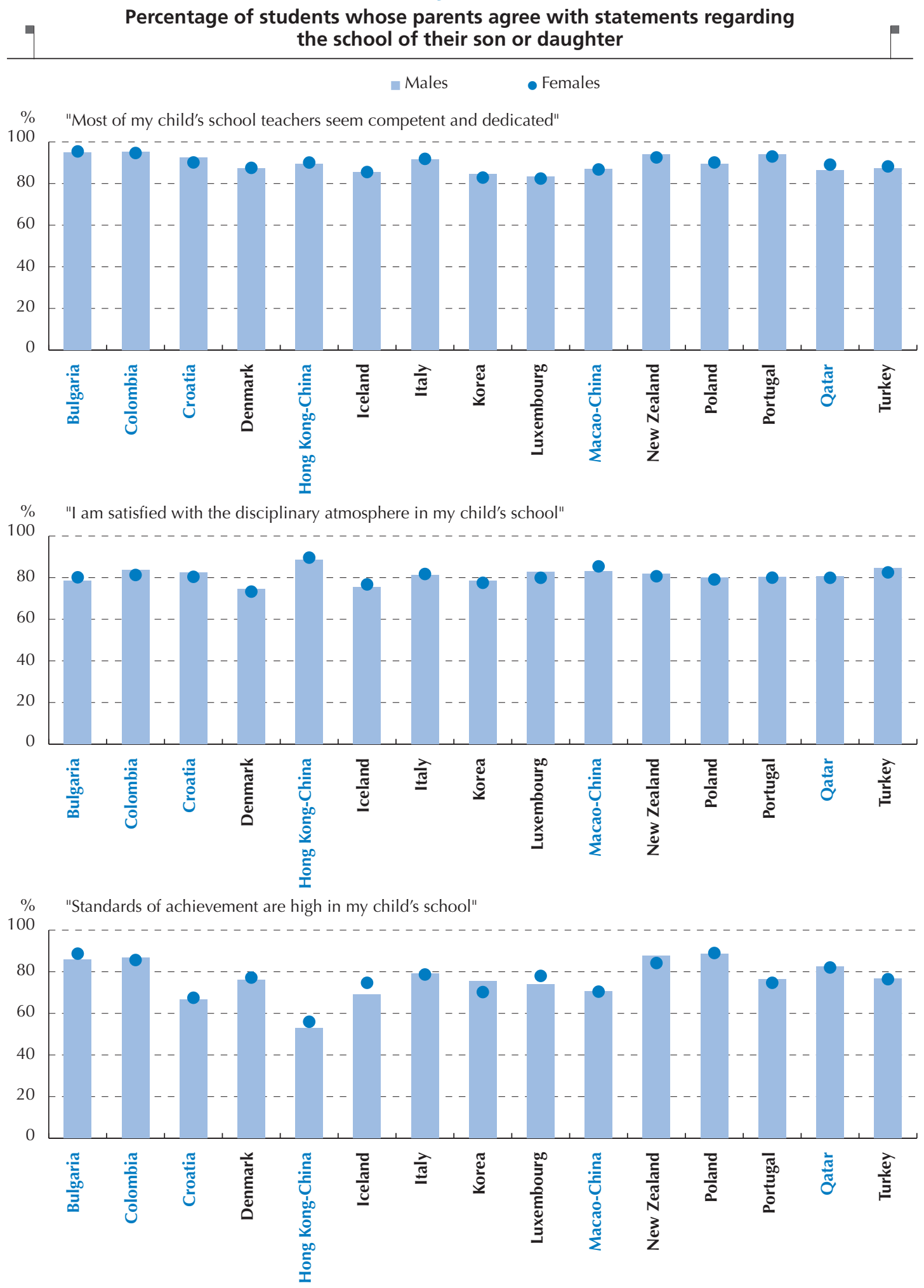

Source: OECD PISA 2006 Database, Table 12. 
and knowledge for a science-related career; ii) the science subjects at my school provide students with the basic skills and knowledge for many different careers; iii) the subjects I study provide me with the basic skills and knowledge for a science-related career; and iv) my teachers equip me with the basic skills and knowledge I need for a science-related career. A four-point scale with the response categories "strongly agree", "agree", "disagree" and "strongly disagree" was used. As with other indices constructed for PISA 2006, this index had an average across OECD countries of zero and a standard deviation of one. Students with a score below zero do not necessarily have a negative view of the question, it is just that they have a less positive view than the OECD average.

Across the OECD there was no overall difference between males and females on this measure. The OECD country with the largest difference in favour of males on this index was Greece (a difference of 0.18), while the largest difference among the partner countries and economies was in Macao-China (0.23).

The students were also asked for their perception of the quality of advice available to them at school about science-related careers. The index of student information on science-related careers was derived from students' beliefs about their level of information on the following topics: i) science-related careers that are available in the job market; ii) where to find information about science-related careers; iii) the steps students need to take if they want a science-related career; and iv) employers or companies that hire people to work in science-related careers. A four-point scale with the response categories "very well informed", "fairly informed", "not well informed" and "not informed at all" was used.

Across the OECD there was a small but significant gender difference observed in the index of student information on science-related careers in favour of males. There were 13 OECD countries and 15 partner countries and economies where males perceived themselves to be better informed than females in this regard. Conversely there were five OECD countries and one partner country where females perceived themselves to be better informed than males. The largest difference in an OECD country was in Mexico (a difference of 0.20 on the index in favour of females), and among the partner countries, Qatar had the largest difference $(0.25$ in favour of females).

\section{Do students expect to pursue a scientific career?}

There were marked differences in the preferred science careers of male and female students who participated in PISA.

In PISA 2006 students also reported their expected career at age 30. From these responses it was possible to identify those students who expected to pursue a science-related career. This was done by coding students' responses using the international standard classification of occupations (ISCO-88 - see Annex A10, OECD 2007a ). In accordance with this definition, science-related careers include those that involve a considerable amount of science, plus careers that involve tertiary education in a scientific field. Thus it includes careers that are beyond the traditional idea of a scientist, such as engineer, weather forecaster, optician and medical doctor.

The percentage of students expecting a science-related career is an indicator of an important educational outcome. In countries where policy makers are concerned about shortages of science professionals in the labour market, analysis of students reporting that they expected science-related careers, in conjunction with other background factors such as the socio-economic background of students and schools, study programmes and gender, could help to identify in which student groups, and to what extent, science orientation may be less pronounced. On average across OECD countries, 25\% of students reported that they expected to be in a science-related career at age 30 (Table 3.12, OECD, 2007a). Between 35 and 40\% 
of students reported that they expected a science-related career in Portugal, the United States and Canada, and in the partner countries Chile, Jordan and Brazil.

In broad terms, PISA 2006 showed only small differences in the kinds of jobs males and females expected to have when they are 30 years old: on average, $27 \%$ of females reported that they expected to have a sciencerelated career at age 30, compared to $24 \%$ of males (Table 3.12, OECD, 2007a). However, when looking at the particular type of science job that students indicated, there were some large differences between males and females.

Across the OECD $17 \%$ of males who expected a scientific career chose computer sciences compared to $2 \%$ of females, with no country showing a higher percentage for females (Table 15). In some countries the difference was very large. In the Slovak Republic, for example, $44 \%$ of males who expected a scientific career chose computer sciences compared to $2 \%$ of females.

There were similar figures for technicians where, across the OECD, an average of $16 \%$ of males who anticipated a scientific career expected to be a technician compared with $5 \%$ of females. There were no OECD countries where a higher percentage of females than males expressed an expectation to be a technician. The largest gender differences were in Poland, with a difference of $30 \%$ between males and females (33\% for males and $2 \%$ for females), and Austria with a difference of 31\% (38\% for males and 6\% for females).

On the other hand there were also occupations which females preferred much more than males. One of these was nursing: across the OECD, 30\% of females who expressed an interest in a scientific career expected to be involved in nursing compared with $4 \%$ of males. In Belgium the equivalent figures were $44 \%$ of females compared with $7 \%$ of males. Another such career area was other occupations relating to health (including medical doctor, dentists, veterinarians and pharmacists) where, across the OECD, 42\% of females who expressed an interest in a scientific career expected to be involved compared with $20 \%$ of males. In France the equivalent figures were $58 \%$ of females and $18 \%$ of males.

In PISA 2006, an index was constructed of student responses to the questions: i) I would like to work in a career involving science; ii) I would like to study science after secondary school; iii) I would like to work on science projects as an adult; and iv) I would like to spend my life doing advanced science. This index is known as the index of future-oriented motivation to learn science and it was found in PISA 2006, that across the OECD a change of one unit in the index was associated with 19.7 score point increase on the science literacy scale.

These observations of 15-year-olds in 2006 are very similar to the patterns of uptake of tertiary education and careers which were described earlier in this report for people (students and employees) who were aged in their twenties. This suggests that there is a very long time-lag for changes to occur. This means that governments which wish to implement changes should do so without delay and should expect this to be a long term project.

\section{School organisation}

\section{Single-sex schooling}

Much research has been done in the area of mixed- and single-sex schooling. The generally accepted view has been that for females, single-sex schooling is more advantageous, whereas for males, mixed-sex schooling is more favourable. Riordan (1994) wrote that females do better academically in single-sex schools and colleges, across a variety of cultures, and that on the basis of the available research, it appeared that 
"single-sex schools for females provide a greater opportunity for educational attainment as measured by standardised cognitive tests, curriculum and course placement, leadership behaviour, number of years of formal education, and occupational achievement."

There is not unanimous agreement on this issue. In the United Kingdom, one study (Malacova, 2007) carried out multilevel modelling on national value-added data to study the effects of single-sex education on the progress of pupils from 2002 Key Stage 3 to 2004 General Certificate of Secondary Education (GCSE). The analysis suggested that pupils in a selective environment achieve higher progress in single-sex schools; however, the advantage of single-sex schooling seems to decrease with increasing prior attainment (for females) or with increasing school 'selectiveness' (for males).

PISA can help to throw some light on this issue. ${ }^{7}$ In order to have a sufficient number of cases to analyse in PISA, there must be a minimum of $3 \%$ of the sample or 30 cases. $^{8}$ In the analysis of single-sex schools, this excludes many countries as they have either no or very small numbers of students attending this type of school.

For the countries that did qualify for analysis there are some interesting findings. Analysis was carried out to find the differences in science performance for students (males and females separately) attending single-sex schools and mixed-sex schools. It was also decided to undertake the analysis taking into account both the students' and the schools' socio-economic background, given that in some countries single-sex education is associated with higher socio-economic intake, fee-paying schools.

There are, therefore, three sets of results (Table 16) - one set for the raw difference in scores between singlesex and mixed-sex schools for males and females, another for the differences after accounting for students' socio-economic background, and a third after accounting for both students' and schools' average socioeconomic background.

It can be seen in Figure 14 and 15 that, generally, the differences tend to diminish after both students' and schools' socio-economic background are taken into account for both males and females. For males there was a significant difference in Korea, Australia and the partner country Thailand between single-sex schools and mixed-sex schools after accounting for students' socio-economic background, but this disappeared after taking schools' socio-economic background into account as well. Significant differences remained in the partner countries and economies Chinese Taipei and Chile where the difference favoured single-sex schools and Macao-China, Jordan and Qatar where the difference favoured the mixed-sex schools.

For females there was a significant difference in Ireland, Luxembourg, Australia and the partner country Thailand between single-sex schools and mixed-sex schools after accounting for student's socio-economic background, but this disappeared after taking school's socio-economic background into account as well. After taking both student's and school's socio-economic background into account there were significant differences in the United Kingdom, New Zealand and the partner economy Macao-China, where the difference favoured single-sex schools and in Japan, Turkey and the partner countries Chile and Qatar where the difference favoured the mixed-sex schools.

Generally speaking, in terms of science performance, the evidence from PISA does not uniformly support the notion that females tend to do better in a single-sex environment. 
Figure 15

Difference in performance of females between single-sex and mixed sex schools, PISA 2006

Raw difference in score (single - mixed)

- Difference after accounting for students ESCS

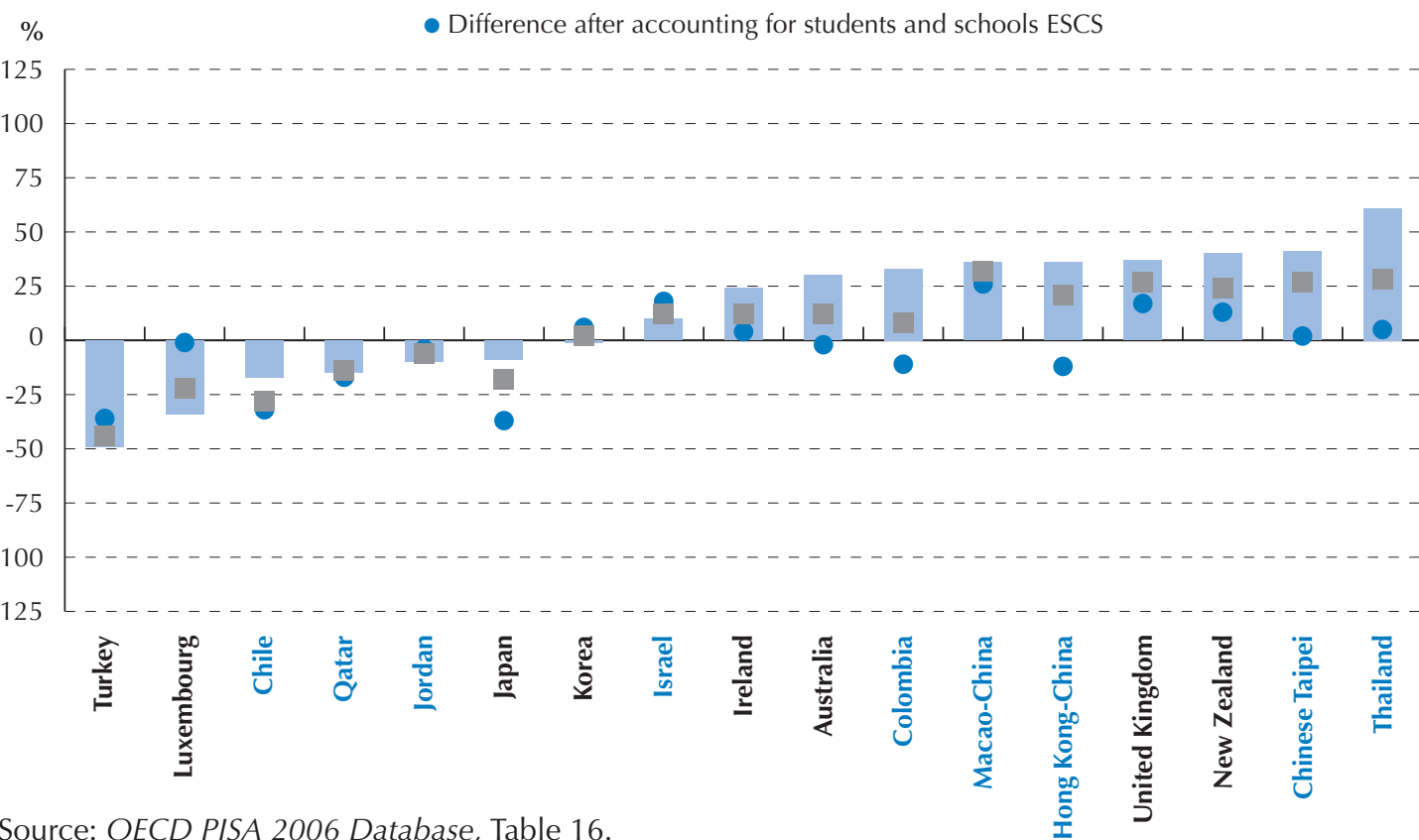

Source: OECD PISA 2006 Database, Table 16.

Figure 16

Difference in performance of males between single-sex and mixed sex schools, PISA 2006

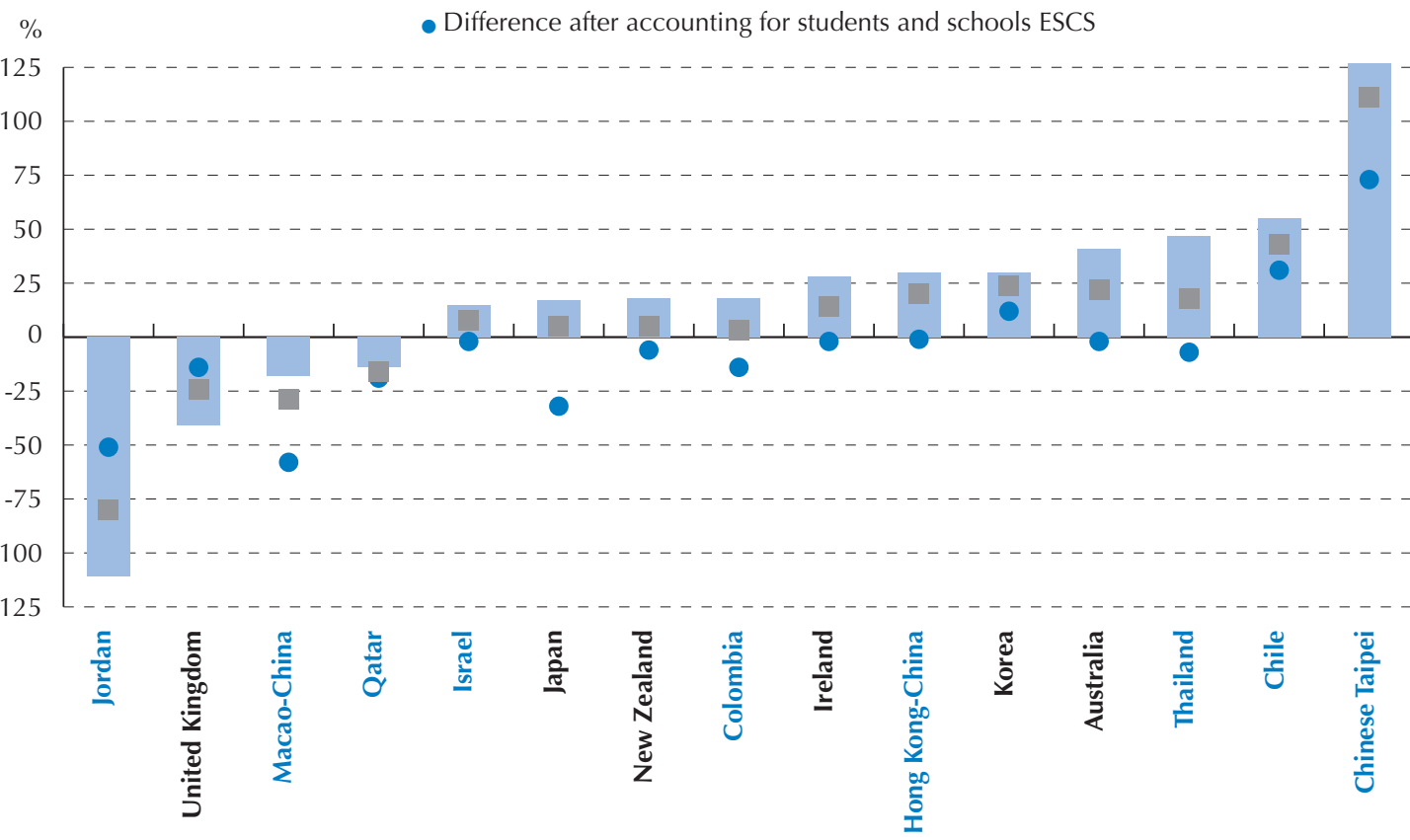

Source: OECD PISA 2006 Database, Table 16. 


\section{Homework}

Homework is used for a number of purposes in schools, but is most usually aimed at allowing students to practise concepts learned during the day to reinforce them, and to encourage students to learn research skills using libraries, the Internet or other resources such as books at home.

In PISA, to find out if students pursued their separate subject areas in studies outside school, they were asked to indicate in addition to their classroom hours, for each of science, reading and mathematics:

- the time spent attending out-of-school-time lessons (at school, at home or somewhere else) - referred to as "out of-school lessons" below;

- the time spent studying or doing homework by themselves - referred to as "self-study" below.

For both these components, the time spent on work outside school was categorised into two or less hours per week and more than two hours per week. It can be seen (Table 17) that most students spend two hours or less doing work outside school and that on average across the OECD there are few differences between males and females for all three subject areas.

The data on time spent on self-study shows greater variation between males and females. For science, on average across the OECD, a greater percentage of females $(27 \%)$ than males $(23 \%)$ spent two or more hours per week on self-study. The outcomes were similar in both mathematics (38\% of females spent two or more hours per week on self-study compared to $32 \%$ of males) and reading ( $36 \%$ of females compared to $26 \%$ of males). So in each of the subject areas females spend more time on self-study than males.

In science, for example, there was a large difference between males and females in Poland with $31 \%$ of males spending two or more hours per week on homework compared to $52 \%$ of females. For mathematics the largest difference occurs in Poland with $35 \%$ of males reporting two or more hours per week compared to $50 \%$ of females and for reading the figures are even a little greater, $36 \%$ for males and $57 \%$ for females. In Italy, $73 \%$ of females report that they spend two or more hours on reading homework per week - this is the highest percentage of students in any of the three subject areas.

The observation that females spend more time on homework is in accord with other research in the area. Wagner, Schober, and Spiel (2008) concluded this in a paper that presents three studies which deal with the time 15-year-old students spend working at home for school. Using diaries as a data collection method they found that the students invested on average 11.7 hours per week in work done at home for school and that females spent more time than males.

Rogers and Hallam (2006) in a study of GCSE students in the United Kingdom also found the same gender differences. Interestingly, their findings suggested that, overall, high-achieving males have better studying strategies than high-achieving females and that they achieve high standards while doing less homework.

\section{CONCLUSION}

The extent to which males and females have different outcomes in education and the labour market is an extremely complex discussion. This report shows that there are, indeed, significant differences in many areas. The evolution of these differences provides some challenging issues for parents and educators.

At the primary education level, studies by the IEA indicate few gender differences in science and mathematics, but a clear advantage to females in reading.

At the secondary level, international data confirm an on-going advantage for females in reading, but also show differences in performance in favour of males in some areas of both mathematics and science. In 
fact, there has been an increase in the gender differences observed in reading from 2000 to 2006. It would seem that policy makers and educators could take note of this trend and investigate ways to arrest its development. The data also show that male and female students are making different tertiary education and career choices in relation to science, with females showing a preference for health related courses and males for computing science. Taking all the observations and analyses together it seems that gender differences are actually increasing as students get older.

Female students have much higher levels of interest in reading than males, with the converse being true in relation to mathematics. The results of PISA 2003 mathematics showed that females generally had higher levels of anxiety about mathematics and that the level of anxiety is associated with performance. At the same time, there were no major gender differences in problem solving - leading to the conclusion that females' capacity in mathematics could be expanded if the levels of anxiety were lower. In relation to science, however, interest and engagement do not differ significantly between male and female students.

In summary, the results show that schools and societies do not always succeed in fostering comparable levels of motivation, interest or self-confidence in different areas among male and female students. Male students need to be helped towards a more positive approach to reading, which requires them to see it as a useful, profitable and enjoyable activity. Teachers need to consider the expectations that they have of students of both sexes and adopt strategies to raise the levels of self-confidence and motivation of students in those areas where each are weak. This cannot be achieved simply through classroom practice, since reading is a cultural practice influenced by the social context. Promoting male reading interest therefore needs to involve the family and society more widely. In similar respects, females need wide support in developing their interest and self-regard in mathematics. In particular, female students who do not have confidence in their mathematical abilities are likely to be constrained in their future choice of career, making it important to aim to build this aspect of their confidence.

At the same time, the influence of the cultural beliefs prevailing in a country and the effect of the media have not been considered in this report, but are influences which cannot be ignored. It is possible that by the time students are reaching the age to make choices for education after secondary school, that these influences are becoming very important. It was seen in the report that females graduate at a higher rate from general programmes at secondary school, but are showing definite preferences when entering tertiary level science education, with much smaller numbers taking up computer sciences compared to life sciences. This weakness in or aversion to computer studies was also shown, in the three countries that participated, by the results obtained in the PISA 2006 CBAS project, where females scored significantly lower than males.

The question of whether males and females are better being schooled in single-sex or mixed-sex surroundings continues to be a vexing one for education authorities around the world. The evidence from PISA does not support the notion that females tend to do better in a single-sex environment. However, caution is needed in interpreting these results because of the relatively small numbers of students and because PISA does not measure either the social environment or the social development of students which is also an important goal of education.

In a number of previous studies of secondary students it has been found that, in general, females do more homework than males. The results from PISA 2006 support this observation in all subject areas.

At the same time, PISA has shown that there are, indeed, areas where some of the accepted pre-conceived notions regarding stereotypic male and female behaviour are simply not true. Females did not score more highly in life sciences as would have been widely expected. The results from PISA 2006 also demonstrated the clear advantage that females have in identifying scientific issues. 


\section{Notes}

1 Further detail on the development and implementation of PISA is provided in the Annex.

2. The Slovak Republic and Turkey did not participate in PISA 2000. while Luxembourg. the Netherlands. the United Kingdom and the United States were not included in the trend comparison for reasons described in the PISA 2006 initial report. PISA 2006: Science Competencies For Tomorrow's World (OECD, 2007).

3. The vast majority of items are retained from one PISA survey to the next to be re-used. so unreleased items cannot be described here.

4. ESCS was derived from the following variables: the higher occupational status of the father or mother; the higher educational level of the father or mother; and the index of home possessions obtained by asking students whether they had at their home various items such as a desk to study at. a room of their own. a quiet place to study. a computer they can use for school. any educational software. a link to the Internet. their own calculator. classic literature. a dishwasher. a DVD player or VCR. the number of cellular phones. televisions. computers. cars and books at home. The rationale for the choice of these variables was that socio-economic status is usually seen as being determined by occupational status. education and wealth. As no direct measure on parental income was available from PISA (except for those countries which undertook the parent questionnaire). access to relevant household items was used as a proxy.

5. In this two-level regression analysis. students serve as Level 1 and schools serve as Level 2. The dependent variables are the five plausible values in science; independent variables at Level 1 are the gender variable $\left(0=\right.$ male and $1=$ female) and students' ${ }^{\prime}$ ESCS; an independent variable at Level 2 is school average ESCS; and the cross-level interaction between gender and school average ESCS is included. Intercepts and slopes for gender are randomised. Students' ESCS and school average ESCS are grand-mean centred. Normalised final students weights as well as normalised replicates are used.

6. For the purpose of this analysis these are those countries in which students with an immigrant background represent at least $3 \%$ of the 15 -year-old student population.

7. It should be noted also that much of the research that has been done so far is in the measurement of effects of single-sex classrooms. rather than single-sex schools. For this PISA is unable to provide any information because the PISA sample is an age-based sample taking students across classes and indeed across grades. There is also no teacher questionnaire in PISA to give information on this.

8. This restriction applies to all analyses in PISA. 


\section{REFERENCES}

- Artelt, C., J. Baumert, N. Julius-McElvany, and J. Peschar (2003), Learners for Life: Student Approaches To Learning: Results From PISA 2000, OECD, Paris.

- Belfield, C.R. and H.M. Levin (eds.) (2007), The Price We Pay: Economic and Social Consequences of Inadequate Education, Brookings, Washington, DC.

- Malacova, E. (2007), "Effect of Single-Sex Education on Progress in GCSE", Oxford Review of Education, Volume 33, pp. 233 - 259.

- Martin, M.O., Mullis, I.V.S., and Foy, P. (with Olson, J.F., Erberber, E., Preuschoff, C., \& Galia, J.) (2008), Chestnut Hill, MA: TIMSS \& PIRLS International Study Center, Boston College, Chestnut Hill, MA.

- Miller, P. H. (2006), "Gender differences in high school students' views about science", International Journal of Science Education, Volume? 28, pp. 363-381.

- Monseur, C. (2005), "An exploratory alternative approach for student non response weight adjustment", Studies in Educational Evaluation, Volume 31(2-3), pp. 129-144.

- Mullis, I.V.S., Martin, M.O., and Foy, P. (with Olson, J.F., Preuschoff, C., Erberber, E., Arora, A., \& Galia, J.) (2008). TIMSS 2007 International Mathematics Report. Chestnut Hill, MA: TIMSS \& PIRLS International Study Center, Boston College, Chestnut Hill, MA.

- Mullis, I.V.S., M.O. Martin, A. Kennedy, and P. Foy (2007), PIRLS 2006 International Report, TIMSS \& PIRLS International Study Center, Boston College, Chestnut Hill, MA.

- OECD (1999), Measuring Student Knowledge and Skills - A New Framework for Student Assessment, OECD, Paris.

- OECD (2001), Knowledge and Skills for Life - First Results from PISA 2000, OECD, Paris.

- OECD (2002), Reading for Change - Performance and Engagement across Countries: Results from PISA 2000, OECD, Paris.

- OECD (2003), The PISA 2003 Assessment Framework - Mathematics, Reading, Science and Problem Solving Knowledge and Skills, OECD, Paris.

- OECD (2004a), Learning for Tomorrow's World - First Results from PISA 2003, OECD, Paris.

- OECD (2004b), Problem Solving for Tomorrow's World - First Measures of Cross Curricular Competencies from PISA 2003, OECD, Paris.

- OECD (2005a), PISA 2003 Technical Report, OECD, Paris.

- OECD (2005b), Where Immigrant Students Succeed - A Comparative Review of Performance and Engagement in PISA 2003, OECD, Paris.

- OECD (2005c), Are Students Ready for a Technology Rich World - What PISA Studies Tell Us, OECD, Paris. 
- OECD (2006a), Assessing Scientific, Reading and Mathematical Literacy: A Framework for PISA 2006, OECD, Paris.

- OECD (2006b), Evolution of Student Interest in Science and Technology Studies - Global Science Forum, OECD, Paris.

- OECD (2007a), PISA 2006 - Science Competencies for Tomorrow's World, OECD, Paris.

- OECD (2007b), Understanding the Brain: The Birth of a Learning Science, OECD, Paris.

- OECD (2008), Education at a Glance 2008 - OECD Indicators, OECD, Paris.

- OECD (2009), PISA 2006 Technical Report, OECD, Paris.

- Ólafsson, R.F., A.M. Halldórsson, and J.K. Björnsson (2003), "Gender and the Urban-rural Differences in Mathematics and Reading: An Overview of PISA 2003 Results in Iceland", in S. Lie, P. Linnakylä and A. Roe (eds.), Northern Lights on PISA: Unity and Diversity in the Nordic Countries in PISA 2000, , Department of Teacher Education and School Development, University of Oslo, Oslo.

- Riordan, C. (1994), The case for single-sex schools, Office of Educational Research and Improvement, US Department of Education, Washington DC.

- Rogers, L. and S. Hallam (2006), "Gender Differences in Approaches to Studying for the GCSE among High-achieving Pupils", Educational Studies, Volume 32, no 1, pp. 59-71.

- Stadler, H. (1999), "Fachdidaktische Analyse der österreichischen SchülerInnenergebnisse bei TIMSS Pop 3 - Betrachtung der Ergebnissein geschlechtsspezifischer Hinsicht" [Analysis of the results of TIMSS Pop 3 with a focus on gender issues], Zweiter Zwischenbericht zum Projekt IMST - Innovations in Mathematics and Science Teaching, Teil I (im Auftrag des BMUK), University of Klagenfurt, Klagenfurt.

- Stake, J. E. (2006), "The critical mediating role of social encouragement for science motivation and confidence among high school females and males", Journal of Applied Social Psychology Volume 36, pp. 1017-1045.

- Taasoobshirazi, G. A. (2008), "Gender Differences in Science: An Expertise Perspective", Educational Psychological Review, Volume 20, pp. 149-169.

- Turner, R. and A. Routitsky (2002), Item Format Types and Their Influence on Cross-National Comparisons of Student Performance, Paper presented at the Annual Meeting of the American Education Research Association.

- Wagner, P., B. Schober, and C. Spiel (2008), "Time Students Spend Working at Home for School", Learning and Instruction, Volume 18, no 4, pp. 309-320.

- Willms, J.D. (2006), Learning Divides: Ten Policy Questions About the Performance and Equity of Schools and Schooling Systems, UNESCO Institute for Statistics, Montreal.

- Willms, J.D. (2003), Student Engagement At School, a Sense Of Belonging And Participation: Results From PISA 2000, OECD, Paris. 


\section{APPENDIX A - BACKGROUND OF PISA}

\section{The development of PISA surveys}

Decisions about the scope and nature of the assessments and the background information to be collected are made by leading experts in participating countries, with the overall project being steered jointly by governments on the basis of shared, policy-driven interests. The frameworks for assessing scientific, reading and mathematical literacy in 2006 are described in full in Assessing Scientific, Reading and Mathematical Literacy: A Framework for PISA 2006 (OECD, 2006a). Substantial efforts and resources are devoted to achieving cultural and linguistic breadth and balance in the assessment materials. Stringent quality assurance mechanisms are applied in translation, sampling and data collection. As a consequence, the results of PISA have a high degree of validity and reliability.

Although PISA was originally created by the governments of OECD countries, 27 partner countries and economies participated in PISA 2006 in addition to the 30 OECD countries, making a total of 57 participating countries.

\section{The PISA student population}

PISA covers students who are aged between 15 years 3 months and 16 years 2 months at the time of the assessment and who have completed at least 6 years of formal schooling, regardless of the type of institution in which they are enrolled and whether they are in full-time or part-time education, whether they attend academic or vocational programmes, and whether they attend public or private schools or foreign schools within the country. The percentage of males and females in the samples in participating countries is shown in Table A. It can be seen that in most countries the percentages of males and females were very similar. The largest difference among OECD countries was in the Czech Republic where $56.6 \%$ of students in the sample were male. Among the partner countries and economies the largest differences were in Thailand (57.4\% female) and in Chile (54\% male).

In addition to reviewing the gender balance in the overall sample, it is important to consider the response rates of males and females, Previous analyses (Monseur, 2005) had shown differential response rates for males and females. In several countries, the difference between male and female response rate was greater than $2 \%$. For instance, in Portugal, the response rate for males was $82.6 \%$ and for females $87.8 \%$. As gender was found to be correlated with performance, particularly in reading literacy, a student non-response adjustment was developed for PISA which compensated for differential grade and gender response rates. All technical details of the design and implementation of PISA are included in the technical reports which are released after the release of the initial international reports - for an example see PISA 2006 Technical Report (OECD, 2009).

\section{Key features of PISA 2006}

\section{Content}

- Although the survey also covered reading and mathematics, the main focus of PISA 2006 was science, 2006 being the first occasion on which science was the major domain.

- The PISA 2006 survey also, for the first time, sought information on students' attitudes to science by including questions on attitudes within the test itself, rather than only through a complementary questionnaire. 
Table A Percentage of males and females in each participating country's sample

\begin{tabular}{|c|c|c|c|c|c|}
\hline & & \multicolumn{2}{|c|}{ Males } & \multicolumn{2}{|c|}{ Females } \\
\hline & & Percentage & S.E. & Percentage & S.E. \\
\hline \multirow{31}{*}{ 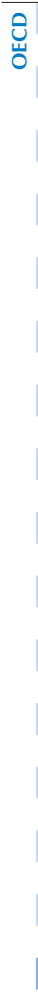 } & Australia & 51 & (1.4) & 49 & (1.4) \\
\hline & Austria & 51 & (1.8) & 49 & (1.8) \\
\hline & Belgium & 52 & (1.4) & 48 & (1.4) \\
\hline & Canada & 50 & $(0.6)$ & 50 & (0.6) \\
\hline & Czech Republic & 57 & (1.9) & 43 & (1.9) \\
\hline & Denmark & 50 & $(0.8)$ & 50 & $(0.8)$ \\
\hline & Finland & 50 & $(0.8)$ & 50 & $(0.8)$ \\
\hline & France & 49 & (1.3) & 51 & (1.3) \\
\hline & Germany & 52 & $(0.9)$ & 48 & (0.9) \\
\hline & Greece & 50 & (1.0) & 50 & (1.0) \\
\hline & Hungary & 52 & (1.9) & 48 & (1.9) \\
\hline & Iceland & 50 & $(0.8)$ & 50 & $(0.8)$ \\
\hline & Ireland & 49 & (1.1) & 51 & (1.1) \\
\hline & Italy & 50 & (1.0) & 50 & (1.0) \\
\hline & Japan & 50 & (2.4) & 50 & (2.4) \\
\hline & Korea & 51 & (3.0) & 49 & (3.0) \\
\hline & Luxembourg & 51 & $(0.7)$ & 49 & $(0.7)$ \\
\hline & Mexico & 48 & $(1.0)$ & 52 & (1.0) \\
\hline & Netherlands & 51 & (0.9) & 49 & (0.9) \\
\hline & New Zealand & 48 & (2.1) & 52 & (2.1) \\
\hline & Norway & 52 & $(0.7)$ & 48 & $(0.7)$ \\
\hline & Poland & 50 & $(0.7)$ & 50 & $(0.7)$ \\
\hline & Portugal & 48 & $(0.8)$ & 52 & $(0.8)$ \\
\hline & Slovak Republic & 51 & $(1.7)$ & 49 & (1.7) \\
\hline & Spain & 51 & $(0.7)$ & 49 & $(0.7)$ \\
\hline & Sweden & 51 & $(0.8)$ & 49 & $(0.8)$ \\
\hline & Switzerland & 52 & $(0.8)$ & 48 & $(0.8)$ \\
\hline & Turkey & 55 & (1.9) & 45 & (1.9) \\
\hline & United Kingdom & 50 & (1.0) & 50 & (1.0) \\
\hline & United States & 51 & $(0.9)$ & 49 & (0.9) \\
\hline & OECD average & 51 & $(0.2)$ & 49 & $(0.2)$ \\
\hline \multirow{27}{*}{ 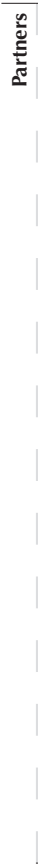 } & Argentina & 47 & (1.4) & 53 & $(1.4)$ \\
\hline & Azerbaijan & 52 & $(0.9)$ & 48 & (0.9) \\
\hline & Brazil & 46 & $(0.8)$ & 54 & $(0.8)$ \\
\hline & Bulgaria & 52 & (1.8) & 48 & (1.8) \\
\hline & Chile & 54 & (1.6) & 46 & (1.6) \\
\hline & Colombia & 46 & (1.9) & 54 & (1.9) \\
\hline & Croatia & 50 & (1.9) & 50 & (1.9) \\
\hline & Estonia & 51 & $(0.9)$ & 49 & (0.9) \\
\hline & Hong Kong-China & 49 & (1.9) & 51 & (1.9) \\
\hline & Indonesia & 51 & $(2.1)$ & 49 & (2.1) \\
\hline & Israel & 50 & (1.4) & 50 & (1.4) \\
\hline & Jordan & 50 & (1.9) & 50 & (1.9) \\
\hline & Kyrgyzstan & 47 & $(0.8)$ & 53 & $(0.8)$ \\
\hline & Latvia & 49 & $(0.7)$ & 51 & $(0.7)$ \\
\hline & Liechtenstein & 46 & (2.3) & 54 & (2.3) \\
\hline & Lithuania & 51 & $(0.7)$ & 49 & $(0.7)$ \\
\hline & Macao-China & 51 & $(0.8)$ & 49 & $(0.8)$ \\
\hline & Montenegro & 52 & (0.6) & 48 & (0.6) \\
\hline & Qatar & 51 & $(0.1)$ & 49 & $(0.1)$ \\
\hline & Romania & 50 & (1.8) & 50 & (1.8) \\
\hline & Russian Federation & 48 & (1.0) & 52 & (1.0) \\
\hline & Serbia & 51 & (1.5) & 49 & (1.5) \\
\hline & Slovenia & 50 & $(0.7)$ & 50 & $(0.7)$ \\
\hline & Chinese Taipei & 52 & (1.5) & 48 & (1.5) \\
\hline & Thailand & 43 & (1.4) & 57 & (1.4) \\
\hline & Tunisia & 48 & $(0.9)$ & 52 & $(0.9)$ \\
\hline & Uruguay & 49 & $(0.9)$ & 51 & (0.9) \\
\hline
\end{tabular}

Source: OECD PISA 2006 Database. 


\section{Methods}

- Around 400000 students participated in PISA 2006, representing about 20 million 15-year-olds in the schools of the 57 participating countries and economies.

- Each participating student spent two hours carrying out pencil-and-paper tasks. In three countries, some students were given additional questions via computer.

- PISA contained tasks requiring students to construct their own answers as well as multiple-choice questions. These were typically organised in units based on a written passage or graphic, of the kind that students might encounter in real life.

- Students also answered a questionnaire that took about 30 minutes to complete and focused on their personal background, their learning habits and their attitudes to science, as well as on their engagement and motivation.

- School principals completed a questionnaire about their school that included demographic characteristics as well as an assessment of the quality of the learning environment at school. In 16 countries parents of the students who participated in PISA also completed a questionnaire.

\section{Outputs}

- A profile of knowledge and skills among 15-year-olds in 2006, consisting of a detailed profile for science, and an update for reading and mathematics.

- Contextual indicators relating performance results to student and school characteristics.

- An assessment of students' attitudes to science.

- A knowledge base for policy analysis and research.

- Trend data on changes in student knowledge and skills in reading and mathematics.

\section{The PISA 2006 science assessment framework}

The establishment of an assessment in PISA begins with the creation of the assessment framework. The primary benefit of developing a framework for any assessment is improved measurement. Developing a framework also improves interpretability, allowing a better understanding of how performances differ. A framework provides a common language for discussing the definition and assumptions surrounding the domain. As mentioned in the introductory section of this report, the frameworks for assessing scientific, reading and mathematical literacy in 2006 are described in full in Assessing Scientific, Reading and Mathematical Literacy: A Framework for PISA 2006 (OECD, 2006a). Further elaboration of the reading and mathematics assessment frameworks can be found in Measuring Student Knowledge and Skills: A New Framework for Assessment (OECD, 1999) and The PISA 2003 Assessment Framework - Mathematics, Reading, Science and Problem Solving Knowledge and Skills (OECD, 2003).

In addition to the competencies and knowledge domains (which are described earlier in this report), PISA frameworks also consider context as an important element. In keeping with the PISA orientation of assessing students' preparation for future life, the PISA 2006 science questions were framed within a wide variety of life situations involving science and technology, namely: "Health", "Natural resources", "Environmental quality", "Hazards" and "Frontiers of science and technology". These situations were related to three major contexts: personal (the self, family and peer groups), social (community) and global (life across the 
world). The contexts used for questions were chosen in the light of relevance to students' interests and lives, representing science-related situations that adults encounter. Almost daily, adults hear about and face decisions concerning health, use of resources, environmental quality, hazard mitigation, and advances in science and technology. The science contexts also align with various issues policy makers confront.

\section{Development of the science items in PISA 2006}

PISA items are arranged in units based around a common stimulus. Many different types of stimulus are used including passages of text, tables, graphs and diagrams, often in combination. Each unit contains up to four items assessing students' scientific competencies and knowledge. In addition, for PISA 2006 about $60 \%$ of the science units contained one or two items designed to assess aspects of students' attitudes towards science. The terms "cognitive items" and "attitudinal items" are used to distinguish these two separate types of items.

There were 37 science units, comprising a total of 108 cognitive items and 31 embedded attitudinal items, representing approximately 210 minutes of testing time for science in PISA 2006. The same amount of time was allocated to the major domain for 2003 (mathematics), although there were no attitudinal items in the 2003 assessment.

The 108 science cognitive items used in the main study included 22 items from the 2003 assessment. The remaining 86 items were selected from a large pool of newly-developed items that had been tested in a field trial conducted in all countries in 2005, one year prior to the main study.

There were four item formats employed for the science cognitive items: simple multiple-choice, complex multiple-choice, short-response, and open-constructed response. The simple multiple-choice items had four responses from which students were required to select the best answer while complex multiple-choice items presented several statements for each of which students were required to choose one of two possible responses (yes/no, true/false, correct/incorrect, etc.). Short-response items required students to construct a numeric response within very limited constraints, or only required a word or short phrase as the answer. Open-constructed response items required more extensive writing than short-response items and frequently required some explanation or justification. In the past cycles of PISA a relationship between gender and item type had been identified. Each attitudinal item required students to express their level of agreement on a four-point scale with two or three statements expressing either interest in science or support for science. Each attitudinal item was formatted distinctively and appeared in a shaded box. 
Table 1 Upper secondary graduation rates (2006)

Percentage of upper secondary graduates in the population at the typical age of graduation. programme orientation and gender

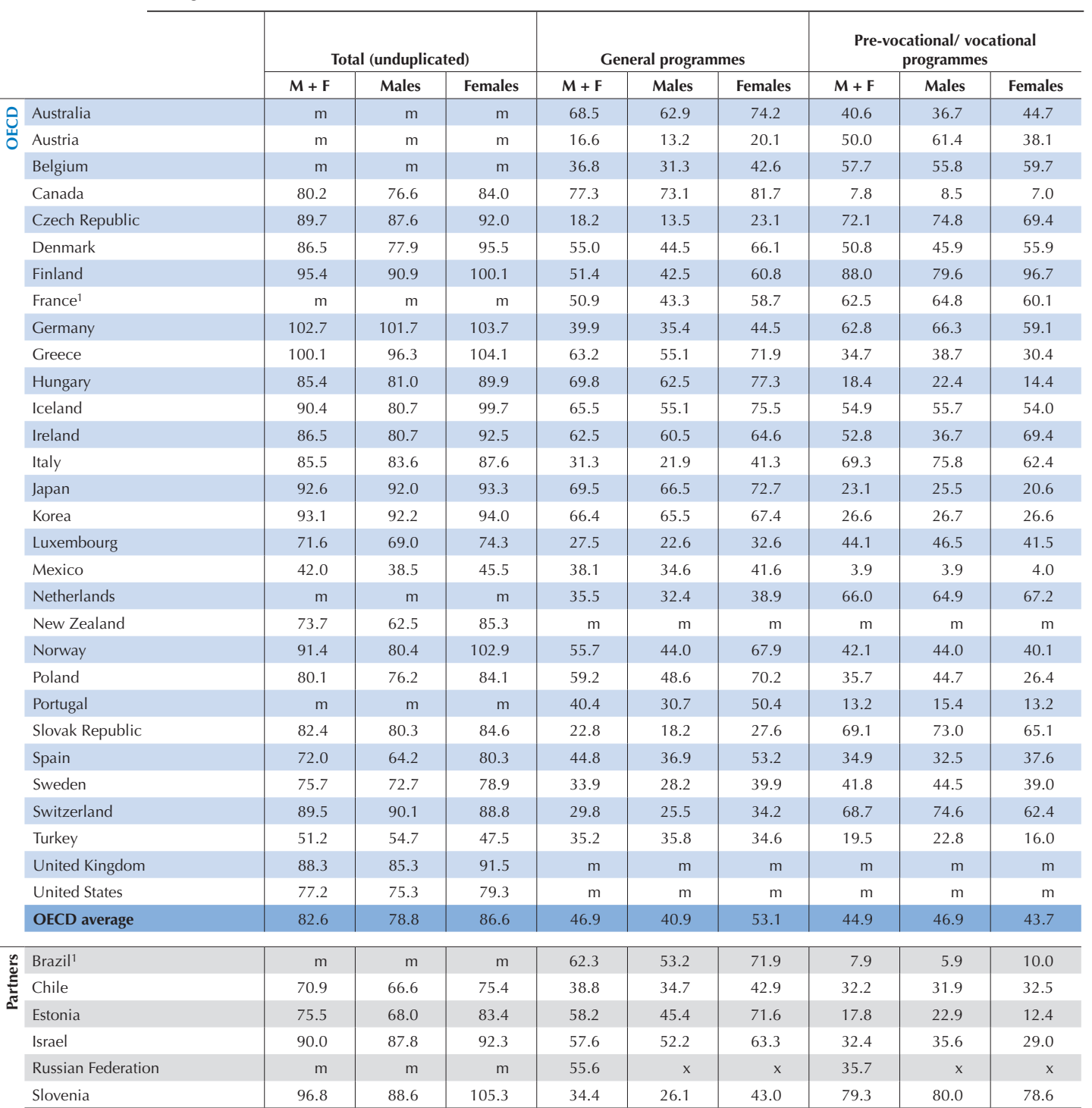

Note: Mismatches between the coverage of the population data and the student/graduate data mean that the participation/graduation rates for those countries that are net exporters of students may be underestimated (for instance Luxembourg) and those that are net importers may be overestimated. 1. Year of reference 2005.

Source: Education at a Glance - OECD Indicators 2008 (OECD, 2008). 
Table 2 Proportion of females among new entrants at tertiary level. by field of education (2006)

\begin{tabular}{|c|c|c|c|c|}
\hline & $\begin{array}{c}\text { Life sciences } \\
\% \\
\end{array}$ & $\begin{array}{c}\text { Physical sciences } \\
\% \\
\end{array}$ & $\begin{array}{c}\text { Mathematics and statistics } \\
\%\end{array}$ & $\begin{array}{c}\text { Computing } \\
\% \\
\end{array}$ \\
\hline Australia & 53.7 & 45.6 & 34.5 & 17.3 \\
\hline Austria & 65.5 & 30.8 & 37.7 & 18.8 \\
\hline Belgium & 55.9 & 31.9 & 44.3 & 7.4 \\
\hline Canada & $\mathrm{m}$ & $\mathrm{m}$ & $\mathrm{m}$ & $\mathrm{m}$ \\
\hline Czech Republic & 69.4 & 46.4 & 48.4 & 15.8 \\
\hline Denmark & 61.9 & 40.1 & 40.5 & 30.8 \\
\hline Finland & 75.2 & 50.5 & 50.4 & 28.1 \\
\hline France & $\mathrm{m}$ & $\mathrm{m}$ & $\mathrm{m}$ & $\mathrm{m}$ \\
\hline Germany & 68.4 & 43.5 & 58.3 & 17.6 \\
\hline Greece & $\mathrm{m}$ & $\mathrm{m}$ & $\mathrm{m}$ & $\mathrm{m}$ \\
\hline Hungary & 61.2 & 37.7 & 39.1 & 20.2 \\
\hline Iceland & 73.5 & 45.9 & 35.5 & 13.8 \\
\hline Ireland & 69.6 & 49.3 & 46.9 & 24.4 \\
\hline Italy & 67.0 & 41.6 & 48.5 & 13.2 \\
\hline Japan & $\mathrm{x}$ & $\mathrm{x}$ & $\mathrm{x}$ & $\mathrm{x}$ \\
\hline Korea & 49.4 & 46.0 & 56.0 & 23.7 \\
\hline Luxembourg & $\mathrm{m}$ & $\mathrm{m}$ & $\mathrm{m}$ & $\mathrm{m}$ \\
\hline Mexico & 54.9 & 49.4 & 42.1 & 34.4 \\
\hline Netherlands & 55.3 & 27.6 & 27.0 & 9.3 \\
\hline New Zealand & 62.4 & 47.1 & 40.5 & 29.2 \\
\hline Norway & 64.2 & 44.5 & 45.5 & 17.7 \\
\hline Poland & 62.0 & 53.5 & 57.3 & 8.6 \\
\hline Portugal & 68.0 & 51.2 & 54.1 & 17.6 \\
\hline Slovak Republic & $\mathrm{m}$ & $\mathrm{m}$ & $\mathrm{m}$ & $\mathrm{m}$ \\
\hline Spain & 63.8 & 45.0 & 48.5 & 14.2 \\
\hline Sweden & 59.8 & 43.8 & 43.1 & 20.6 \\
\hline Switzerland & 50.8 & 31.0 & 34.1 & 12.8 \\
\hline Turkey & 53.4 & 37.3 & 44.0 & 31.6 \\
\hline United Kingdom & 49.7 & 42.5 & 38.4 & 25.1 \\
\hline United States & $\mathrm{m}$ & $\mathrm{m}$ & $\mathrm{m}$ & $\mathrm{m}$ \\
\hline OECD average & 61.5 & 42.7 & 44.1 & 19.7 \\
\hline Brazil & $\mathrm{m}$ & $\mathrm{m}$ & $\mathrm{m}$ & $\mathrm{m}$ \\
\hline Chile & 53.0 & 48.1 & 42.5 & 14.4 \\
\hline Estonia & 72.9 & 35.9 & 70.1 & 22.6 \\
\hline Israel & 62.7 & 35.1 & 26.9 & $x$ \\
\hline Russian Federation & $\mathrm{m}$ & $\mathrm{m}$ & $\mathrm{m}$ & $\mathrm{m}$ \\
\hline Slovenia & 76.2 & 52.2 & 66.8 & 13.3 \\
\hline
\end{tabular}

Source: Education at a Glance - OECD Indicators 2008 (OECD, 2008). 
Table 3 Categorisation of readers (PISA 2000)

\begin{tabular}{l|c|c|c}
\hline Cluster & Percentage of males & Percentage of females & \multicolumn{1}{c}{ Reading profile } \\
\hline Least diversified readers & 20.9 & 23.6 & $\begin{array}{c}\text { Little diversification in reading. only frequently reading } \\
\text { magazines. Small percentages reading fiction. Do not } \\
\text { read for pleasure. }\end{array}$ \\
Moderately diversified readers & 29.8 & 24.7 & $\begin{array}{c}\text { Majority of students frequently read magazines and } \\
\text { newspapers. rarely read any type of book (fiction or } \\
\text { non-fiction). almost never read comics. }\end{array}$ \\
Diversified readers in short texts & 33.8 & 22.9 & $\begin{array}{c}\text { Majority frequently read magazines. newspapers and } \\
\text { comics. Moderate readers of fiction and non-fiction. } \\
\text { Diversified but focus on short. non-demanding texts. }\end{array}$ \\
Diversified readers in long texts & 15.5 & 28.8 & $\begin{array}{c}\text { Majority frequently read magazines. newspapers. } \\
\text { fiction and to a lesser extent non-fiction books. Very } \\
\text { small percentage read comics frequently. }\end{array}$ \\
\hline
\end{tabular}

Source: Reading for Change - Performance and Engagement across Countries: Results from PISA 2000 (OECD, 2002). 
Table 4 Gender differences (males - females) in standard deviation for science, mathematics and reading (PISA 2006)

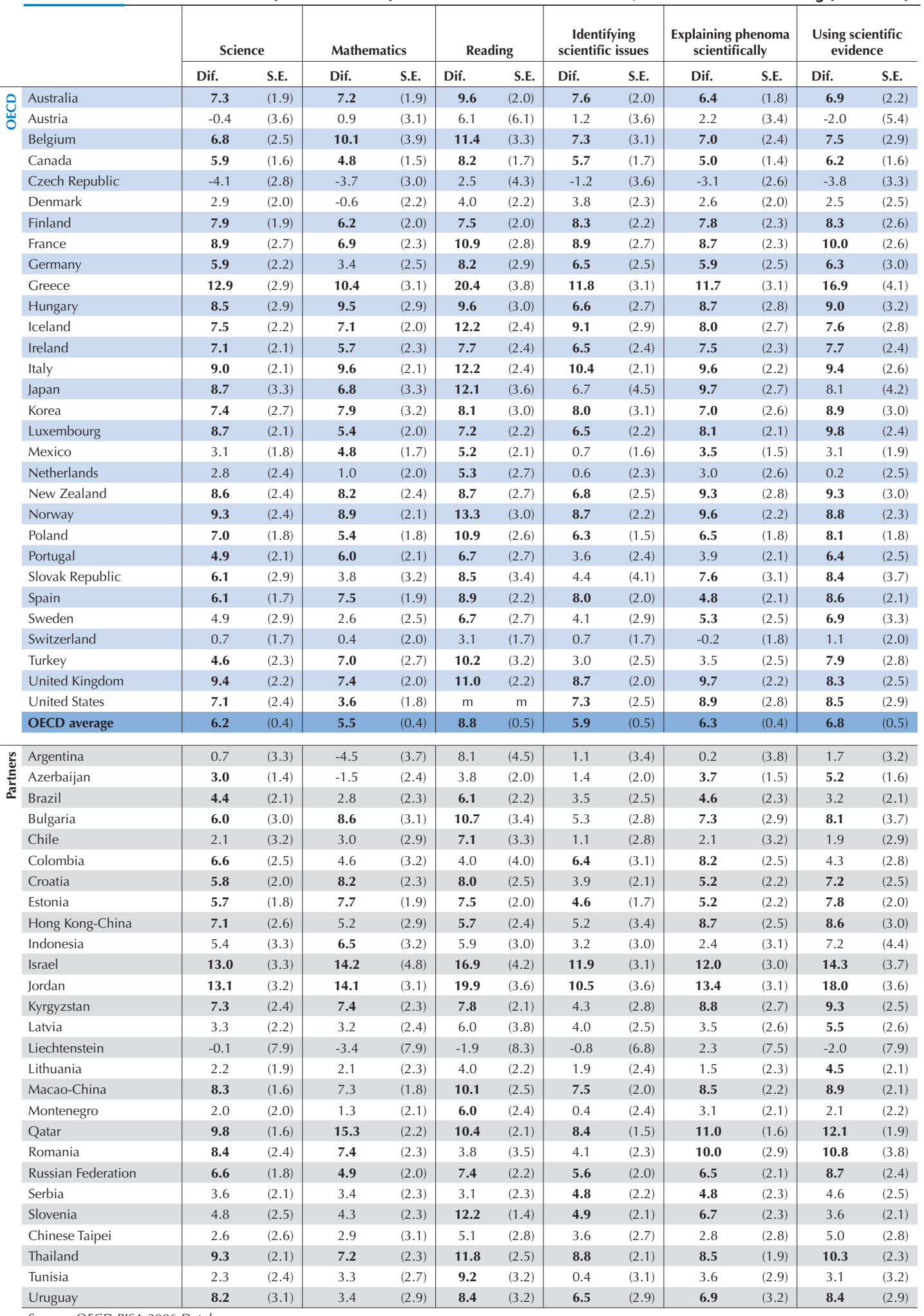

Source: OECD PISA 2006 Database. 
Table 5 [Part 1/2] Percentage correct for males and females for each science item (PISA 2006)

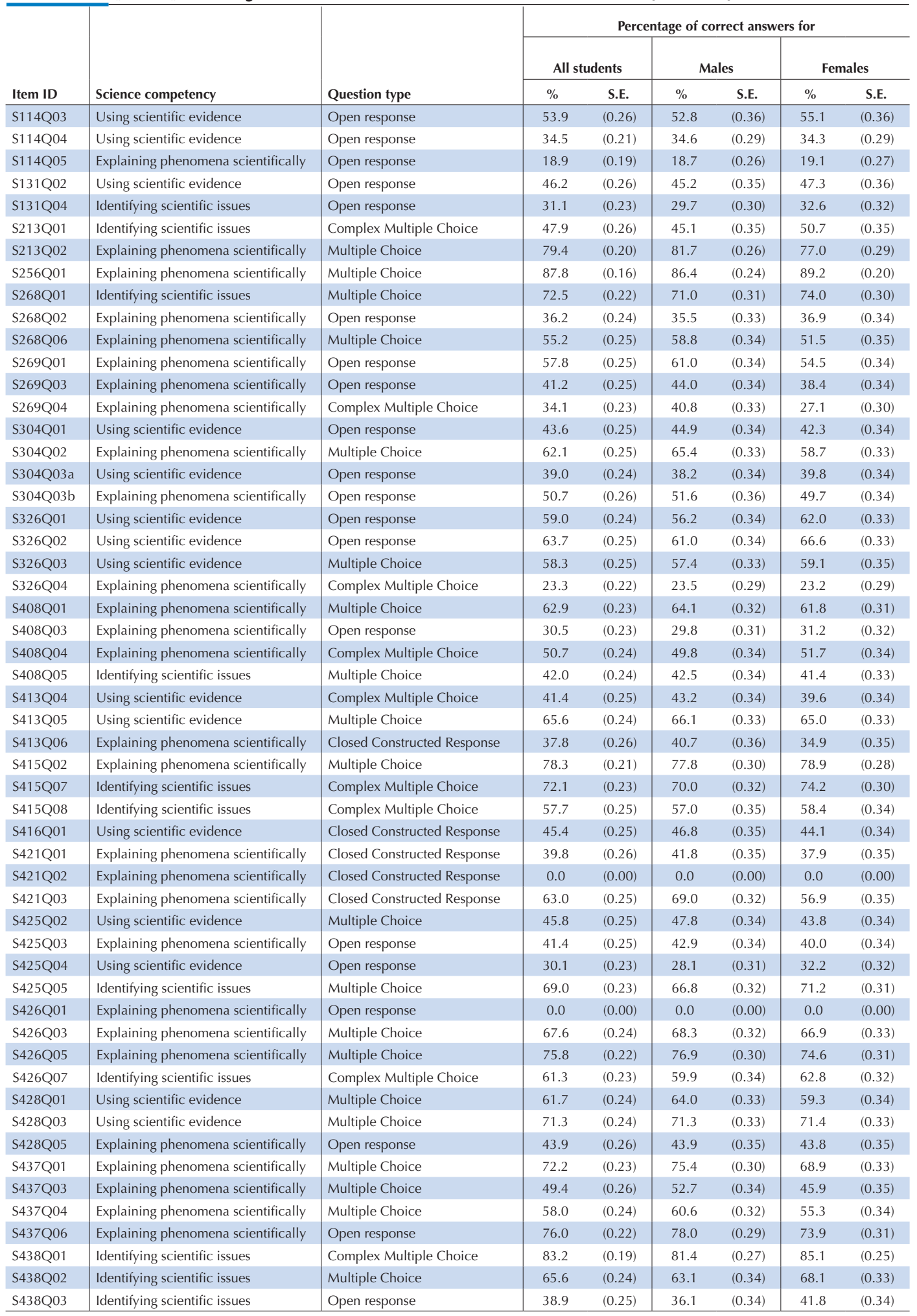

Source: OECD PISA 2006 Student Compendium. 
Table 5 [Part 2/2] Percentage correct for males and females for each science item (PISA 2006)

\begin{tabular}{|c|c|c|c|c|c|c|c|c|}
\hline \multirow[b]{3}{*}{ Item ID } & \multirow[b]{3}{*}{ Science competency } & \multirow[b]{3}{*}{ Question type } & \multicolumn{6}{|c|}{ Percentage of correct answers for } \\
\hline & & & \multicolumn{2}{|c|}{ All students } & \multicolumn{2}{|c|}{ Males } & \multicolumn{2}{|c|}{ Females } \\
\hline & & & $\%$ & S.E. & $\%$ & S.E. & $\%$ & S.E. \\
\hline S447Q02 & Identifying scientific issues & Multiple Choice & 40.5 & $(0.24)$ & 38.1 & $(0.32)$ & 43.0 & $(0.34)$ \\
\hline S447Q03 & Identifying scientific issues & Multiple Choice & 58.3 & $(0.23)$ & 56.3 & $(0.31)$ & 60.3 & $(0.33)$ \\
\hline S447Q04 & Identifying scientific issues & Multiple Choice & 43.0 & $(0.24)$ & 41.7 & $(0.33)$ & 44.3 & $(0.34)$ \\
\hline S447Q05 & Using scientific evidence & Open response & 27.1 & $(0.22)$ & 25.8 & $(0.30)$ & 28.4 & $(0.32)$ \\
\hline S456Q01 & Explaining phenomena scientifically & Complex Multiple Choice & 0.0 & $(0.00)$ & 0.0 & $(0.00)$ & 0.0 & $(0.00)$ \\
\hline S456Q02 & Explaining phenomena scientifically & Multiple Choice & 0.0 & $(0.00)$ & 0.0 & $(0.00)$ & 0.0 & $(0.00)$ \\
\hline S458Q01 & Explaining phenomena scientifically & Open response & 16.3 & $(0.19)$ & 18.2 & $(0.27)$ & 14.3 & $(0.24)$ \\
\hline S458Q02 & Using scientific evidence & Complex Multiple Choice & 56.2 & $(0.25)$ & 54.2 & $(0.35)$ & 58.3 & $(0.35)$ \\
\hline S465Q01 & Using scientific evidence & Open response & 50.2 & $(0.22)$ & 50.5 & $(0.30)$ & 49.9 & $(0.31)$ \\
\hline S465Q02 & Explaining phenomena scientifically & Multiple Choice & 60.9 & $(0.24)$ & 60.8 & $(0.34)$ & 61.0 & $(0.34)$ \\
\hline S465Q04 & Explaining phenomena scientifically & Multiple Choice & 36.3 & $(0.24)$ & 38.6 & $(0.34)$ & 33.8 & $(0.32)$ \\
\hline S466Q01 & Identifying scientific issues & Complex Multiple Choice & 71.0 & $(0.22)$ & 69.3 & $(0.32)$ & 72.7 & $(0.30)$ \\
\hline S466Q05 & Using scientific evidence & Multiple Choice & 55.7 & $(0.24)$ & 58.3 & $(0.33)$ & 53.0 & $(0.35)$ \\
\hline S466Q07 & Identifying scientific issues & Complex Multiple Choice & 74.9 & $(0.22)$ & 71.5 & $(0.31)$ & 78.3 & $(0.29)$ \\
\hline S476Q01 & Explaining phenomena scientifically & Multiple Choice & 70.7 & $(0.24)$ & 72.5 & $(0.31)$ & 68.8 & $(0.33)$ \\
\hline S476Q02 & Explaining phenomena scientifically & Multiple Choice & 70.9 & $(0.22)$ & 74.3 & $(0.29)$ & 67.2 & $(0.32)$ \\
\hline S476Q03 & Explaining phenomena scientifically & Multiple Choice & 60.1 & $(0.25)$ & 62.8 & $(0.34)$ & 57.3 & $(0.33)$ \\
\hline S477Q02 & Explaining phenomena scientifically & Multiple Choice & 74.9 & $(0.22)$ & 72.6 & $(0.31)$ & 77.2 & $(0.30)$ \\
\hline S477Q03 & Explaining phenomena scientifically & Multiple Choice & 75.1 & $(0.22)$ & 75.3 & $(0.30)$ & 74.9 & $(0.30)$ \\
\hline S477Q04 & Explaining phenomena scientifically & Open response & 61.7 & $(0.25)$ & 58.5 & $(0.33)$ & 65.0 & $(0.33)$ \\
\hline S478Q01 & Explaining phenomena scientifically & Multiple Choice & 42.8 & $(0.23)$ & 42.0 & $(0.33)$ & 43.7 & $(0.33)$ \\
\hline S478Q02 & Using scientific evidence & Complex Multiple Choice & 51.0 & $(0.25)$ & 52.2 & $(0.34)$ & 49.7 & $(0.35)$ \\
\hline S478Q03 & Explaining phenomena scientifically & Complex Multiple Choice & 67.7 & $(0.23)$ & 65.2 & $(0.33)$ & 70.3 & $(0.31)$ \\
\hline S485Q02 & Explaining phenomena scientifically & Open response & 57.7 & $(0.26)$ & 59.8 & $(0.35)$ & 55.5 & $(0.36)$ \\
\hline S485Q03 & Using scientific evidence & Multiple Choice & 66.7 & $(0.25)$ & 68.3 & $(0.33)$ & 65.1 & $(0.34)$ \\
\hline S485Q05 & Identifying scientific issues & Open response & 35.5 & $(0.18)$ & 33.5 & $(0.25)$ & 37.6 & $(0.25)$ \\
\hline S493Q01 & Explaining phenomena scientifically & Complex Multiple Choice & 52.6 & $(0.25)$ & 51.9 & $(0.34)$ & 53.5 & $(0.34)$ \\
\hline S493Q03 & Explaining phenomena scientifically & Complex Multiple Choice & 82.4 & $(0.18)$ & 81.7 & $(0.26)$ & 83.1 & $(0.24)$ \\
\hline S493Q05 & Explaining phenomena scientifically & Open response & 45.1 & $(0.25)$ & 49.3 & $(0.34)$ & 40.8 & $(0.34)$ \\
\hline S495Q01 & Using scientific evidence & Complex Multiple Choice & 42.1 & $(0.24)$ & 39.6 & $(0.33)$ & 44.8 & $(0.34)$ \\
\hline S495Q02 & Using scientific evidence & Complex Multiple Choice & 57.6 & $(0.25)$ & 60.9 & $(0.35)$ & 54.2 & $(0.34)$ \\
\hline S495Q03 & Using scientific evidence & Open response & 38.6 & $(0.26)$ & 38.8 & $(0.35)$ & 38.3 & $(0.36)$ \\
\hline S495Q04 & Identifying scientific issues & Complex Multiple Choice & 50.2 & $(0.25)$ & 48.0 & $(0.33)$ & 52.5 & $(0.35)$ \\
\hline S498Q02 & Identifying scientific issues & Complex Multiple Choice & 46.9 & $(0.24)$ & 47.7 & $(0.35)$ & 46.2 & $(0.34)$ \\
\hline S498Q03 & Identifying scientific issues & Multiple Choice & 42.6 & $(0.24)$ & 41.5 & $(0.33)$ & 43.8 & $(0.34)$ \\
\hline S498Q04 & Using scientific evidence & Open response & 59.9 & $(0.25)$ & 57.1 & $(0.34)$ & 62.8 & $(0.32)$ \\
\hline S508Q02 & Identifying scientific issues & Complex Multiple Choice & 60.9 & $(0.23)$ & 58.5 & $(0.34)$ & 63.5 & $(0.33)$ \\
\hline S508Q03 & Identifying scientific issues & Multiple Choice & 73.6 & $(0.23)$ & 72.7 & $(0.32)$ & 74.4 & $(0.31)$ \\
\hline S508Q04 & Identifying scientific issues & Open response & 0.0 & $(0.00)$ & 0.0 & $(0.00)$ & 0.0 & $(0.00)$ \\
\hline S510Q01 & Explaining phenomena scientifically & Complex Multiple Choice & 53.9 & $(0.23)$ & 57.8 & $(0.33)$ & 49.9 & $(0.33)$ \\
\hline S510Q04 & Explaining phenomena scientifically & Open response & 41.0 & $(0.24)$ & 45.4 & $(0.34)$ & 36.5 & $(0.33)$ \\
\hline S514Q02 & Using scientific evidence & Open response & 85.2 & $(0.20)$ & 85.6 & $(0.26)$ & 84.8 & $(0.27)$ \\
\hline S514Q03 & Explaining phenomena scientifically & Open response & 46.6 & $(0.25)$ & 48.9 & $(0.36)$ & 44.3 & $(0.34)$ \\
\hline S514Q04 & Using scientific evidence & Complex Multiple Choice & 52.2 & $(0.27)$ & 49.7 & $(0.37)$ & 54.7 & $(0.35)$ \\
\hline S519Q01 & Using scientific evidence & Open response & 35.3 & $(0.21)$ & 33.3 & $(0.28)$ & 37.3 & $(0.30)$ \\
\hline S519Q02 & Explaining phenomena scientifically & Complex Multiple Choice & 52.6 & $(0.25)$ & 54.4 & $(0.35)$ & 50.8 & $(0.34)$ \\
\hline S519Q03 & Identifying scientific issues & Open response & 28.7 & $(0.22)$ & 27.5 & $(0.30)$ & 30.0 & $(0.30)$ \\
\hline S521Q02 & Explaining phenomena scientifically & Multiple Choice & 55.9 & $(0.24)$ & 58.6 & $(0.33)$ & 53.1 & $(0.34)$ \\
\hline S521Q06 & Explaining phenomena scientifically & Multiple Choice & 88.1 & $(0.18)$ & 86.8 & $(0.25)$ & 89.5 & $(0.23)$ \\
\hline S524Q06 & Using scientific evidence & Complex Multiple Choice & 64.3 & $(0.24)$ & 64.4 & $(0.33)$ & 64.1 & $(0.33)$ \\
\hline S524Q07 & Using scientific evidence & Open response & 36.5 & $(0.24)$ & 37.3 & $(0.33)$ & 35.7 & $(0.32)$ \\
\hline S527Q01 & Using scientific evidence & Complex Multiple Choice & 16.1 & $(0.18)$ & 17.6 & $(0.26)$ & 14.6 & $(0.23)$ \\
\hline S527Q03 & Explaining phenomena scientifically & Complex Multiple Choice & 58.0 & $(0.25)$ & 59.0 & $(0.34)$ & 56.9 & $(0.34)$ \\
\hline S527Q04 & Explaining phenomena scientifically & Complex Multiple Choice & 53.7 & $(0.24)$ & 54.8 & $(0.34)$ & 52.6 & $(0.34)$ \\
\hline
\end{tabular}

Source: OECD PISA 2006 Student Compendium. 
Table 6 Results from computer based assessment of science (CBAS) (PISA 2006)

\begin{tabular}{|c|c|c|c|c|c|c|}
\hline & \multicolumn{2}{|c|}{ Males } & \multicolumn{2}{|c|}{ Females } & \multicolumn{2}{|c|}{ Difference (M-F) } \\
\hline \multicolumn{7}{|l|}{ CBAS } \\
\hline Denmark & 486 & (6.2) & 440 & (7.4) & 45 & (8.8) \\
\hline Iceland & 485 & (2.5) & 459 & $(2.2)$ & 25 & (3.4) \\
\hline \multicolumn{7}{|c|}{ Scientific literacy (CBAS sample) } \\
\hline Denmark & 492 & (7.0) & 469 & (8.2) & 23 & $(9.0)$ \\
\hline Iceland & 467 & (2.6) & 474 & (2.5) & -7 & (3.8) \\
\hline Korea & 502 & (6.2) & 503 & (6.4) & -1 & $(9.2)$ \\
\hline \multicolumn{7}{|c|}{ Scientific literacy (full sample) } \\
\hline
\end{tabular}

Source: OECD PISA 2006 Computer Based Assessment Database. 
Table 7 PISA index of economic, social and cultural status (ESCS) for males and females (PISA 2006)

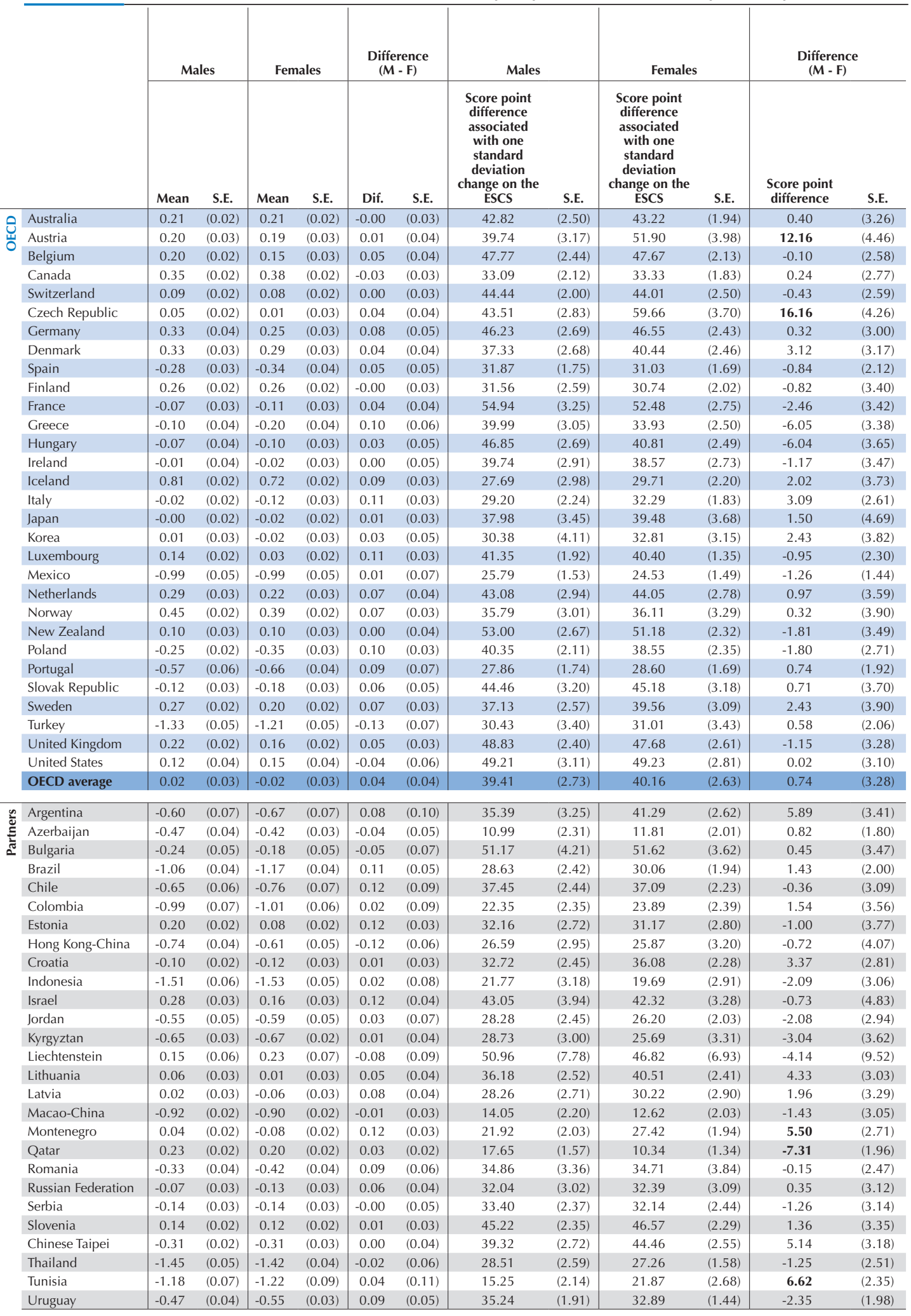

Source: OECD PISA 2006 Database. 
Table 8 Gender differences in performance after accounting for the PISA index of economic. social and cultural status of students (ESCS) (PISA 2006)

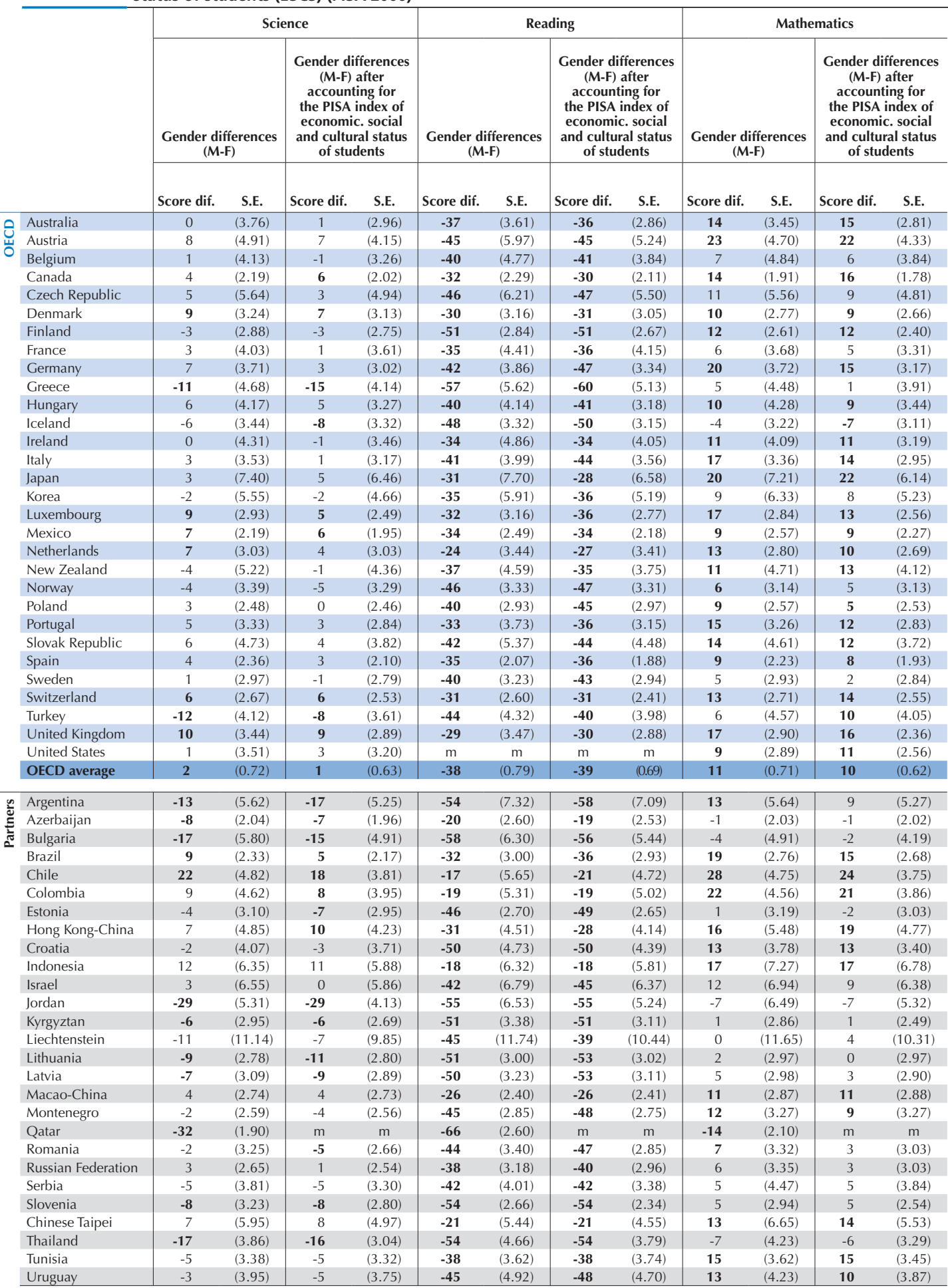

Note: Values that are statistically significant are indicated in bold.

Source: OECD PISA 2006 Database. 
Table 9 Variation of within-school gender differences according to the socio-economic background of student and school (ESCS) (PISA 2006)

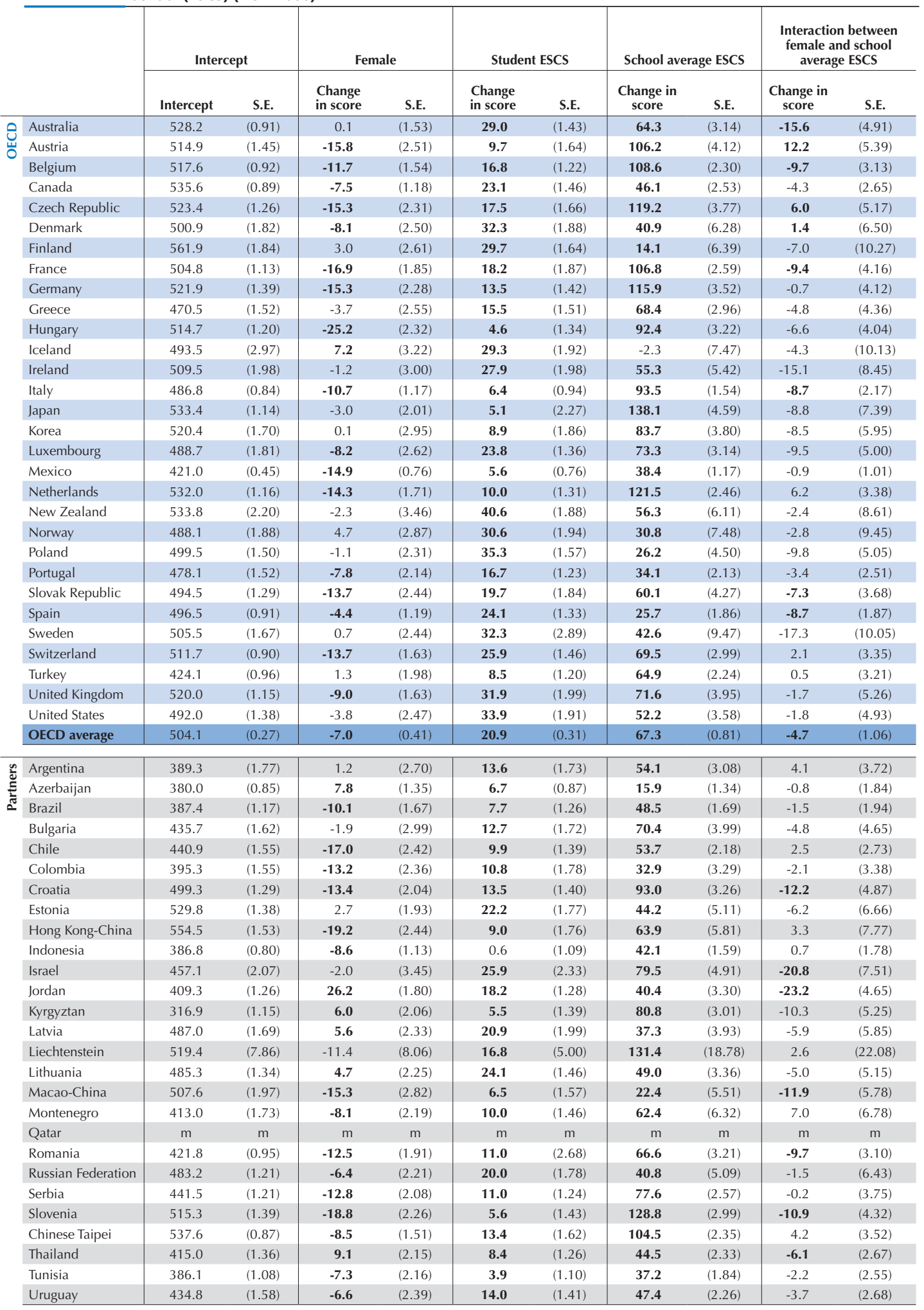

Note: Values that are statistically significant are indicated in bold.

Source: OECD PISA 2006 Database. 
Table 10 Performance difference between native students and immigrant students (PISA 2006)

\begin{tabular}{|c|c|c|c|c|c|c|c|c|c|c|c|c|}
\hline & \multicolumn{6}{|c|}{ Males } & \multicolumn{6}{|c|}{ Females } \\
\hline & \multicolumn{2}{|c|}{ Native } & \multicolumn{2}{|c|}{ Immigrant } & \multicolumn{2}{|c|}{\begin{tabular}{|c|c|}
$\begin{array}{c}\text { Difference } \\
\text { (Native - Immigrant) }\end{array}$ \\
\end{tabular}} & \multicolumn{2}{|c|}{ Native } & \multicolumn{2}{|c|}{ Immigrant } & \multicolumn{2}{|c|}{\begin{tabular}{|c} 
Difference \\
(Native - Immigrant) \\
\end{tabular}} \\
\hline & Mean & S.E. & Mean & S.E. & Dif. & S.E. & Mean & S.E. & Mean & S.E. & Dif. & S.E. \\
\hline Australia & 529 & $(2.59)$ & 531 & $(8.45)$ & -2 & $(8.07)$ & 530 & $(2.78)$ & 523 & $(4.40)$ & 6 & $(4.39)$ \\
\hline Austria & 526 & (4.13) & 442 & $(7.24)$ & 84 & (7.38) & 521 & $(4.38)$ & 426 & (16.56) & 95 & $(17.50)$ \\
\hline Belgium & 524 & (3.14) & 437 & $(8.81)$ & 87 & $(8.84)$ & 522 & $(2.97)$ & 437 & $(6.62)$ & 85 & $(6.76)$ \\
\hline Canada & 543 & (2.29) & 527 & $(5.26)$ & 16 & $(5.42)$ & 539 & (1.95) & 520 & $(5.05)$ & 18 & $(5.08)$ \\
\hline Czech Republic & 517 & $(4.28)$ & 464 & (15.20) & 53 & (15.58) & 512 & $(4.76)$ & 441 & $(25.37)$ & 71 & (25.34) \\
\hline Denmark & 508 & $(3.43)$ & 425 & $(9.40)$ & 83 & (9.02) & 498 & (3.25) & 407 & $(9.72)$ & 92 & $(9.80)$ \\
\hline Finland & 565 & (2.58) & 472 & $(17.81)$ & 92 & $(17.92)$ & 567 & (2.35) & 471 & $(17.76)$ & 95 & $(17.61)$ \\
\hline France & 506 & $(4.62)$ & 452 & $(8.75)$ & 55 & (9.65) & 503 & (3.65) & 451 & (10.37) & 51 & $(11.07)$ \\
\hline Germany & 535 & (4.15) & 450 & (10.50) & 85 & (10.17) & 529 & (3.34) & 443 & $(6.17)$ & 86 & (5.79) \\
\hline Greece & 472 & $(4.47)$ & 427 & (10.29) & 45 & (10.11) & 483 & (3.46) & 439 & (11.91) & 44 & (12.18) \\
\hline Hungary & 508 & (3.34) & 494 & (18.13) & 15 & (19.06) & 501 & $(3.44)$ & 509 & (16.82) & -8 & (15.92) \\
\hline Iceland & 493 & (2.58) & 413 & (18.98) & 80 & (18.71) & 496 & (2.19) & 426 & (19.42) & 70 & (19.67) \\
\hline Ireland & 510 & $(4.18)$ & 494 & (12.59) & 16 & (11.84) & 511 & (3.13) & 505 & (16.19) & 6 & (15.96) \\
\hline Italy & 482 & $(2.64)$ & 417 & (12.99) & 65 & (12.60) & 477 & $(2.56)$ & 425 & $(7.22)$ & 52 & $(7.50)$ \\
\hline Japan & 534 & $(4.85)$ & 503 & (35.37) & 30 & (34.83) & 530 & (5.11) & 470 & $(67.91)$ & 60 & $(66.97)$ \\
\hline Korea & 523 & $(4.76)$ & $\mathrm{C}$ & c & C & c & 524 & (3.81) & 593 & (28.21) & -69 & (28.55) \\
\hline Luxembourg & 516 & $(2.29)$ & 447 & (3.55) & 69 & $(4.66)$ & 506 & (2.35) & 443 & $(3.17)$ & 64 & $(4.16)$ \\
\hline Mexico & 418 & (3.12) & 317 & (14.70) & 101 & (14.25) & 413 & (2.44) & 320 & $(8.83)$ & 92 & $(8.44)$ \\
\hline Netherlands & 539 & (2.99) & 460 & $(9.91)$ & 79 & $(9.88)$ & 530 & $(2.67)$ & 458 & (11.59) & 72 & (11.93) \\
\hline New Zealand & 535 & $(4.08)$ & 521 & $(7.62)$ & 14 & (8.09) & 537 & (3.56) & 519 & $(6.83)$ & 18 & $(6.68)$ \\
\hline Norway & 493 & (3.13) & 426 & (11.77) & 66 & (11.07) & 493 & (2.88) & 443 & (10.98) & 50 & (10.65) \\
\hline Poland & 501 & $(2.67)$ & 433 & (79.11) & 68 & (78.67) & 497 & $(2.62)$ & 535 & (34.69) & -38 & (34.55) \\
\hline Portugal & 480 & (3.68) & 434 & (13.08) & 46 & (12.68) & 477 & (2.94) & 415 & $(11.77)$ & 61 & (11.96) \\
\hline Slovak Republic & 493 & (3.89) & 427 & $(32.81)$ & 66 & (32.65) & 486 & (3.04) & 466 & (26.89) & 21 & (26.68) \\
\hline Spain & 497 & $(2.71)$ & 430 & (10.10) & 67 & $(9.92)$ & 491 & (2.59) & 438 & $(7.81)$ & 53 & $(7.62)$ \\
\hline Sweden & 512 & $(2.51)$ & 459 & $(8.40)$ & 53 & $(7.81)$ & 512 & (3.15) & 444 & $(6.24)$ & 68 & $(6.95)$ \\
\hline Switzerland & 534 & (2.89) & 450 & $(6.04)$ & 84 & $(5.50)$ & 527 & (3.59) & 449 & $(5.18)$ & 79 & $(4.90)$ \\
\hline Turkey & 419 & $(4.60)$ & 427 & $(20.27)$ & -8 & (20.16) & 432 & $(4.11)$ & 462 & (18.12) & -30 & $(17.44)$ \\
\hline United Kingdom & 526 & $(2.51)$ & 485 & (12.68) & 40 & (12.46) & 514 & (2.61) & 489 & (10.56) & 25 & (10.46) \\
\hline United States & 500 & $(5.28)$ & 453 & $(7.57)$ & 46 & $(7.79)$ & 498 & $(4.03)$ & 447 & $(7.34)$ & 51 & $(7.66)$ \\
\hline OECD average & 508 & $(0.65)$ & 452 & $(3.82)$ & 55 & $(3.80)$ & 505 & $(0.60)$ & 460 & (3.52) & 45 & (3.50) \\
\hline Argentina & 386 & $(6.71)$ & 378 & (17.86) & 8 & $(17.61)$ & 399 & $(6.97)$ & 379 & $(9.24)$ & 20 & $(10.52)$ \\
\hline Azerbaijan & 381 & (3.25) & 377 & $(8.00)$ & 4 & $(8.82)$ & 387 & $(2.86)$ & 387 & $(8.23)$ & 0 & (8.35) \\
\hline Brazil & 398 & (3.26) & 348 & (11.90) & 50 & (12.18) & 388 & (2.88) & 349 & (10.91) & 40 & (10.80) \\
\hline Bulgaria & 428 & $(6.54)$ & 365 & (47.49) & 62 & $(47.01)$ & 445 & $(6.87)$ & 362 & (29.15) & 83 & $(29.80)$ \\
\hline Chile & 450 & (5.55) & 382 & (39.31) & 67 & (39.15) & 428 & $(4.46)$ & 412 & (23.93) & 16 & (23.96) \\
\hline Colombia & 396 & (4.15) & 344 & (22.25) & 52 & (22.64) & 386 & $(4.03)$ & 269 & (29.68) & 117 & (29.99) \\
\hline Croatia & 495 & $(3.46)$ & 478 & $(6.10)$ & 17 & $(6.55)$ & 498 & (3.14) & 476 & $(5.64)$ & 22 & $(5.37)$ \\
\hline Estonia & 536 & (3.08) & 501 & $(6.63)$ & 35 & $(6.85)$ & 538 & $(2.89)$ & 507 & $(6.07)$ & 30 & $(6.13)$ \\
\hline Hong Kong-China & 552 & $(4.38)$ & 541 & $(4.98)$ & 11 & $(6.76)$ & 542 & $(4.35)$ & 534 & $(3.89)$ & 8 & $(4.69)$ \\
\hline Indonesia & 400 & $(8.06)$ & 295 & $(7.72)$ & 105 & $(11.41)$ & 388 & (3.74) & 297 & (10.54) & 91 & $(10.93)$ \\
\hline Israel & 467 & $(5.50)$ & 459 & $(7.82)$ & 7 & $(6.68)$ & 457 & $(4.42)$ & 453 & $(7.09)$ & 4 & $(6.69)$ \\
\hline Jordan & 408 & $(4.25)$ & 435 & $(7.33)$ & -27 & $(7.15)$ & 434 & $(3.52)$ & 459 & $(4.61)$ & -25 & $(5.03)$ \\
\hline Kyrgyztan & 322 & $(3.32)$ & 368 & (18.76) & -46 & $(17.91)$ & 326 & (2.96) & 378 & (14.55) & -52 & (14.08) \\
\hline Latvia & 489 & (3.53) & 485 & (8.05) & 4 & $(8.27)$ & 495 & $(3.29)$ & 493 & $(6.66)$ & 2 & $(6.95)$ \\
\hline Liechtenstein & 531 & $(9.64)$ & 492 & $(14.83)$ & 39 & $(18.42)$ & 547 & $(7.76)$ & 493 & (13.84) & 54 & $(17.33)$ \\
\hline Lithuania & 485 & $(3.17)$ & 485 & (14.50) & 1 & (15.10) & 493 & (3.17) & 490 & (15.73) & 3 & (16.13) \\
\hline Macao-China & 502 & $(3.68)$ & 518 & $(2.16)$ & -16 & $(4.30)$ & 505 & $(2.72)$ & 512 & $(1.92)$ & -6 & (3.35) \\
\hline Montenegro & 411 & $(2.01)$ & 422 & $(9.03)$ & -11 & $(9.75)$ & 412 & $(1.74)$ & 436 & $(8.24)$ & -24 & $(8.48)$ \\
\hline Qatar & 309 & $(1.69)$ & 377 & $(2.32)$ & -68 & $(3.11)$ & 347 & (1.49) & 399 & $(2.76)$ & -52 & $(3.30)$ \\
\hline Romania & 417 & $(4.13)$ & 551 & (23.25) & -134 & (23.78) & 419 & $(4.81)$ & 547 & (38.86) & -127 & $(39.00)$ \\
\hline Russian Federation & 483 & $(4.33)$ & 471 & $(6.50)$ & 11 & $(7.72)$ & 480 & (3.85) & 464 & $(8.13)$ & 16 & $(8.01)$ \\
\hline Serbia & 433 & $(3.47)$ & 439 & $(5.62)$ & -6 & $(6.04)$ & 438 & $(3.72)$ & 449 & (7.19) & -11 & $(6.73)$ \\
\hline Slovenia & 522 & $(2.07)$ & 468 & $(6.13)$ & 54 & $(6.43)$ & 529 & $(2.25)$ & 471 & $(7.67)$ & 58 & $(8.79)$ \\
\hline Chinese Taipei & 539 & $(4.09)$ & 487 & (19.77) & 51 & (19.88) & 530 & $(5.03)$ & 482 & (22.19) & 49 & (20.93) \\
\hline Thailand & 413 & (3.31) & 309 & (31.06) & 104 & (30.78) & 429 & (2.49) & 375 & $(68.42)$ & 54 & $(68.57)$ \\
\hline Tunisia & 385 & $(3.21)$ & 304 & (20.66) & 80 & (21.18) & 389 & (3.54) & 321 & (14.85) & 68 & $(14.63)$ \\
\hline Uruguay & 429 & (3.99) & 445 & $(59.21)$ & -15 & $(58.82)$ & 431 & $(2.70)$ & 438 & (29.78) & -7 & (29.28) \\
\hline
\end{tabular}

Source: OECD PISA 2006 Database. 
Table 11 Percentage of students whose parents report various science activities at age 10 very often and regularly

\begin{tabular}{|c|c|c|c|c|c|c|c|c|c|c|c|c|c|c|c|c|c|c|c|c|}
\hline & \multicolumn{4}{|c|}{$\begin{array}{c}\text { Watching science TV } \\
\text { programmes }\end{array}$} & \multicolumn{4}{|c|}{ Reading science books } & \multicolumn{4}{|c|}{ Reading science fiction } & \multicolumn{4}{|c|}{$\begin{array}{l}\text { Visiting science } \\
\text { websites }\end{array}$} & \multicolumn{4}{|c|}{$\begin{array}{l}\text { Belonging to a science } \\
\text { club }\end{array}$} \\
\hline & \multicolumn{2}{|c|}{ Males } & \multicolumn{2}{|c|}{ Females } & \multicolumn{2}{|c|}{ Males } & \multicolumn{2}{|c|}{ Females } & \multicolumn{2}{|c|}{ Males } & \multicolumn{2}{|c|}{ Females } & \multicolumn{2}{|c|}{ Males } & \multicolumn{2}{|c|}{ Females } & \multicolumn{2}{|c|}{ Males } & \multicolumn{2}{|c|}{ Females } \\
\hline Bulgaria & 38.5 & (1.3) & 26.2 & (1.3) & 11.3 & $(1.0)$ & 11.4 & $(0.7)$ & 36.3 & (1.5) & 24.1 & (0.9) & 19.9 & (1.1) & 14.4 & $(0.9)$ & $\mathrm{m}$ & $\mathrm{m}$ & $\mathrm{m}$ & $\mathrm{m}$ \\
\hline Colombia & 42.5 & (1.4) & 32.2 & (1.8) & 26.9 & (1.5) & 23.3 & $(1.2)$ & 59.9 & (1.3) & 48.4 & (1.4) & 15.7 & (1.0) & 11.8 & (1.0) & 6.3 & $(0.7)$ & 6.3 & (0.6) \\
\hline Germany & 31.3 & (1.1) & 16.7 & $(1.0)$ & 16.0 & $(1.0)$ & 9.4 & $(0.8)$ & 18.3 & $(0.9)$ & 6.9 & $(0.6)$ & 3.9 & $(0.4)$ & 2.2 & $(0.3)$ & 3.3 & $(0.5)$ & 2.8 & $(0.5)$ \\
\hline Hong Kong-China & 16.3 & $(1.0)$ & 10.4 & $(0.6)$ & 11.3 & (0.8) & 7.3 & (0.6) & 10.5 & $(0.7)$ & 10.0 & $(0.6)$ & 6.4 & $(0.5)$ & 3.8 & $(0.4)$ & 5.1 & $(0.5)$ & 4.5 & (0.4) \\
\hline Iceland & 27.4 & (1.4) & 10.4 & (0.8) & 16.3 & (1.1) & 5.7 & $(0.6)$ & 12.1 & (1.1) & 4.8 & $(0.6)$ & 5.8 & (0.8) & 2.3 & $(0.4)$ & 1.8 & $(0.3)$ & 0.8 & (0.3) \\
\hline Italy & 38.9 & (0.9) & 22.6 & $(0.7)$ & 15.8 & $(0.6)$ & 9.4 & $(0.6)$ & 47.4 & $(1.0)$ & 38.5 & (0.8) & 7.6 & $(0.5)$ & 4.0 & $(0.4)$ & 3.8 & $(0.4)$ & 2.8 & (0.3) \\
\hline Portugal & 27.7 & $(1.2)$ & 19.3 & (0.8) & 11.9 & (0.8) & 9.8 & $(0.7)$ & 24.2 & (1.3) & 17.1 & (0.8) & 8.3 & (0.8) & 5.9 & $(0.5)$ & 2.4 & $(0.4)$ & 3.4 & (0.5) \\
\hline Qatar & 32.3 & (1.0) & 24.5 & (1.0) & 17.5 & (0.9) & 13.3 & $(0.7)$ & 35.3 & (1.1) & 27.4 & (0.9) & 15.8 & (0.9) & 11.3 & $(0.7)$ & 15.0 & (0.9) & 7.3 & (0.5) \\
\hline Turkey & 16.7 & (1.0) & 13.8 & (0.8) & 16.5 & (1.0) & 15.5 & $(0.7)$ & 42.5 & (1.3) & 31.0 & (1.3) & 13.6 & (0.8) & 4.6 & $(0.5)$ & 4.8 & $(0.6)$ & 3.6 & (0.6) \\
\hline
\end{tabular}

Source: OECD PISA 2006 Database.

Table 12 Percentage of students whose parents agree with statements regarding the school of their son or daughter

\begin{tabular}{|c|c|c|c|c|c|c|c|c|c|c|c|c|}
\hline & \multicolumn{2}{|c|}{ Males } & \multicolumn{2}{|c|}{ Females } & \multicolumn{2}{|c|}{ Males } & \multicolumn{2}{|c|}{ Females } & \multicolumn{2}{|c|}{ Males } & \multicolumn{2}{|c|}{ Females } \\
\hline & $\%$ & S.E. & $\%$ & S.E. & $\%$ & S.E. & $\%$ & S.E. & $\%$ & S.E. & $\%$ & S.E. \\
\hline Bulgaria & 95.5 & $(0.7)$ & 95.3 & $(0.5)$ & 82.5 & $(1.1)$ & 78.1 & $(1.2)$ & 86.3 & $(1.1)$ & 88.1 & (0.9) \\
\hline Colombia & 95.6 & $(0.6)$ & 93.3 & $(0.8)$ & 83.0 & $(1.2)$ & 82.5 & (1.4) & 85.7 & $(1.2)$ & 86.6 & (1.6) \\
\hline Croatia & 93.2 & $(0.5)$ & 91.3 & $(0.6)$ & 80.9 & $(1.0)$ & 83.5 & $(1.0)$ & 62.5 & $(1.5)$ & 68.8 & $(1.2)$ \\
\hline Germany & 79.7 & $(0.9)$ & 79.8 & $(0.8)$ & 74.4 & $(1.1)$ & 73.2 & $(1.3)$ & 69.9 & (1.3) & 72.8 & (1.3) \\
\hline Hong Kong-China & 90.1 & $(0.7)$ & 89.4 & $(0.7)$ & 87.1 & $(0.9)$ & 90.0 & $(0.7)$ & 51.9 & $(1.7)$ & 55.6 & (1.7) \\
\hline Iceland & 85.5 & $(1.0)$ & 86.4 & $(0.8)$ & 78.6 & (1.1) & 74.0 & (1.1) & 69.5 & (1.3) & 74.9 & (1.2) \\
\hline Italy & 91.8 & $(0.4)$ & 90.7 & (0.6) & 79.9 & (0.8) & 81.8 & (0.6) & 78.6 & (0.8) & 81.5 & (0.6) \\
\hline Korea & 86.3 & $(0.7)$ & 80.2 & (1.1) & 80.1 & (0.9) & 76.6 & (1.3) & 72.3 & (1.2) & 70.6 & (1.5) \\
\hline Portugal & 94.1 & $(0.6)$ & 93.6 & $(0.6)$ & 81.9 & $(1.2)$ & 79.0 & $(1.2)$ & 77.4 & $(1.2)$ & 75.0 & (1.1) \\
\hline Qatar & 85.1 & (0.9) & 88.2 & $(0.7)$ & 79.2 & (1.0) & 79.5 & (0.9) & 78.0 & (1.0) & 82.3 & $(0.8)$ \\
\hline Turkey & 86.2 & (0.8) & 87.4 & (0.9) & 83.0 & $(0.8)$ & 80.5 & (1.1) & 70.4 & (1.3) & 75.8 & (1.3) \\
\hline
\end{tabular}

Source: OECD PISA 2006 Database. 
Table 13 [Part 1/2] Index of students' perceptions of school preparation for science-related careers Results based on students' self-reports

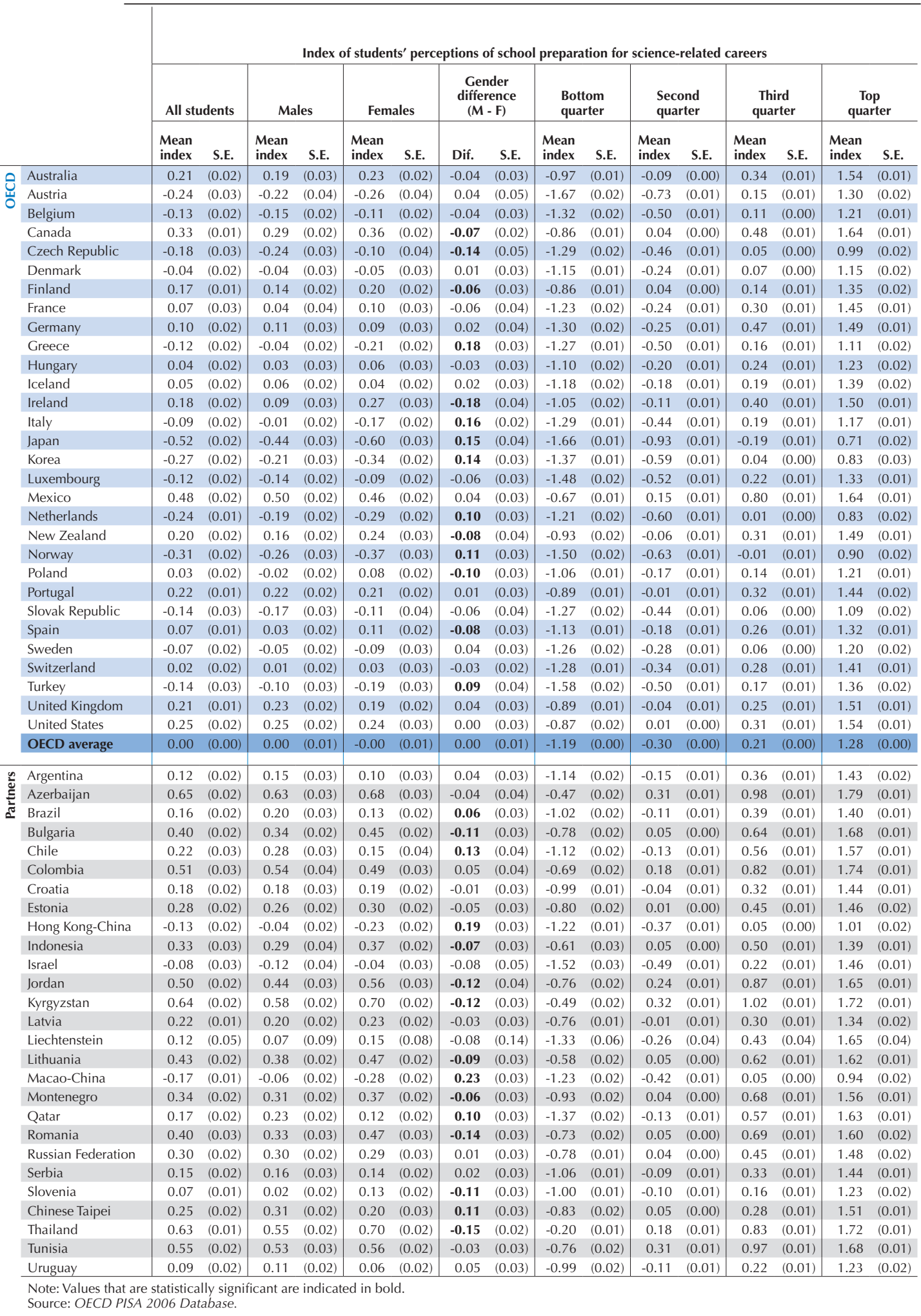


Table 13 [Part 2/2] Index of students' perceptions of school preparation for science-related careers Results based on students' self-reports

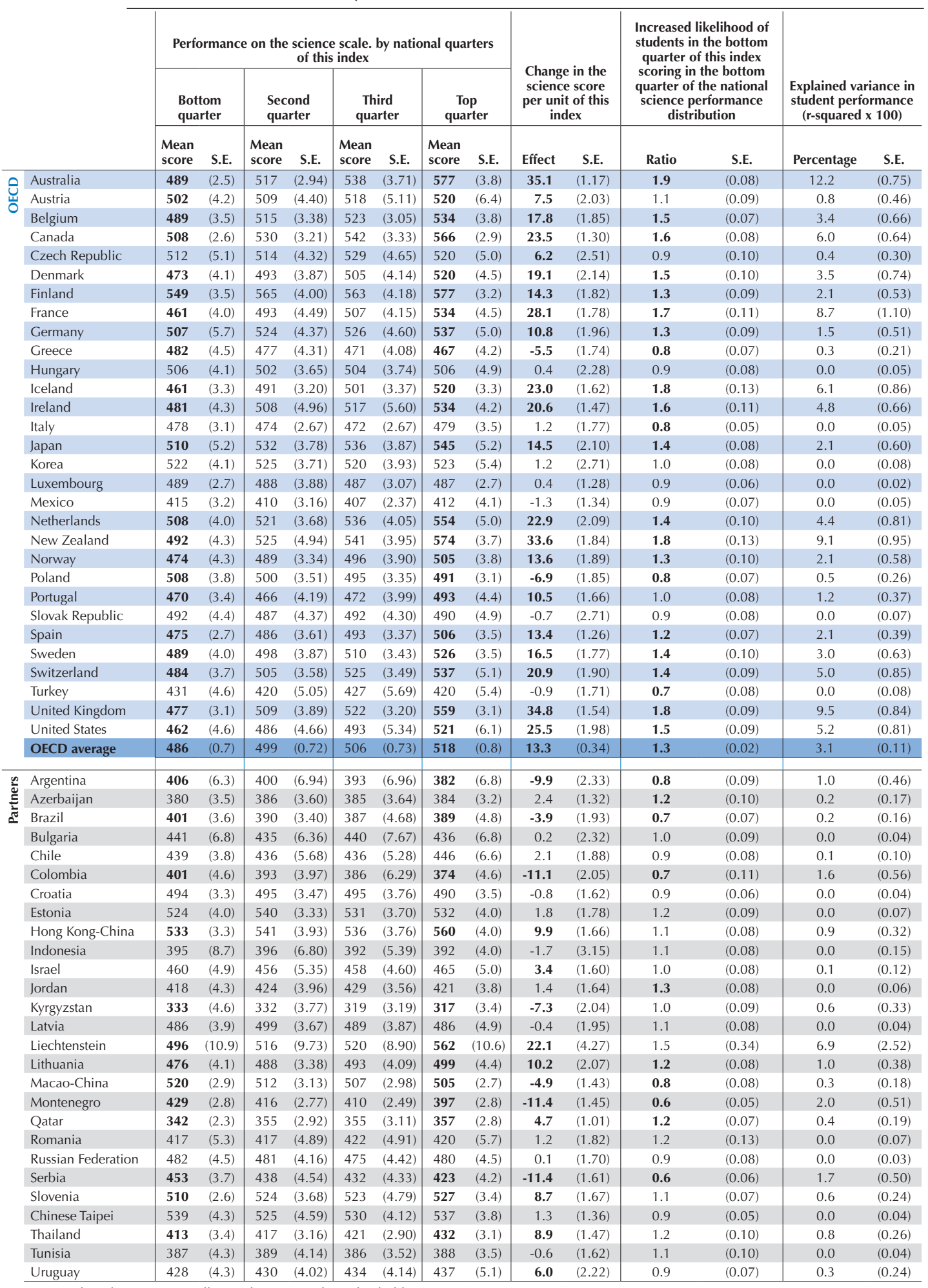

Note: Values that are statistically significant are indicated in bold.

Source: OECD PISA 2006 Database. 
Table 14 [Part 1/2] Index of student information on science-related careers Results based on students' self-reports

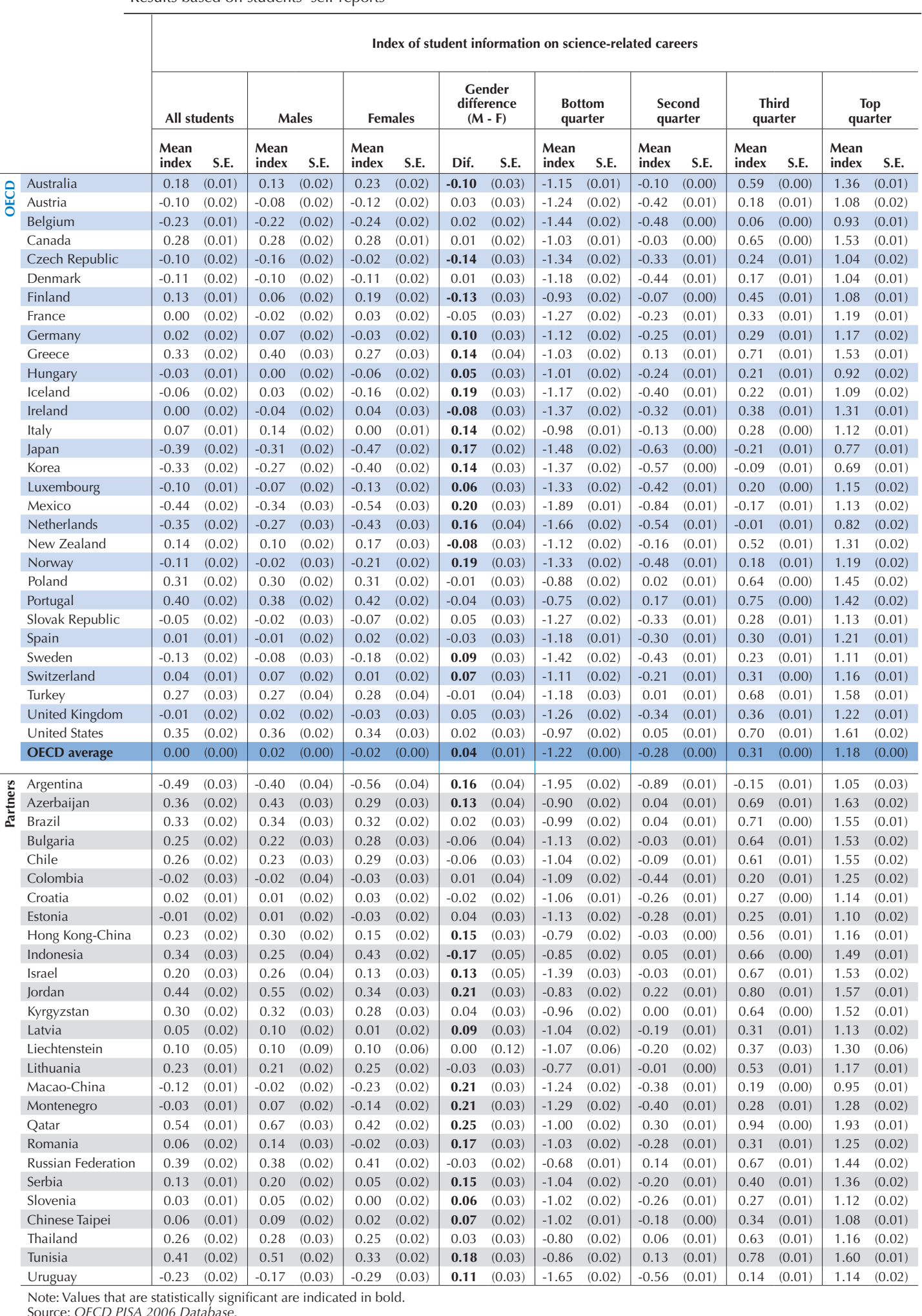


Table 14 [Part 2/2] Index of student information on science-related careers Results based on students' self-reports

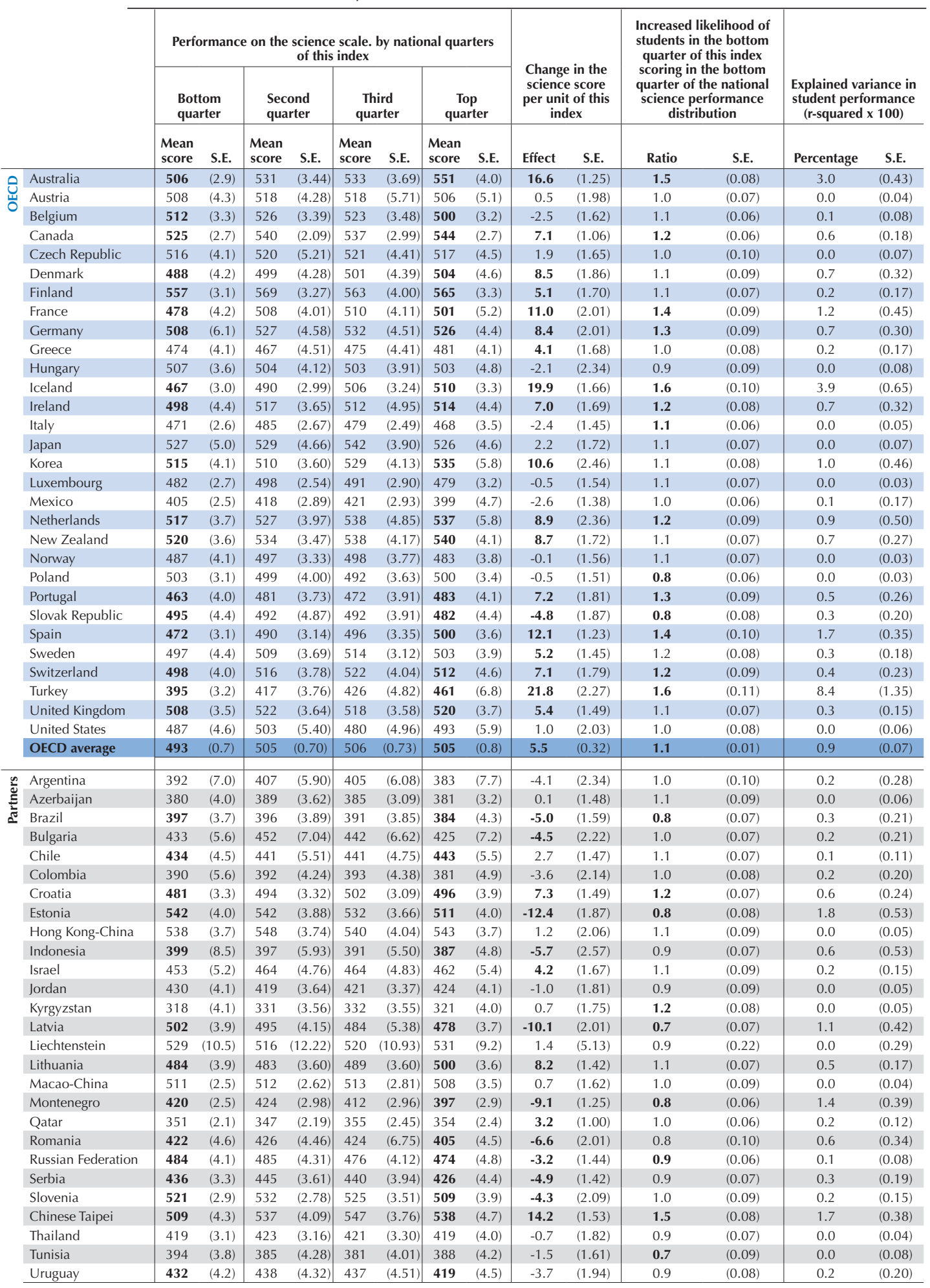

Note: Values that are statistically significant are indicated in bold.

Source: OECD PISA 2006 Database. 
Table 15 [Part 1/2] Percentage of students expecting a particular career at age 30, by field of science

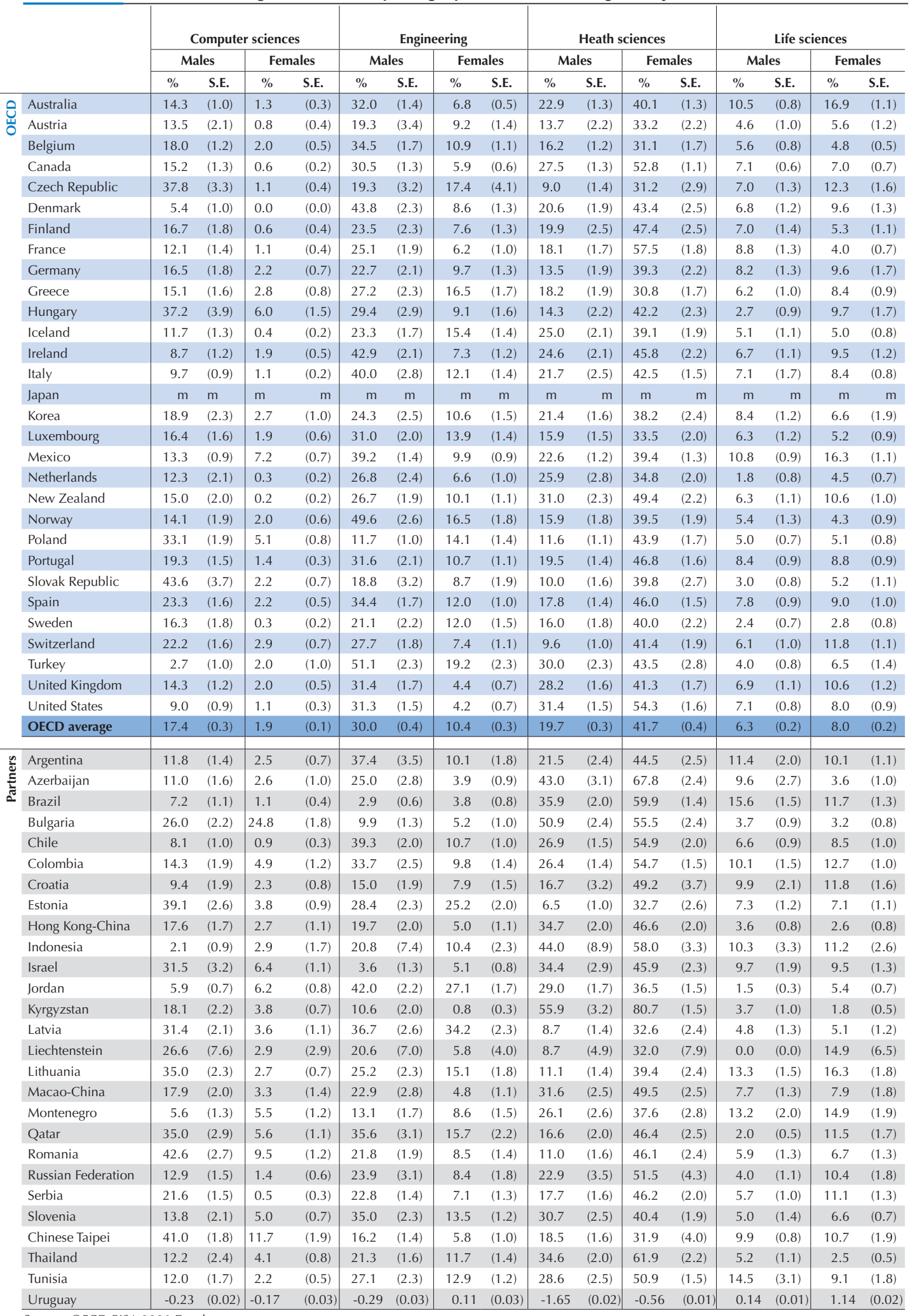

Source: OECD PISA 2006 Database 
Table 15 [Part 2/2] Percentage of students expecting a particular career at age 30, by field of science

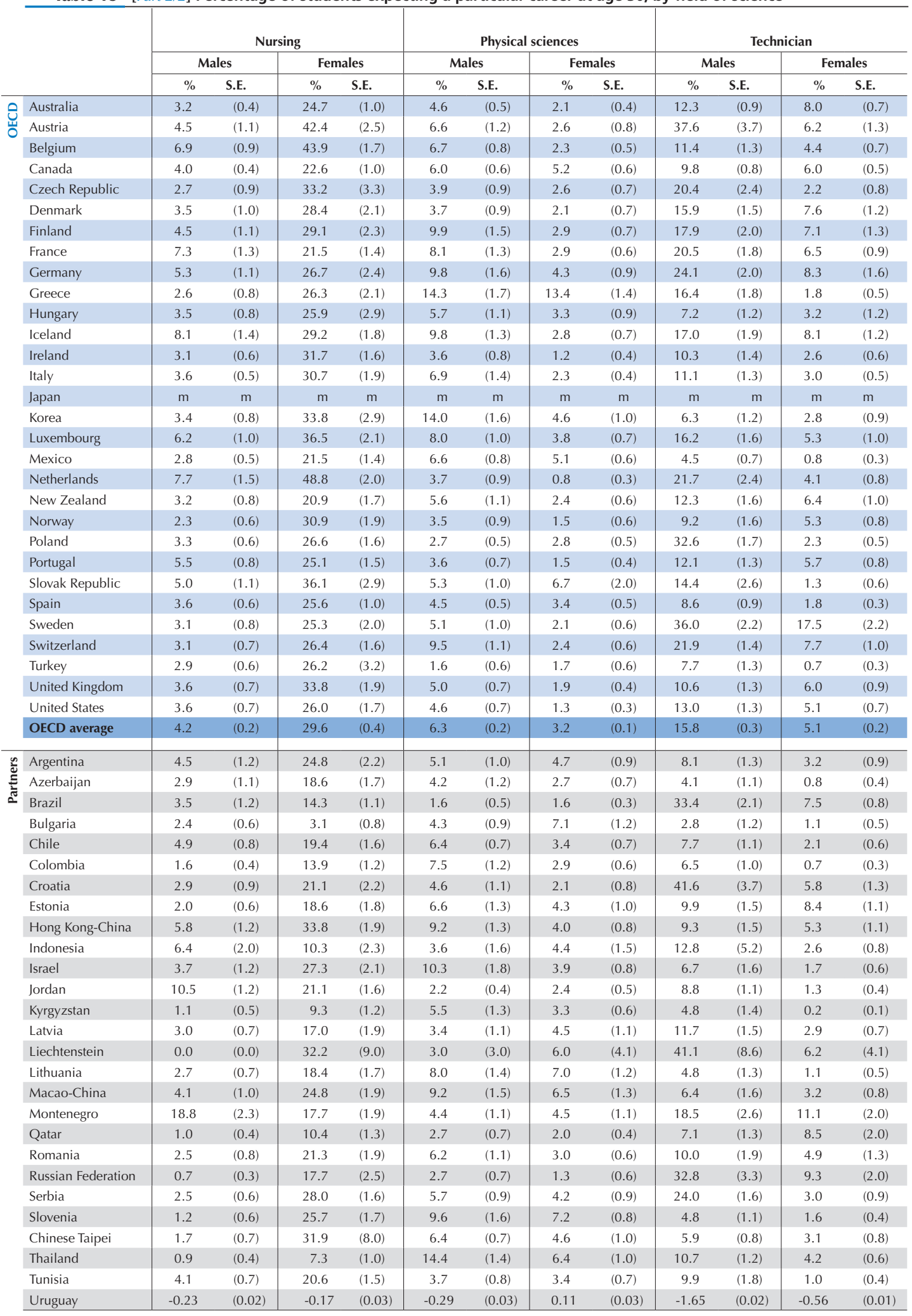

Source: OECD PISA 2006 Database. 
Table 16 Performance difference between single and mixed schools by gender. before and after accounting the socio-economic background of students and schools (ESCS)

\begin{tabular}{|c|c|c|c|c|c|c|c|c|c|c|}
\hline & \multicolumn{2}{|c|}{ Single-sex schools } & \multicolumn{2}{|c|}{ Mixed-sex schools } & \multicolumn{2}{|c|}{$\begin{array}{l}\text { Raw difference in score } \\
\text { (single - mixed) }\end{array}$} & \multicolumn{2}{|c|}{$\begin{array}{l}\text { Difference after } \\
\text { accounting for student } \\
\text { ESCS }\end{array}$} & \multicolumn{2}{|c|}{$\begin{array}{l}\text { Difference after } \\
\text { accounting for student } \\
\text { and school ESCS }\end{array}$} \\
\hline & Mean & S.E. & Mean & S.E. & Score dif. & S.E. & Score dif. & S.E. & Score dif. & S.E. \\
\hline \multicolumn{11}{|l|}{ Males } \\
\hline Australia & 560 & $(12.41)$ & 520 & $(2.93)$ & 41 & (12.74) & 22 & (10.18) & -2 & $(8.72)$ \\
\hline Colombia & 411 & $(5.93)$ & 393 & $(4.15)$ & 18 & $(6.88)$ & 3 & $(7.55)$ & -14 & $(8.04)$ \\
\hline Hong Kong-China & 573 & $(27.97)$ & 543 & $(3.43)$ & 30 & (28.76) & 20 & $(23.51)$ & -1 & $(17.58)$ \\
\hline Ireland & 526 & $(8.09)$ & 498 & $(5.00)$ & 28 & $(9.54)$ & 14 & $(7.64)$ & -2 & $(7.07)$ \\
\hline Israel & 468 & $(16.41)$ & 453 & $(5.70)$ & 15 & (17.16) & 8 & (15.59) & -2 & (15.24) \\
\hline Japan & 549 & $(34.50)$ & 531 & $(4.74)$ & 17 & (35.50) & 5 & $(31.62)$ & -32 & $(23.41)$ \\
\hline New Zealand & 541 & (11.08) & 524 & $(4.02)$ & 18 & $(12.13)$ & 5 & $(9.11)$ & -6 & $(8.89)$ \\
\hline Qatar & 324 & $(2.24)$ & 337 & $(1.55)$ & -14 & $(2.87)$ & -16 & $(2.87)$ & -19 & $(2.82)$ \\
\hline Chinese Taipei & 662 & $(6.34)$ & 535 & (4.16) & 127 & $(7.55)$ & 111 & $(7.86)$ & 73 & (8.89) \\
\hline Thailand & 457 & $(5.07)$ & 411 & $(3.37)$ & 47 & $(6.11)$ & 18 & $(6.48)$ & -7 & $(6.31)$ \\
\hline United Kingdom & 481 & $(23.12)$ & 521 & (2.98) & -41 & (23.58) & -24 & (13.15) & -14 & $(7.37)$ \\
\hline \multicolumn{11}{|l|}{ Females } \\
\hline Australia & 551 & $(6.40)$ & 521 & $(2.63)$ & 30 & (6.89) & 12 & $(5.26)$ & -2 & (5.19) \\
\hline Chile & 410 & $(26.52)$ & 427 & $(4.64)$ & -17 & $(27.51)$ & -28 & (15.19) & -32 & $(8.76)$ \\
\hline Colombia & 416 & (27.14) & 383 & $(4.22)$ & 33 & (27.68) & 8 & $(25.52)$ & -11 & (23.48) \\
\hline Luxembourg & 452 & $(4.23)$ & 486 & $(1.85)$ & -34 & (4.33) & -22 & $(4.27)$ & -1 & $(4.28)$ \\
\hline Macao-China & 540 & (3.16) & 505 & (1.79) & 36 & $(3.75)$ & 32 & $(3.92)$ & 26 & $(4.02)$ \\
\hline New Zealand & 558 & $(7.05)$ & 518 & $(3.61)$ & 40 & $(8.25)$ & 24 & $(6.28)$ & 13 & $(6.04)$ \\
\hline Qatar & 355 & (1.99) & 370 & $(1.62)$ & -15 & $(2.46)$ & -14 & $(2.51)$ & -17 & $(2.46)$ \\
\hline Chinese Taipei & 566 & (32.75) & 525 & $(5.01)$ & 41 & (34.06) & 27 & $(27.32)$ & 2 & (14.88) \\
\hline Thailand & 486 & $(8.66)$ & 425 & $(2.66)$ & 61 & $(9.30)$ & 28 & $(5.83)$ & 5 & $(6.18)$ \\
\hline Turkey & 386 & $(7.78)$ & 435 & $(4.29)$ & -49 & (9.19) & -44 & $(7.28)$ & -36 & $(6.77)$ \\
\hline United Kingdom & 543 & $(16.41)$ & 506 & (2.95) & 37 & (17.05) & 27 & (12.03) & 17 & $(8.11)$ \\
\hline
\end{tabular}

Source: OECD PISA 2006 Database. 
Table 17 [Part 1/2] Percentage of males and females doing homework for science. mathematics and reading

\begin{tabular}{|c|c|c|c|c|c|c|c|c|c|c|c|c|}
\hline & \multicolumn{4}{|c|}{ Out of school - Science } & \multicolumn{4}{|c|}{ Self study - Science } & \multicolumn{4}{|c|}{ Out of school - Mathematics } \\
\hline & \multicolumn{2}{|c|}{ Males } & \multicolumn{2}{|c|}{ Females } & \multicolumn{2}{|c|}{ Males } & \multicolumn{2}{|c|}{ Females } & \multicolumn{2}{|c|}{ Males } & \multicolumn{2}{|c|}{ Females } \\
\hline & $\begin{array}{l}2 \text { or } \\
\text { more } \\
\text { hours }\end{array}$ & S.E. & $\begin{array}{l}2 \text { or } \\
\text { more } \\
\text { hours }\end{array}$ & S.E. & $\begin{array}{l}2 \text { or } \\
\text { more } \\
\text { hours }\end{array}$ & S.E. & $\begin{array}{l}2 \text { or } \\
\text { more } \\
\text { hours }\end{array}$ & S.E. & $\begin{array}{l}2 \text { or } \\
\text { more } \\
\text { hours }\end{array}$ & S.E. & $\begin{array}{l}2 \text { or } \\
\text { more } \\
\text { hours }\end{array}$ & S.E. \\
\hline Australia & 6.3 & $(0.3)$ & 4.3 & $(0.2)$ & 19.2 & $(0.8)$ & 18.8 & $(0.8)$ & 15.5 & (0.6) & 11.6 & $(0.5)$ \\
\hline Austria & 4.4 & $(0.4)$ & 2.9 & $(0.4)$ & 22.1 & (1.3) & 20.6 & (1.0) & 8.6 & (0.6) & 9.2 & $(0.7)$ \\
\hline Belgium & 5.6 & $(0.5)$ & 4.4 & (0.4) & 18.1 & $(0.8)$ & 23.8 & $(0.9)$ & 10.4 & $(0.5)$ & 8.4 & $(0.5)$ \\
\hline Canada & 8.2 & $(0.4)$ & 9.2 & $(0.5)$ & 23.7 & $(0.9)$ & 35.0 & $(0.9)$ & 16.5 & $(0.8)$ & 18.0 & $(0.6)$ \\
\hline Czech Republic & 7.6 & (0.6) & 9.8 & $(0.7)$ & 13.4 & $(0.9)$ & 18.8 & (1.1) & 13.2 & $(0.7)$ & 12.0 & $(0.8)$ \\
\hline Denmark & 10.8 & $(0.7)$ & 9.0 & $(0.7)$ & 12.6 & $(0.8)$ & 13.9 & (1.0) & 27.2 & (1.1) & 28.2 & (1.1) \\
\hline Finland & 4.6 & $(0.5)$ & 3.4 & $(0.4)$ & 10.7 & $(0.8)$ & 14.1 & $(0.9)$ & 5.6 & $(0.5)$ & 3.9 & $(0.4)$ \\
\hline France & 7.6 & (0.6) & 7.7 & (0.6) & 19.4 & (1.2) & 23.8 & (1.1) & 14.7 & $(0.8)$ & 17.7 & (0.9) \\
\hline Germany & 9.9 & $(0.7)$ & 7.2 & $(0.5)$ & 29.3 & (1.0) & 33.8 & $(1.0)$ & 15.8 & (0.9) & 15.0 & $(0.8)$ \\
\hline Greece & 43.5 & (1.3) & 45.0 & (1.3) & 38.1 & (1.2) & 38.1 & $(1.2)$ & 48.3 & (1.6) & 52.4 & (1.4) \\
\hline Hungary & 18.6 & $(0.8)$ & 17.8 & (1.1) & 27.0 & (1.2) & 33.8 & (1.2) & 22.6 & (0.9) & 25.1 & (1.1) \\
\hline Iceland & 5.7 & (0.6) & 3.3 & (0.4) & 16.4 & $(0.9)$ & 16.2 & $(0.8)$ & 11.7 & $(0.7)$ & 14.1 & (0.8) \\
\hline Ireland & 5.3 & $(0.5)$ & 3.7 & $(0.5)$ & 19.5 & (1.1) & 20.0 & (1.1) & 12.6 & $(0.8)$ & 12.4 & (0.9) \\
\hline Italy & 12.1 & $(0.5)$ & 8.9 & (0.4) & 41.5 & (1.1) & 46.5 & (1.3) & 18.1 & $(0.7)$ & 16.6 & (0.6) \\
\hline Japan & 5.0 & $(0.5)$ & 2.6 & $(0.2)$ & 7.6 & $(0.5)$ & 5.1 & $(0.5)$ & 14.1 & $(0.8)$ & 12.5 & (1.1) \\
\hline Korea & 23.3 & (1.5) & 20.9 & (1.3) & 19.2 & (1.8) & 19.6 & (1.1) & 50.8 & (1.7) & 52.2 & (1.7) \\
\hline Luxembourg & 9.4 & $(0.6)$ & 7.3 & $(0.5)$ & 17.6 & $(0.9)$ & 21.1 & $(0.9)$ & 15.6 & $(0.8)$ & 14.8 & $(0.7)$ \\
\hline Mexico & 19.7 & (1.0) & 17.5 & (0.8) & 39.3 & (1.1) & 43.9 & $(0.8)$ & 23.5 & $(0.8)$ & 21.5 & (1.0) \\
\hline Netherlands & 9.3 & $(0.7)$ & 7.1 & (0.6) & 18.9 & (1.0) & 22.5 & $(0.8)$ & 11.1 & $(0.8)$ & 10.2 & $(0.7)$ \\
\hline New Zealand & 6.4 & $(0.6)$ & 5.6 & $(0.5)$ & 19.0 & $(0.8)$ & 23.3 & $(1.2)$ & 12.0 & $(0.8)$ & 11.2 & $(0.7)$ \\
\hline Norway & 14.9 & $(0.7)$ & 12.5 & (0.8) & 18.1 & $(0.8)$ & 19.0 & $(1.2)$ & 18.4 & $(0.8)$ & 15.1 & (1.0) \\
\hline Poland & 8.9 & $(0.7)$ & 9.1 & (0.6) & 30.5 & $(0.9)$ & 51.5 & (1.1) & 10.7 & (0.6) & 10.2 & $(0.7)$ \\
\hline Portugal & 10.8 & (0.6) & 12.2 & $(0.7)$ & 36.5 & (1.3) & 49.2 & $(1.2)$ & 12.8 & $(0.7)$ & 15.2 & (0.9) \\
\hline Slovak Republic & 8.1 & $(0.6)$ & 11.3 & $(0.8)$ & 22.4 & (1.0) & 30.9 & (1.6) & 11.7 & $(0.8)$ & 15.6 & (1.0) \\
\hline Spain & 13.4 & $(0.7)$ & 14.4 & $(0.7)$ & 29.0 & $(0.9)$ & 40.8 & (1.1) & 19.1 & (0.6) & 22.7 & (0.7) \\
\hline Sweden & 6.7 & $(0.5)$ & 6.0 & (0.6) & 12.9 & $(0.8)$ & 15.2 & (1.0) & 9.1 & (0.6) & 7.8 & $(0.5)$ \\
\hline Switzerland & 7.0 & $(0.5)$ & 5.2 & $(0.4)$ & 14.1 & $(0.7)$ & 16.4 & $(0.8)$ & 12.7 & $(0.7)$ & 10.4 & (0.6) \\
\hline Turkey & 26.0 & (1.3) & 27.4 & (1.5) & 31.7 & (1.2) & 36.0 & (1.6) & 40.9 & (1.3) & 47.7 & (1.6) \\
\hline United Kingdom & 7.4 & $(0.5)$ & 5.7 & $(0.5)$ & 23.5 & (1.1) & 26.4 & (1.0) & 10.7 & (0.6) & 8.4 & $(0.5)$ \\
\hline United States & 14.2 & $(0.8)$ & 12.0 & $(0.7)$ & 28.9 & $(0.9)$ & 35.2 & (1.2) & 22.6 & (1.0) & 20.8 & (1.0) \\
\hline OECD average & 11.4 & $(0.1)$ & 10.4 & $(0.1)$ & 22.7 & $(0.2)$ & 27.1 & $(0.2)$ & 17.9 & $(0.2)$ & 18.0 & $(0.2)$ \\
\hline Argentina & 8.9 & $(0.8)$ & 8.2 & $(0.6)$ & 24.0 & (1.5) & 33.5 & (1.2) & 13.4 & (1.0) & 14.0 & (1.0) \\
\hline Azerbaijan & 28.0 & (1.0) & 24.9 & (1.3) & 50.5 & (1.1) & 55.1 & (1.4) & 37.9 & (1.5) & 29.0 & (1.3) \\
\hline Brazil & 13.0 & $(0.8)$ & 13.7 & $(0.7)$ & 28.8 & $(0.9)$ & 34.2 & $(1.2)$ & 21.8 & (1.1) & 24.1 & (1.0) \\
\hline Bulgaria & 18.9 & $(0.9)$ & 18.3 & (1.2) & 35.5 & (1.5) & 46.0 & (2.1) & 21.3 & (1.2) & 22.1 & (1.1) \\
\hline Chile & 12.7 & $(0.7)$ & 14.5 & $(0.7)$ & 25.5 & $(0.9)$ & 30.8 & (1.2) & 16.7 & $(0.8)$ & 18.3 & (1.0) \\
\hline Colombia & 15.7 & (1.0) & 17.4 & (1.2) & 30.5 & (1.3) & 38.1 & (1.5) & 23.3 & (1.3) & 24.3 & (1.0) \\
\hline Croatia & 7.3 & $(0.6)$ & 7.8 & $(0.5)$ & 25.3 & (1.2) & 35.9 & (1.3) & 14.3 & $(0.8)$ & 14.9 & $(0.9)$ \\
\hline Estonia & 13.9 & $(0.9)$ & 11.9 & $(0.8)$ & 24.1 & (1.1) & 34.4 & (1.0) & 17.7 & (1.3) & 17.7 & (1.1) \\
\hline Hong Kong-China & 20.2 & (1.1) & 15.5 & $(0.9)$ & 30.7 & (1.1) & 26.5 & $(1.2)$ & 27.7 & (1.1) & 27.3 & (1.2) \\
\hline Indonesia & 17.0 & (1.3) & 20.1 & (1.3) & 27.5 & (1.2) & 38.3 & (1.3) & 24.6 & (1.6) & 28.2 & (1.3) \\
\hline Israel & 18.7 & (1.1) & 17.5 & $(0.9)$ & 28.0 & (1.5) & 26.5 & $(1.2)$ & 43.0 & (1.5) & 47.5 & (1.5) \\
\hline Jordan & 35.6 & (1.3) & 28.5 & (1.1) & 50.2 & (1.1) & 59.7 & (1.4) & 42.4 & (1.3) & 36.2 & (1.4) \\
\hline Kyrgyzstan & 23.1 & (1.0) & 27.1 & (1.0) & 35.2 & (1.1) & 45.3 & (1.1) & 26.0 & (1.1) & 31.1 & (1.1) \\
\hline Latvia & 12.0 & $(0.8)$ & 9.0 & $(0.8)$ & 29.1 & (1.1) & 41.7 & (1.5) & 22.4 & (1.3) & 22.8 & (1.4) \\
\hline Liechtenstein & 9.8 & (2.4) & 8.2 & (2.0) & 16.0 & (2.7) & 13.4 & (2.5) & 9.7 & (2.3) & 8.8 & (1.7) \\
\hline Lithuania & 8.6 & $(0.6)$ & 8.6 & (0.6) & 26.0 & (1.2) & 38.3 & (1.1) & 10.5 & $(0.7)$ & 11.0 & (0.8) \\
\hline Macao-China & 18.4 & $(0.8)$ & 15.9 & (1.1) & 23.0 & $(0.9)$ & 26.1 & (1.1) & 22.4 & (1.0) & 20.4 & (1.0) \\
\hline Montenegro & 19.8 & $(0.8)$ & 19.5 & $(0.9)$ & 38.9 & $(1.2)$ & 47.0 & (1.2) & 18.1 & $(0.9)$ & 16.3 & $(0.8)$ \\
\hline Qatar & 32.7 & (1.0) & 27.2 & $(0.8)$ & 42.6 & (1.0) & 44.5 & $(0.9)$ & 42.6 & (1.1) & 34.4 & $(0.9)$ \\
\hline Romania & 18.7 & $(0.9)$ & 17.2 & $(0.8)$ & 28.0 & (1.2) & 31.7 & (1.7) & 27.6 & (1.1) & 31.8 & (1.1) \\
\hline Russian Federation & 20.3 & $(1.2)$ & 19.4 & $(0.8)$ & 53.5 & (1.6) & 66.0 & (1.4) & 18.0 & (1.1) & 18.3 & (1.0) \\
\hline Serbia & 14.3 & $(0.7)$ & 13.7 & $(0.8)$ & 29.6 & (1.3) & 40.0 & $(1.2)$ & 19.1 & $(0.8)$ & 15.9 & (0.8) \\
\hline Slovenia & 11.2 & $(0.8)$ & 10.8 & $(0.7)$ & 23.0 & (1.0) & 33.0 & $(0.8)$ & 17.8 & (0.8) & 19.1 & (0.8) \\
\hline Chinese Taipei & 18.5 & $(0.8)$ & 16.0 & (0.6) & 23.7 & $(0.8)$ & 21.1 & $(0.9)$ & 38.6 & (1.3) & 36.9 & (1.4) \\
\hline Thailand & 19.6 & (1.2) & 18.2 & (1.1) & 29.1 & (1.4) & 37.4 & $(1.2)$ & 18.6 & (1.2) & 19.0 & (1.1) \\
\hline Tunisia & 38.3 & (1.1) & 41.2 & (1.2) & 50.8 & (1.4) & 56.9 & (1.1) & 49.7 & (1.1) & 50.8 & (1.3) \\
\hline Uruguay & 9.7 & $(0.6)$ & 11.3 & $(0.7)$ & 17.4 & $(0.9)$ & 27.3 & (1.2) & 15.5 & (1.0) & 15.5 & $(0.9)$ \\
\hline
\end{tabular}

Source: OECD PISA 2006 Database.

EQUALLY PREPARED FOR LIFE? HOW 15-YEAR-OLD BOYS AND GIRLS PERFORM IN SCHOOL - ISBN 978-92-64-06394-5 - ( ) OECD 2009 
Table 17 [Part 2/2] Percentage of males and females doing homework for science. mathematics and reading

\begin{tabular}{|c|c|c|c|c|c|c|c|c|c|c|c|c|c|c|c|c|c|c|c|c|c|c|}
\hline & \multicolumn{6}{|c|}{ Self study - Mathematics } & & & \multicolumn{8}{|c|}{ Self study - Reading } & & & & & & \\
\hline & & & & & & & & & & & & & & & & & & & & & & \\
\hline & $\begin{array}{l}2 \text { or } \\
\text { more } \\
\text { hours }\end{array}$ & S.E. & & S.E. & & S.E. & $\begin{array}{l}2 \text { or } \\
\text { more } \\
\text { hours }\end{array}$ & & & & & & $\begin{array}{l}\text { or } \\
\text { ore } \\
\text { urr }\end{array}$ & S.I & $\begin{array}{l}\text { or } \\
\text { ore } \\
\text { purs }\end{array}$ & & $\begin{array}{l}\text { or } \\
\text { ore } \\
\text { urs }\end{array}$ & S.E. & $\begin{array}{l}2 \text { or } \\
\text { more } \\
\text { hours }\end{array}$ & S.E. & $\begin{array}{l}2 \text { or } \\
\text { more } \\
\text { hours }\end{array}$ & S.E. \\
\hline Australia & 34.5 & $(0.9)$ & & (1.1) & & $(0.5)$ & & & & & & & 5.7 & & 2.5 & & 1.4 & $(0.5$ & 29.1 & $(0.9)$ & 35.3 & $(0.8)$ \\
\hline Austria & 41.2 & (1.4) & & (1.2) & & (0.6) & & & & & & & 6.1 & (1. & 4.9 & & 3.1 & $(0.4$ & 24.0 & (1.2) & 27.8 & (1.3) \\
\hline Belgium & 31.7 & $(0.9)$ & & (1.3) & & $(0.4)$ & & & & & & & 1.4 & $(1$. & 8.0 & & 7.5 & $(0.5$ & 17.4 & $(0.7)$ & 24.8 & $(0.8)$ \\
\hline Canada & 33.8 & $(0.9)$ & & $(0.9)$ & & $(0.5)$ & & & & & & & 5.7 & $(0$ & 3.7 & & 7.4 & $(0.7$ & 26.6 & $(0.8)$ & 39.3 & $(0.8)$ \\
\hline Czech Republic & 21.0 & (1.0) & & (1.0) & & (0.6) & 11.2 & & & & & & 9.2 & (1. & 8.4 & & 1.2 & $(0.6$ & 14.4 & $(0.9)$ & 18.9 & (1.2) \\
\hline Denmark & 32.1 & (1.0) & & (1.2) & & (1.1) & 41.3 & & & & & & 7.5 & & 1.8 & & 1.3 & $(1.1$ & 40.3 & (1.1) & 53.9 & (1.4) \\
\hline Finland & 13.8 & $(0.9)$ & & & & $(0.5)$ & & & & & & & 7.7 & (1. & 4.7 & & 4.7 & $(0.4$ & 8.6 & $(0.7)$ & 17.3 & (1.0) \\
\hline France & 28.5 & (1.3) & & (1.1) & & $(0.7)$ & & & & & & & 9.2 & (1. & 0.6 & & 5.1 & $(0.8$ & 19.5 & (0.9) & 35.0 & (1.0) \\
\hline Germany & 43.0 & (1.1) & & (1.3) & & $(0.8)$ & 10.3 & & & & & & 5.0 & $(1$. & 2.3 & & 0.3 & $(0.7$ & 33.0 & $(0.8)$ & 41.7 & (1.3) \\
\hline Greece & 41.7 & (1.3) & & (1.2) & & (1.0) & & & & & & & 1.6 & (1. & 9.5 & & 0.9 & $(1.0$ & 32.5 & (1.1) & 47.2 & (1.1) \\
\hline Hungary & 32.1 & (1.1) & & (1.4) & & $(0.9)$ & 29.5 & & & & & & 9.6 & (1. & 1.2 & & 9.5 & $(1.1$ & 29.4 & (1.0) & 43.9 & (1.5) \\
\hline Iceland & 30.0 & (1.1) & & (1.0) & & $(0.7)$ & & & & & & & 5.9 & (1. & 8.5 & & 5.7 & $(0.6$ & 24.4 & $(0.9)$ & 31.1 & $(0.9)$ \\
\hline Ireland & 31.8 & (1.2) & & (1.2) & & $(0.8)$ & & & & & & & 6.9 & (1. & 2.0 & & 0.5 & $(0.7$ & 28.8 & (1.0) & 36.8 & (1.4) \\
\hline Italy & 49.7 & (1.1) & & (1.1) & & (0.6) & & & & & & & 7.2 & (1. & 6.0 & & 5.8 & $(0.6$ & 54.3 & (1.0) & 72.8 & $(0.8)$ \\
\hline Japan & 25.1 & (1.5) & & (2.0) & & $(0.6)$ & & & & & & & 7.6 & (2. & 7.8 & & 5.8 & $(0.6$ & 12.5 & $(0.9)$ & 12.9 & (1.1) \\
\hline Korea & 44.7 & (2.0) & & (1.5) & & (1.6) & & & & & & & 7.8 & (1. & 3.9 & & 2.9 & $(1.7$ & 22.9 & (1.0) & 25.7 & (1.0) \\
\hline Luxembourg & 28.6 & (1.0) & & $(0.9)$ & & $(0.7)$ & & & & & & & 5.5 & (0. & 1.5 & & 3.6 & $(0.6$ & 19.2 & $(0.9)$ & 24.0 & $(0.8)$ \\
\hline Mexico & 41.6 & (1.0) & & $(0.9)$ & & (1.0) & & & & & & & 5.8 & $(0$ & 2.9 & & 0.0 & $(0.9$ & 36.5 & (1.0) & 41.4 & (1.0) \\
\hline Netherlands & 24.3 & (1.2) & & (1.3) & & $(0.7)$ & & & & & & & 8.9 & & 9.6 & & 0.1 & $(0.8$ & 17.7 & $(0.9)$ & 21.2 & (1.0) \\
\hline New Zealand & 26.8 & (1.1) & & (1.2) & & $(0.9)$ & & & & & & & 0.4 & (1. & 1.3 & & 1.3 & $(0.6$ & 23.5 & (1.2) & 32.7 & (1.0) \\
\hline Norway & 22.3 & $(1.0)$ & & (1.3) & & $(0.8)$ & 21.4 & & & & & & 6.0 & & 8.5 & & 1.4 & $(0.9$ & 20.9 & $(0.8)$ & 29.8 & (1.4) \\
\hline Poland & 34.5 & (1.0) & & (1.0) & & $(0.7)$ & 10.1 & & & & & & 0.4 & & 9.9 & & 0.1 & $(0.8$ & 35.6 & (1.2) & 57.3 & $(0.9)$ \\
\hline Portugal & 33.0 & (1.3) & & (1.1) & & $(0.7)$ & & & & & & & 6.7 & & 8.7 & & 9.5 & $(0.7$ & 26.1 & (1.0) & 39.9 & (1.3) \\
\hline Slovak Republic & 30.6 & (1.3) & & (1.4) & & $(0.7)$ & 18.2 & & & & & & 7.1 & & 0.4 & 0 & 3.2 & $(1.0$ & 27.5 & (1.1) & 43.6 & (1.4) \\
\hline Spain & 34.0 & (1.0) & & (1.1) & & $(0.7)$ & 10.6 & & & & & & 7.1 & & 1.9 & 0 & 0.6 & $(0.6$ & 30.7 & (1.0) & 45.4 & (1.0) \\
\hline Sweden & 14.5 & $(0.8)$ & & $(0.8)$ & & (0.6) & 11.1 & & & & & & 5.7 & $(0$. & 9.2 & & 1.1 & $(0.7$ & 14.6 & $(0.8)$ & 20.5 & (1.0) \\
\hline Switzerland & 29.0 & (1.0) & & $(1.0)$ & & $(0.5)$ & & & & & & & 4.3 & (1. & 8.1 & & 7.3 & $(0.5$ & 19.0 & $(0.7)$ & 23.4 & $(0.8)$ \\
\hline Turkey & 44.2 & (1.3) & & (1.8) & & $(1.2)$ & & & & & & & 2.9 & (1. & 3.4 & & 2.7 & $(1.6$ & 38.1 & (1.2) & 51.0 & (1.7) \\
\hline United Kingdom & 24.0 & $(0.8)$ & & (1.0) & & $(0.7)$ & & & & & & & 6.3 & $(1$. & 0.3 & & 9.1 & $(0.6$ & 25.1 & $(0.9)$ & 32.2 & (1.1) \\
\hline United States & 37.2 & (1.1) & & (1.0) & & (1.0) & 24.4 & & & & & & 5.8 & (1. & 8.3 & & 4.4 & $(0.8$ & 30.2 & (1.2) & 43.3 & $(1.2)$ \\
\hline OECD average & 32.0 & $(0.2)$ & & $(0.2)$ & & $(0.1)$ & & & & & & & 8.2 & (0. & 4.3 & & 5.9 & $(0.2$ & 26.1 & $(0.2)$ & 35.7 & $(0.2)$ \\
\hline Argentina & 30.6 & (1.5) & & (1.6) & & $(0.8)$ & & & & & & & 6.4 & & 8.8 & & 5.3 & $(0.7$ & 23.8 & (1.5) & 32.0 & (1.5) \\
\hline Azerbaijan & 57.6 & (1.5) & & (1.5) & & (1.3) & & & & & & & 5.4 & $(1$. & 7.8 & & 4.0 & $(1.3$ & 57.2 & (1.1) & 64.3 & (1.4) \\
\hline Brazil & 29.0 & (1.0) & & (1.1) & & $(0.9)$ & 24.4 & & & & & & 7.1 & & 0.2 & & 4.4 & $(0.9$ & 28.2 & $(0.9)$ & 34.8 & (1.0) \\
\hline Bulgaria & 36.1 & (1.6) & & (1.9) & & (1.1) & 20.9 & & & & & & 6.3 & & 1.4 & & 0.9 & $(1.2$ & 35.7 & (1.4) & 47.7 & (1.9) \\
\hline Chile & 29.0 & (1.1) & & (1.3) & & (1.0) & 19.3 & & & & & & 9.4 & & 7.1 & & 9.3 & $(1.1$ & 24.5 & (1.0) & 30.2 & (1.3) \\
\hline Colombia & 36.2 & (1.3) & & (1.4) & & $(1.2)$ & 22.8 & & & & & & 7.9 & (1. & 1.2 & & 2.8 & $(1.2$ & 30.7 & (1.3) & 38.0 & (1.5) \\
\hline Croatia & 32.2 & $(1.0)$ & & $(1.2)$ & & $(0.8)$ & & & & & & & 1.4 & (1. & 8.6 & & 5.4 & $(0.5$ & 25.3 & (1.0) & 35.6 & (1.3) \\
\hline Estonia & 32.6 & (1.0) & & (1.3) & & (1.0) & 16.3 & & & & & & 7.3 & (1. & 5.5 & & 5.3 & $(1.0$ & 25.7 & (1.1) & 35.5 & (1.3) \\
\hline Hong Kong-China & 43.3 & (1.3) & & (1.4) & & $(0.9)$ & 13.0 & & & & & & 7.9 & $(1$. & 4.6 & & 3.0 & $(0.9$ & 27.1 & (1.1) & 33.9 & (1.1) \\
\hline Indonesia & 33.0 & (1.2) & & (1.0) & & (1.5) & 22.9 & & & & & & 4.4 & (1. & 2.7 & & 2.9 & $(1.2$ & 27.3 & (1.3) & 36.0 & (1.0) \\
\hline Israel & 47.0 & (1.9) & & (1.7) & & (1.4) & 28.0 & & & & & & 9.1 & (1. & 5.5 & & 3.0 & $(1.1$ & 29.9 & (1.5) & 33.2 & $(1.2)$ \\
\hline Jordan & 52.0 & (1.1) & & (1.3) & & (1.6) & 36.0 & & & & & & 7.6 & $(1$. & 9.8 & & 5.0 & $(1.4$ & 49.8 & (1.5) & 56.5 & (1.2) \\
\hline Kyrgyzstan & 35.2 & (1.1) & & (1.3) & & (1.0) & 36.4 & & & & & & 6.7 & (1. & 8.2 & & 5.4 & $(1.2$ & 37.5 & (1.1) & 51.7 & (1.3) \\
\hline Latvia & 45.7 & (1.4) & & (1.5) & & (1.0) & 13.9 & & & & & & 8.4 & $(1$. & 6.2 & & 3.9 & $(1.2$ & 36.6 & (1.2) & 46.2 & (1.3) \\
\hline Liechtenstein & 23.8 & (3.7) & & (3.3) & & (1.8) & & & & & & & 6.5 & & 5.2 & & 3.7 & $(1.2$ & 12.8 & (2.7) & 15.8 & (2.9) \\
\hline Lithuania & 28.4 & (1.1) & & (1.2) & & (0.6) & 10.2 & & & & & & 1.5 & (1. & 0.5 & & 0.2 & $(0.7$ & 28.3 & (1.1) & 43.6 & (1.2) \\
\hline Macao-China & 35.1 & (1.1) & & (1.2) & & (1.0) & 17.7 & & & & & & 6.4 & (1. & 8.6 & & 7.7 & $(1.0$ & 22.3 & (1.0) & 27.6 & (1.1) \\
\hline Montenegro & 36.0 & (1.1) & & $(1.2)$ & & $(0.8)$ & 14.1 & & & & & & 8.3 & (1. & 3.4 & & 4.1 & $(0.8$ & 32.6 & (1.1) & 42.3 & (1.1) \\
\hline Qatar & 45.9 & $(1.0)$ & & $(0.9)$ & & (1.0) & 28.4 & & & & & & 6.5 & $(0$. & 5.7 & & 3.4 & $(0.9$ & 41.1 & (1.0) & 39.8 & $(0.9)$ \\
\hline Romania & 38.9 & (1.3) & & (1.1) & & $(1.2)$ & 34.9 & & & & & & 3.7 & $(1$. & 6.7 & & 4.9 & $(1.4$ & 36.0 & (1.2) & 51.9 & (1.5) \\
\hline Russian Federation & 40.3 & (1.5) & & (1.3) & & $(0.6)$ & 11.3 & & & & & & 0.4 & (1. & 1.6 & 0 & 1.3 & $(0.8$ & 23.4 & (1.4) & 27.1 & (1.0) \\
\hline Serbia & 33.8 & (1.1) & & (1.1) & & $(0.8)$ & 17.2 & & & & & & 8.4 & $(1$. & 7.6 & & 7.2 & $(0.8$ & 28.4 & (1.2) & 37.2 & (1.0) \\
\hline Slovenia & 32.4 & (1.0) & & (1.0) & & $(0.7)$ & 11.4 & & & & & & 3.5 & (1. & 3.2 & & 1.4 & $(0.7$ & 22.6 & $(0.9)$ & 27.8 & (1.0) \\
\hline Chinese Taipei & 37.7 & $(1.2)$ & & (1.5) & & $(0.7)$ & 15.2 & & & & & & 0.4 & (1. & 3.0 & & 5.2 & $(0.6$ & 30.4 & $(0.9)$ & 40.7 & (1.2) \\
\hline Thailand & 28.6 & (1.5) & & $(1.2)$ & & (1.1) & & & & & & & 7.4 & (1. & 3.3 & & 7.8 & $(0.7$ & 26.5 & (1.4) & 32.0 & (1.1) \\
\hline Tunisia & 47.7 & $(1.2)$ & & (1.2) & & $(1.2)$ & 38.8 & & & & & & 3.8 & (1. & 1.8 & & 8.8 & (1.5 & 37.3 & (1.2) & 45.9 & (1.5) \\
\hline Uruguay & 22.6 & $(1.2)$ & & (1.1) & & (0.9) & & & & & & & 0.4 & & 0.2 & & 1.9 & $(0.7$ & 16.3 & (0.9) & 27.3 & (1.1) \\
\hline
\end{tabular}

Source: OECD PISA 2006 Database. 
OECD PUBLISHING, 2, rue André-Pascal, 75775 PARIS CEDEX 16 PRINTED IN FRANCE

(98 2009091 P) ISBN 978-92-64-06394-5 - No. 569632009 


\section{Equally Prepared for Life? \\ HOW 15-YEAR-OLD BOYS AND GIRLS PERFORM IN SCHOOL}

In the past few decades there has been an increasing interest in the different educational experiences, successes and eventual outcomes that prevail for men and women world wide.

Compelling moral, social and economic incentives for individuals and societies have motivated research to better understand gender differences from early childhood through to labour market participation. Research focusing on gender differences can inform policy endorsing gender equity. More specifically, research on educational performance and attitudes can be effective in promoting quality student outcomes and equity.

The OECD's Programme for International Student Assessment (PISA) explores the educational performance and attitudes of 15-year-old girls and boys. This report begins with a general summary of gender differences measured outside of the PISA assessment programme. It then considers the knowledge gained about gender-related issues from previous PISA cycles. Some key findings include:

- In reading in PISA 2000, girls significantly outscored boys in all countries.

- In mathematics in PISA 2003, boys outscored girls somewhat.

- In the combined science scale in PISA 2006, there was no overall significant difference observed between boys and girls. However, when examining the various science competencies, knowledge components and attitudes to science, there were some marked differences.

\section{FURTHER READING}

The first results from PISA 2006 were published in PISA 2006: Science Competencies for Tomorrow's World (OECD, 2007)

\section{THE OECD PROGRAMME FOR INTERNATIONAL STUDENT ASSESMENT (PISA)}

PISA is a collaborative process among the 30 member countries of the OECD and nearly 30 partner countries and economies. It brings together expertise from the participating countries and economies and is steered by their governments on the basis of shared, policy-driven interests. Its unique features include:

- The literacy approach: PISA defines each assessment area (science, reading and mathematics) not mainly in terms of mastery of the school curriculum, but in terms of the knowledge and skills needed for full participation in society.

- A long-term commitment: It enables countries to monitor regularly and predictably their progress in meeting key learning objectives.

- The age-group covered: By assessing 15-year-olds, i.e. young people near the end of their compulsory education, PISA provides a significant indication of the overall performance of school systems.

- The relevance to lifelong learning: PISA does not limit itself to assessing students' knowledge and skills but also asks them to report on their own motivation to learn, their beliefs about themselves and their learning strategies, as well as on their goals for future study and careers.

The full text of this book is available on line via this link:

www.sourceoecd.org/education/9789264063945

Those with access to all OECD books on line should use this link:

www.sourceoecd.org/9789264063945

SourceOECD is the OECD's online library of books, periodicals and statistical databases.

For more information about this award-winning service and free trials ask your librarian, or write to us

at SourceOECD@oecd.org.

OECDpublishing www.oecd.org/publishing

www.pisa.oecd.org
ISBN 978-92-64-06394-5

982009091P

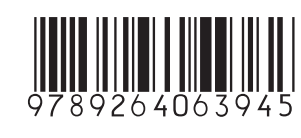

